Portland State University

PDXScholar

4-2004

\title{
Applying the Transtheoretical Model to Cigarette Smoking by Pregnant and Parenting Adolescent Females
}

\author{
Barbara Mary Sussex \\ Portland State University
}

Follow this and additional works at: https://pdxscholar.library.pdx.edu/open_access_etds

Part of the Social Work Commons

Let us know how access to this document benefits you.

\section{Recommended Citation}

Sussex, Barbara Mary, "Applying the Transtheoretical Model to Cigarette Smoking by Pregnant and Parenting Adolescent Females" (2004). Dissertations and Theses. Paper 5896.

https://doi.org/10.15760/etd. 7767

This Dissertation is brought to you for free and open access. It has been accepted for inclusion in Dissertations and Theses by an authorized administrator of PDXScholar. Please contact us if we can make this document more accessible: pdxscholar@pdx.edu. 


\title{
APPLYING THE TRANSTHEORETICAL MODEL TO CIGARETTE \\ SMOKNG BY PREGNANT AND PARENTING ADOLESCENT FEMALES
}

by

BARBARA MARY SUSSEX

A dissertation submitted in partial fulfillment of the requirements for the degree of

\section{DOCTOR OF PHILOSOPHY}

in

SOCIAL WORK AND SOCIAL RESEARCH

\author{
Portland State University \\ (C) 2004
}




\section{DISSERTATION APPROVAL}

The abstract and dissertation of Barbara Mary Sussex for the Doctor of

Philosophy in Social Work and Social Research were presented April 8, 2004, and accepted by the dissertation committee and the doctoral program.

COMMITTEE APPROVALS:

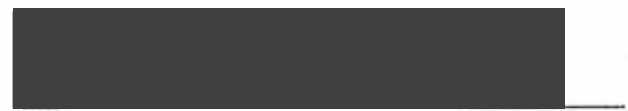

Sandra C. Anderson, Chair

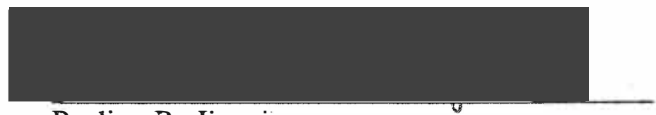

Pauline R. Jivanjee

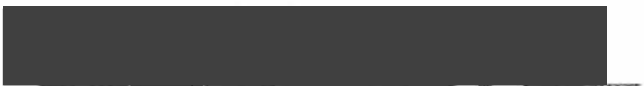

Nancy M/ Koroloff

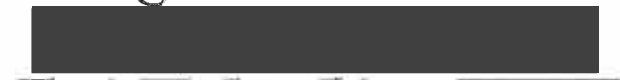

J6a F. Shireman

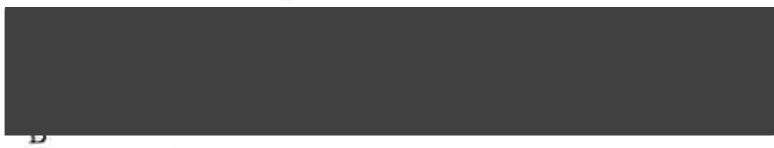

Representative of the Office of Graduate Studies

DOCTORAL PROGRAM APPROVAL:

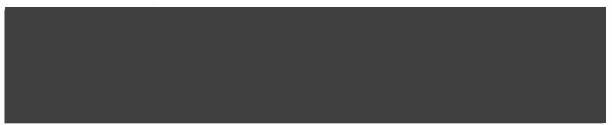

Ph.D. Program in Social Work and Social Research 


\begin{abstract}
An abstract of the dissertation of Barbara Mary Sussex for the Doctor of Philosophy in Social Work and Social Research presented April 8, 2004.
\end{abstract}

Title: Applying the Transtheoretical Model to Cigarette Smoking by Pregnant and Parenting Adolescent Females

An unacceptably high number of pregnant and parenting adolescent females smoke cigarettes, and the majority who quit during pregnancy relapse within six months postpartum. This dissertation examined measures from the Transtheoretical Model of Change (TMC) and variables associated with smoking behavior in a population of pregnant and parenting females 18 years-of-age and under. Data were from the baseline survey of 245 young women enrolled in a three-year randomized controlled trial through a teen parent program in Portland, Oregon. The objectives were: 1) to investigate whether factors identified in the literature as associated with initiating and quitting smoking were associated with never smokers and teens in the stages of change, 2) to determine whether stage effects (i.e., theoretically predicted associations between the stages and TMC measures) were exhibited for the TMC constructs of decisional balance, 
temptations to smoke, processes of change, and self-efficacy for the total sample and by pregnancy status.

Measures included the Decisional Balance Scale and Temptation to Smoke Scale used in a study by Plummer et al. (2001), an abbreviated Processes of Change measure, several standardized scales and measures of psychosocial constructs, and substance use measures from national surveys.

Significant associations by categories of never smokers and TMC stages of change were found for several psychosocial variables including pregnancy status, perceived wrong and harm of smoking, partner and friends' smoking, current alcohol and marijuana use, smoking self-efficacy, and smoking intention. Interactions between TMC measures and stages of change showed little influence for the role of peer pressure in smoking; rather, smoking as a means to deal with stress and frustration and to avoid unpleasant emotions were significant factors. Also, lack of use of stage-appropriate internal processes of change and coping methods may indicate that teens who have quit smoking are at high risk for relapse. Implications of these and other findings as well as recommendations for social work research, policy, and practice are discussed. 


\section{DEDICATION}

This dissertation is dedicated to the loving memory of my mother Mildred

Ruth Sussex, who always believed in me and was so very proud when I entered the doctoral program. 


\section{ACKNOWLEDGMENTS}

I want to thank my partner, Zoa Smith, for her love, support, patience, humor, and for bringing me food and water when I was in my office being possessed by my computer. I am especially appreciative to Dr. Kevin Corcoran for his advice, time spent, and constant encouragement. Thank you als to Dr. Diane Yatchmenoff, who has been both an inspiration and a friend.

I wish to express my appreciation and my respect for the members of my dissertation committee, Dr. Sandra Anderson, Dr. Nancy Koroloff, Dr. Pauline Jivanjee, Dr. Joan Shireman, and Dr. Brian Stipak. All of whom guided me, inspired me, and challenged me to do my best. Thank you to Francine Morlock for her invaluable assistance over the years and for answering all of my questions.

I give special thanks to the staff of Insights Teen Parent Program and to Diane Cohen-Alpert, the executive director, for her support and for making the agency's resources available to me. Thank you also to Jana Boyer, STAGES project manager, and to Britt Girvan, intake manager, for their friendship, encouragement, and runs to Starbucks. I am especially appreciative to Britt for her commitment and skill with recruitment and her ability to laugh at herself no matter what. Thank you also to the STAGES surveyors for doing such a reliable job. Finally, I offer my admiration and appreciation to the many teen parents who voluntarily participated in this study. 


\section{TABLE OF CONTENTS}

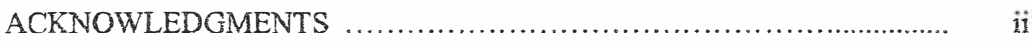

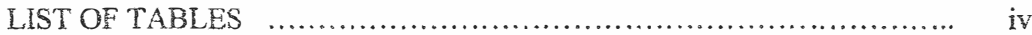

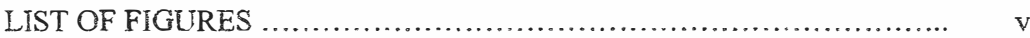

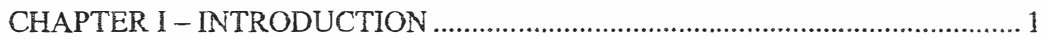

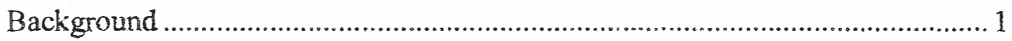

Synopsis of the Transtheoretical Model of Change ………................................... 2

Synopsis of Current Study .................................................................................. 4

Relevance to Social Work Research, Policy, and Practice .................................... 5

CHAPTER II - LITERATURE REVIEW ........................................................ 11

General Nature and Prevalence of the Problem .................................................. 11

Factors Associated with Smoking Initiation, Progression, and Cessation ........... 16

The Transtheoretical Model of Change ............................................................. 30

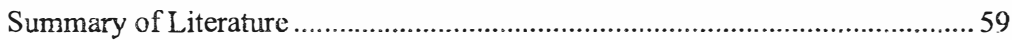

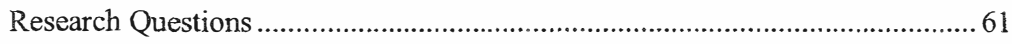

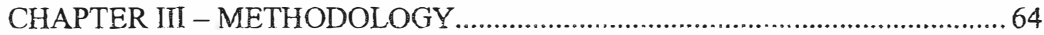

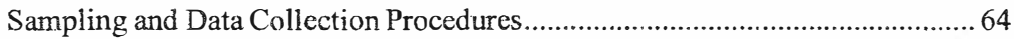

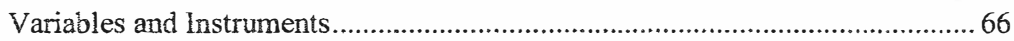

Demographic and Psychosocial Variables......................................................... 72

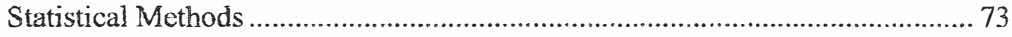

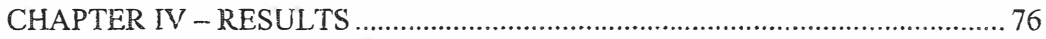

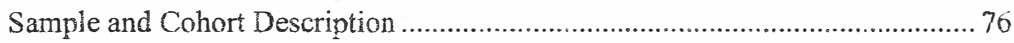

Examination of Variables for Normality and Reliability ...................................... 78

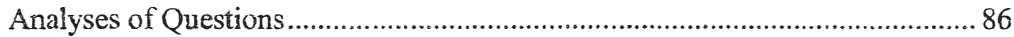

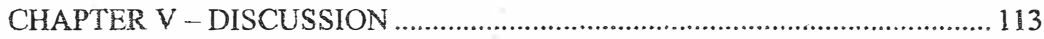

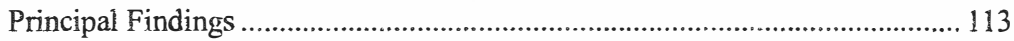

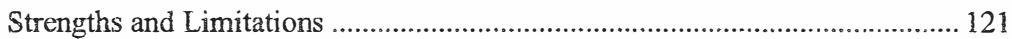

Implications for Research, Policy and Practice................................................ 122

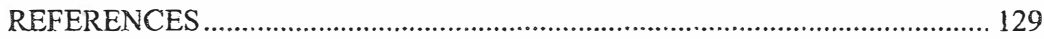

APPENDICES

Appendix A - Questions from Stages Survey ………………........................... 151

Appendix B - TMC Measures ................................................................. 160

Appendix C - Description of the STAGES Intervention ................................... 164

Appendix D - Copyright Permissions............................................................ 170 


\section{LIST OF TABLES}

1. Associates of Smoking Stage and/or Progression .................................................24

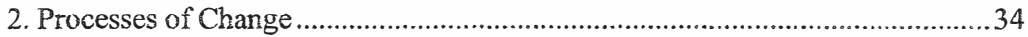

3. Coefficient Alphas for the Decisional Balance Scale.........................................68

4. Coefficient Alphas for the Temptation Scale …………...................................69

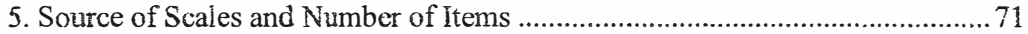

6. Characteristics of Sample by Cohort (\%) ......................................................... 76

7. Chi-square Results for Categorical Variables by Cohort (\%) .............................78

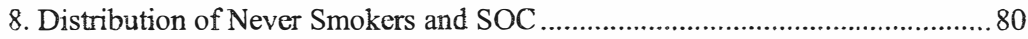

9. Characteristics of Psychosocial Scales - Means, SD, Crønbach's $\alpha$................... 81

10. Shape, Symmetry and Results of K-S test on Psychosocial Scales.....................82

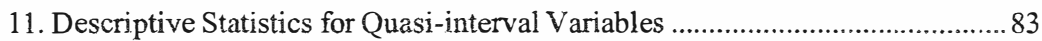

12. Tukey Subsets for Age and Perceived Wrong.................................................... 84

13. Descriptive Statistics for Substance Use Continuous Variables .........................85

14. Results of ANOVA for Never Smokers/SOC for Continuous Measures ............88

15. Kruskal-Wallis and Chi-square Results for Never Smokers/SOC Categories ... 90

16. Characteristics of Decisional Balance Scale ....................................................94

17. Characteristics of Temptation Scale ............................................................. 95

18. Item Means and Inter-item Correlations of the Processes of Change Scale.......97

19. Decisional Balance and Temptation Scale by SOC .......................................... 101

20. Behavioral Processes by SOC ……………………....................................... 105

21. Processes of Change by Pregnancy and Smoking Status ................................... 108

22. Temptation Subscales by Pregnancy and Smoking Status .................................110

23. Kruskal-Wallis Test of Self-efficacy by Pregnancy and Smoking Status ........ 112

24. Characteristics of Never Smokers and Stage of Change .................................. 126 


\section{LIST OF FIGURES}

1. Transtheoretical Model of Change: Stage effects ...................... 38

2. Decisional Balance T-scores ...................................... 102

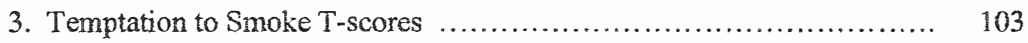

4. Processes of Change T-scores..................................... 104

5. Significant Behavioral Processes T-scores …....................... 106

5. Processes of change by Pregnancy and Smoking Status ................ 109

7. T-scores of Temptation Subscales by Pregnancy and Smoking Status ..... 110 


\section{CHAPTER I - INTRODUCTION}

\section{Background}

Over the past decade, considerable national attention and funding for both research and interventions have been directed at the prevention of teenage pregnancy, adolescent substance use, and cigarette smoking. The decade began with a teenage pregnancy rate of 116.3 pregnancies per 1,000 teens aged $15-19$, which was the highest rate since 1976 (Ventura, Mosher, Curtin, \& Abma, 2001). It continued with a seven-year upsurge in cigarette smoking and illicit drug use by high school students (Johnston, O’Malley, \& Bachman, 2003a). As well, there were increased rates in cigarette smoking during pregnancy from 1994 to 1999 for teens 15-19 years following several years of decline (Matthews, 2001). Rates were especially high for non-Hispanic White pregnant teens, with increases from $28.1 \%$ in 1994 to $29.6 \%$ in 1999 .

In response to these disturbing trends, the Center for Substance Abuse Prevention (CSAP) funded a multi-site study called the Parenting Adolescents Initiative (PAI) from 1998-2001 to field test interventions to prevent and reduce substance use among pregnant and parenting female adolescents (hereinafter referred to as pregnant/parenting teens). Insights Teen Parent Program (ITPP) of Portland, Oregon was one of ten sites to participate in the nationwide study and called its 
project CHOICES. This author was the lead evaluator. Over 2,500 young women participated in PAI projects nationwide, with 286 participants in CHOICES. A number of questions from national youth surveys as well as standardized measures were used, which resulted in reliability estimates for this population.

Additional funding from CSAP was secured by this author in 2001 for a three-year study called STAGES (Strong Teens Achieving Goals, Efficacy, and Sufficiency). STAGES was a randomized field trial of a nine-month intervention consisting of weekly, in-home counseling sessions coupled with five, weckly educational/support groups for pregnant/parenting teens. This study used selected data from the baseline survey of 245 participants in the STAGES study. A description of both the STAGES study and intervention including samples of recruitment materials may be found in Appendix C. Sampling, recruitment and data collection procedures for STAGES are discussed in Chapter III.

The design of the STAGES intervention was based largely on the Transtheoretical Model of Change (TMC) (Prochaska \& DiClemente, 1983) and motivational interviewing (Miller \& Rollnick, 1991). In addition to demographic variables and questions that ascertained substance use, the STAGES survey instrument was comprised of several scales of psychosocial constructs associated with substance use and constructs from the TMC that measure smoking behavior. Synopsis of the Transtheoretical Model of Change

A brief overview of the TMC is presented here; a comprehensive discussion of the TMC is provided in Chapter II. The TMC, often called simply the stages of 
change model, is a framework for examining and understanding behavioral change. It also provides a guide for developing and guiding interventions, commonly referred to as stage-based or stage-matched interventions. The central organizing construct is the temporal dimension, known as the stages of change (SOC) and currently represented by five distinct stages- Precontemplation, Contemplation, Preparation, Action, and Maintenance (Stern, Prochaska, Velicer, \& Elder, 1987). Transitions from stage to stage are mediated by 10 independent variables known as the processes of change, which are the experiential and behavioral strategies individuals use to move from through the stages. Two other constructs that facilitate movement are (1) decisional balance (how a person weighs the advantages and disadvantages of making the behavioral change), and (2) self-efficacy, the confidence one has in her/his ability to make the change. The Decisional Balance construct forms two independent factors - the pros of changing and the cons of changing. TMC measures for self-efficacy can be operationalized as either a situation-specific selfefficacy/confidence measure or a temptation scale with three subscales. The associations between the decisional balance, self-efficacy/temptation, and processes of change constructs with the stages of change are referred to by the term stage effects and can be explored with a variety of parametric and nonparametric tests.

The model postulates that there are predictable, mathematical patterns of the constructs as people move through the stages and that "using the right processes at the right time contributes to stage progression" (Spencer, Pagell, Hallion, \& Adams, 2002, p. 9). Accordingly, by knowing what stage an individual is in, the practitioner 
and/or the individual herself can focus on the appropriate process or strategy to promote change. For example, decisional balance is a key variable in understanding the decision making process of adolescents. It can be used either to guide interventions or as an outcome measure for early stage progress.

Proponents of the model claim that TMC measures are more sensitive to the process of change and more powerful in detecting change than discrete, point prevalence measures of the target behavior (e.g., smoking or not smoking) (Velicer, Norman, Fava \& Prochaska, 1999). Hence, the model provides an alternative measure of success because it indicates the location of an individual along the change continuum. The model has been used in the design of stage-matched interventions among diverse populations and across a variety of problems (see review of studies in Spencer et al., 2002).

\section{Synopsis of Current Study}

The dissertation consists of secondary analysis using baseline data from 245 pregnant/parenting teens enrolled in the STAGES study. The study is primarily exploratory with three objectives: (1) to determine the potential value of using the TMC with this population by examining whether the theoretically predicted stage effects are evidenced between the stages of change and the other key constructs; (2) to compare the similarities and differences in processes of change, self-efficacy, and temptation to smoke between pregnant and nonpregnant quitters and smokers; and (3) to examine the relationship between the stage of change (SOC) and important 
demographic and psychosocial factors identified in the literature as associated with smoking behavior.

This dissertation differs from the STAGES study in several ways. First, STAGES was a randomized, outcome study with six- and twelve-month follow-up measures for the purpose of examining the efficacy of the STAGES intervention. The dissertation uses only the baseline data from STAGES, and the treatment condition was not relevant. Second, the hypotheses and outcome measures for STAGES were constructed around a decrease in substance use and concomitant problems and an increase in protective factors. While measures from the TMC were used in the STAGES study, the research questions of this dissertation as well as the proposed analysis were not used in the STAGES study. Third, the dissertation focuses on cigarette smoking only and not other substance use.

Relevance to Social Work Research, Policy, and Practice Tobacco Use as a Social Work Issue.

Although the social work literature is replete with research and practice articles on alcohol and other addictive drugs, there has been scant attention to the problem of tobacco use. Several social workers have called the profession to task for (a) their non-involvement in advocacy against the tobacco industry, (b) their lack of policy activities toward the development of a smoke-free society, and (c) their failure to view cigarette smoking as a substance abuse problem and respond to it as the addiction it is (Bogolub, 1990; Gorin, 2001; Kaplan \& Weiler, 1997; Keigher \& Taylor-Brown, 2001; Valentich, 1994). Valentich (1994) speculates that social 
worker's silence on the issue of tobacco abuse may relate to their own smoking habits, to the degree of the profession's commitment to a health paradigm and to changing the physical aspects of the person in environment as compared to the psychosocial aspects, and to conflicts between the adoption of an anti-smoking stance and a client's right to self-determination. Whatever the reason, she argues that a rationale for social work involvement derives from a health-oriented perspective that values physical well-being and also seeks to help the socially and economically vulnerable, many of whom smoke.

The literature on the relationship between poverty, inequality and health persuasively demonstrates that health is essentially a "biopsychosocial phenomenon" (Gorin, 201, p. 273). Social and socioeconomic inequality results in emotional, physical and psychological factors and stresses that lead to behaviors such as smoking and other drug use. From a person-in-cnvironment perspective, cigarette smoking is influenced, maintained and reinforced by social, economic and political structures. For example, the tobacco industry invests billions of dollars in media campaigns targeted at people of color, gay and lesbian people, and adolescents (King \& Siegel, 2001; United States Department of Health and Human Services [USDHHS], 2001, 2002). These groups are at high-risk for smoking and have the most difficulty quitting smoking (Ryan, Wortley, Easton, Pederson, \& Greenwood, 2001; USDHHS, 2001). Many social work clients come from these groups, and social justice and advocacy for these populations have been central to social work's mission. 
Because most cigarette smoking occurs in the home, women and children are increasingly vulnerable to the harmful effects of tobacco use. Keigher and TaylorBrown (2001) note that gender-related inequities result in the neglect of women and children's health and disparities in their vulnerability to risk factors as well as access to health care. They question whether "poor health and differential social expectations cause gender inequality or does gender inequality contribute to poor health" (p. 68)?

Finally, the relationship between cigarette smoking and reproductive health politics is important for social workers to examine as there are significant implications for practice and policy within the child welfare field. Oaks (2001) offers a feminist analysis of the social construction of smoking during pregnancy as a problem and a critique of what she calls fetal politics in the U.S. She states that mothers and other caretakers who smoke have lost custody of their children, noting that increasingly child custody cases admit smoking as evidence of unfit parenting and smoking during pregnancy as fetal abuse. The issues of fetal protection, fetal abuse, and women's right to choose are often at variance and warrant discourse among social workers.

This author concurs with Kaplan and Weiler (1997) who recommend a "change in policy and practice from viewing smoking not just as a public health concern that touches social work peripherally but also as a larger social problern affecting quality of life among disadvantaged populations" (p. 47). 


\section{Relevance of the Transtheoretical Medel of Change}

Over the past twenty years, the TMC has guided research on the processes involved in changing behavior and is being used by professionals around the world as a diagnostic guide for treatment planning and as a heuristic guide for evaluating treatment efficacy. The literature supports the usefulness of treatments using the TMC in a variety of addiction behaviors (see e.g., Connors, Donovan, \& DiClemente, 2001; Miller, 1999; Velasquez, Maurer, Crouch, DiClemente, 2001). The model also has been applied to the process of change in psychotherapy and shown to be predictive of who remains in treatment (Brogan, Prochaska, \& Prochaska, 1999). While the focus of research has been on smoking cessation and addictions, the TMC has been used with diverse populations and behaviors such as co-occurring disorders (Finnell, 2003), clinical HIV protection and safer sex (Polacsek, Clentano, O’Campo, \& Santelli, 1999), domestic violence (Brown, 1977), and exercise acquisition and obesity (Dallow \& Anderson, 2003). Social workers as well have found the TMC useful to guide their practice with alcoholism treatment (Wunschel \& Rohsenow, 1993), resistant drug abusers (Barber, 1995), outpatient mental health clients (O'Hare, 1996b), and court-ordered and other types of involuntary clients (O’Hare, 1996a).

The TMC is a model for voluntary change. It fosters a client-centered approach and exemplifies the values and practice principles of social work. Social workers often work with individuals who have problems in multiple areas of their life and who face formidable barriers to accessing resources. Snow, Prochaska and 
Rossi (1991) point out that as we work with multiple risk factors, we need to know more about simultaneous and sequential behavior change strategies. They note that "for those who change sequentially, we need to know which problem behavior to target first in order to maximize the likelihood of successful change" (p. 115). We also have much to learn from individuals who can change two or more problem behaviors simultaneously.

There is an emergent literature on the use of the TMC with populations of adult pregnant women (see e.g., Ruggiero, Tsoh, Everett, Fava, \& Guise, 2000; Stotts, DiClemente, \& Dolan-Mullen, 2002; Spencer et al., 2002). These studies not only have advanced our understanding of the variation and disparity in smoking behavior between pregnant and nonpregnant women but also have led to the development of pregnancy-tailored measures of decisional balance (Bane, Ruggiero, Dryfoos, \& Rossi, 1999) and stage-based interventions using interactive computer systems (Ruggiero, Redding, Rossi, \& Prochaska, 1997).

In contrast, the use of the TMC with adolescents is relatively new. Development of psychometrically sound measures of key TMC constructs is important, and we are at an exciting place in model and measurement development. Recently, Plummer et al. (2001) published data on the psychometric properties of modified measures of the Temptation to Smoke and Decisional Balance scales for both smoking acquisition and cessation among adolescents. These measures are currently being used in a four-year, individualized computer- based intervention study with 2,808 students from 22 Rhode Island high schools. Both measures were 
used in this study.

No research to date has profiled the TMC with pregnant/parenting teens. Examination of the applicability of the TMC measures for this population augments current research endeavors among adult pregnant women and adolescents. Both the research and treatment field for pregnant/parenting teens is new, and programs that work for adult pregnant women and other adolescent populations may not generalize to this population. Information on the smoking patterns of pregnant/parenting teens, the patterning of stage effects, and accurate classification of SOC are prerequisites for the development of efficacious, stage-matched treatments.

Social workers have a unique opportunity and contribution to make to both smoking cessation research and intervention with adolescents. Best practice approaches used in traditional high schools and school-based health programs may not reach pregnant/parenting teens, since many have dropped out of school or attend school sporadically. Social workers are frequently employed in settings that serve at-risk adolescents and pregnant teens, such as non-profit community practice settings and family and child treatment agencies. Research informing practice is clearly needed, and it is consistent with the philosophy of the profession that social work contribute to this undertaking. 


\section{CHAPTER II - LITERATURE REVIEW}

General Nature and Prevalence of the Problem

Cigarette smoking by pregnant/parenting teens presents a direct risk to the fetus, an ongoing hazard to the child through environmental tobacco smoke, an increased likeiihood for adverse developmental outcomes as the child grows, and an extended risk for habitual smoking by the teen herself.

The devastating impact of smoking on women of all ages and especially during pregnancy is now well known (see review of studies in Ernster, 2001; USDHHS, 2001). Adverse reproductive outcomes and health effects include a twofold increased risk of low birth-weight infants, maternal bleeding, delays in child development, stillbirth and neonatal death, infant deaths from SIDS, increased hospitalizations due to lung complications, and transfer of tobacco-specific carcinogens to the fetus (Cnattingius, Haglund, \& Meirik, 1988; Cornelius, Taylor, Geva, \& Day, 1995; Kohlendorfer, Kiechl, \& Sperl, 1998; Milunsky, Carmella, Ye, \& Hecht, 2000; Wilcox, 1993). The morbidity and mortality risks are even greater for pregnant adolescents who already are at the highest risk for poor pregnancy outcomes and for health problems later in life (Scholl, Hediger, \& Belsky, 1994).

Health effects for children as a result of exposure to second hand smoking in the home have been well documented (see review of studies in Samet \& Yang, 2001) as has the association between prenatal smoking and a myriad of developmental 
difficulties that include childhood negativity (Brook, Brook, \& Whiteman, 2000), child anxiety and depression (Cornelius, Leech, Goldschmidt, \& Day, 2000), adolescent obesity (Von Kries, Toschke, Koletzko, \& Slikker, 2002), leaming disabilities, impulsivity, and hyperactivity in school-aged children (Rush, 1992).

Moreover, prenatal smoking has been linked to an increased risk of children smoking and of adolescent drug use. In a study by Comelius et al. (2000) of 589 tenyear-olds followed since gestation, there was a five-fold likelihood that the child would have tried tobacco by age 10 if the mother smoked at least a half-pack of cigarettes per day during pregnancy. A study by Kandel and Udry (1999) showed that prenatal maternal smoking was significantly associated with daughters smoking by age 13 and persisting with smoking. Preadolescent girls whose mothers smoked at least a pack of cigarettes during their pregnancies were seven times as likely to smoke as were girls whose mothers did not smoke during pregnancy. In a longitudinal study by Weissman, Warner, Wickramaratne, and Kandel (1999) of offspring assessed over ten years, there was a greater than five-fold increased risk of adolescent onset drug dependence in girls whose mothers smoked 10 or more cigarettes almost daily during pregnancy. Smoking is also known to be a gateway drug to alcohol, cocaine, heroin, crack, and marijuana use with consistent associations across age, race, and gender (Chen et al., 2002; Lai, Lai, Page, \& McCoy, 2000).

Adolescents underestimate the addictiveness of nicotine and the consequences of smoking; $73 \%$ of teen daily smokers who think they can easily quit 
are still smoking five to six years later (USDHHS, 1994). The vast majority of adult women smokers try their first cigarette before age 18, and approximately $40 \%$ of women who try smoking escalate to regular patterns of use (USDHHS, 2001). Findings from a study of two-year aggregate data from the National Household Survey of Drug Abuse (cited in USDHHS, 2001) showed that 63.1\% of girls aged 12 -17 who were current smokers had at least one indicator of nicotine dependence.

The issue of potential error in self-report of smoking is important to review briefly since both national surveys and empirical studies often rely on self-report. Pregnant women are likely to under-report smoking due to social stigma (Windsor \& Orleans, 1986), and pregnant adolescents may be more likely to do so with the added issue of smoking illegality. Empirical studies of the accuracy of reported smoking during pregnancy using biochemical validation have yielded variable results (Klebanoff, Levine, Clemens, DerSimonian, \& Wilkins, 1998; Klebanoff et al., 2001). Inconsistencies have been reported ranging from $13.8 \%$ to $26.2 \%$ (Boyd, Windsor, Perkins, \& Lowe, 1998). However, in a review of studies of adolescent pregnancy and substance use where many studies used biochemical confirmation of self-report, Flanagan \& Kokotailo (1999) concluded that there had been considerable concordance.

In a review of the literature on methodological issues in measuring treanent outcome for adolescents, Mermelstein et al. (2002) report that adolescents display three self-report patterns: (a) under-reporting the frequency and/or quantity of smoking because of social desirability concerns, (b) over-reporting if the setting is 
conducive to social reinforcement from peers, and/or (c) unintentional inaccuracy. The latter is due to both irregular smoking patterns and sporadic smoking patterns by teenagers. For example, teenagers who smeke only with certain friends or during certain occasions may not consider themselves smokers. In an analysis of self-report data compared with biomarker data from three adolescent smoking interventions, Mermelstein et al. found a mean deception rate of $16 \%$ at follow-up. They report that this rate is about three times the deception rate found in survey studies with adolescents (see Dolcini, Adler, \& Ginsberg, 1996 and Gritz et al., 1998 cited in Mermelstein et al.).

National data on the prevalence of smoking by pregnant women have been available via self-report on birth certificates since 1989; however, many question the validity of birth certificate data. Matthews (2001) cautions that the self-report nature of the data along with the fact that the question on the birth certificate lacks specific time referents may result in the underestimate of smoking rates, in particular during cases of poor birth outcome when the mother may be reluctant to admit having smoked. Other sources of national data on the prevalence of smoking among reproductive-aged and/or pregnant women include the National Health Interview Survey, the Behavioral Risk Factor Surveillance System, the National Natality Survey, and the Pregnancy Risk Assessment Monitoring System (PRAMS) of the Centers for Disease Control.

Rates of smoking based on birth certificates show that since 1996 teenagers have had the highest rate of smoking among pregnant women (Matthew's, 2001). In 
$2000,18 \%$ of young women aged $15-19$ reported smoking during pregnancy ${ }^{I}$ (Martin, Hamilton, Ventura, Menacker, \& Park, 2002). Teens aged 18-19 years had the highest rate (19.2\%), with $20 \%$ smoking one-half a pack or more per day. In keeping with national trends since 1990, there were large disparities in smoking rates for racial/ethnic subgroups. For example, the proportion smoking was $3.2 \%$ for Mexican teens $15-19$ years, $8.9 \%$ for non-Hispanic Black teens, and $30.8 \%$ for nonHispanic White teens. Non-Hispanic White mothers have had the highest smoking rates every year since 1990, followed by American Indian teens. Rates for Hispanic, non-Hispanic Black, and Asian-Pacific Islander teenagers have ranged from five to nine percent over the decade.

Cross-sectional studies of smoking by pregnant/parenting teens have reported smoking rates between $27 \%$ and $62 \%$ (Albrecht et al., 1999; Cornelius, Geva, Day, Cornelius, \& Taylor, 1994; Gilchrist, Hussey, Gillmore, Lohr, \& Morrison, 1996; O'Campo, Faden, Brown, \& Gielen, 1992), depending on education and economic levels, ethnicity, and age.

Pregnancy itself appears to be a motivator for many women to quit smoking. Studies of adult pregnant women show that up to $48 \%$ cease smoking at some stage during their pregnancy (see review by Lu, Tong, \& Oldenburg, 2001), however the

${ }^{1}$ Excludes data for California, which did not require reporting of tobacco use during pregnancy. 
majority who quit relapse within one year postpartum (Colman \& Joyce, 2003; Dolan-Mullen, Richardson, Quinn, \& Ershoff, 1997).

There is some evidence that teenagers are more likely than adults to quit during pregnancy but also are more likely to resume smoking postpartum. Colman and Joyce (2003) examined population-based data of ten states from PRAMS and found that for women under age $20,47 \%$ quit smoking during pregnancy and $59.6 \%$ relapsed between two and six months postpartum. They noted that these rates exceeded those by adults. Gilchrist et al. (1996) collected data from adolescent mothers at 18 months following birth and found that while the use of all substances decreased substantially during pregnancy, there was a significant increasing linear trend for smoking through 18 months postpartum. One exception to this trend is a study of 199 pregnant teens by Cornelius et al. (1994) where smoking was prevalent and, unlike the decreases in other substances, increased from 59\% during the first trimester to $62 \%$ during the third trimester.

Factors Associated with Smoking Initiation, Progression, and Cessation A central focus in social research since the landmark 1964 Surgeon General's report (USDHHS, 1964) has been identifying factors that influence the initiation of cigarette smoking among adolescents in order to design primary prevention programs (see reviews in Aghi, Asma, Yeong, \& Vaithinathan, 2001; Tyas \& Pederson, 1998; USDHHS, 1994, 2001). The data on cessation of smoking, and in particular among pregnant/parenting teens, have not been as extensive. To better understand the smoking behavior of this population, the literature on smoking among 
female adolescents and adult pregnant women is reviewed. This section does not include a discussion of studies of the TMC with adolescents or adult pregnant women; this literature is reviewed at the end of the chapter following the presentation of the model itself.

\section{Relationship between Teen Pregnancy and Smoking}

While the relationship between teen pregnancy and cigarette smoking is unclear, there appears to be covariation of risk factors (Archie, Anderson, \& Gruber, 1997; Gilchrist et al., 1996). In a review of studies on substance use among pregnant/parenting adolescents, Flanagan and Kokotailo (1999) note that risk-taking behaviors appear to cluster within individual adolescents and that teenagers who become pregnant before completing high school "may be at higher risk than the general population for substance use, at least cigarettes, alcohol, and marijuana" ( $p$. 197).

Socio-demographic and psychosocial factors common to both adolescent pregnancy and smoking include low socioeconomic status, an inclination to risk taking and rebellious behavior, growing up in a single-parent home, lax parental supervision or adult expectations, under achievement and/or disinterest in school, low religious commitment, and having experienced childhood sexual or physical abuse (see review in Kaufman, 1996; see also Berenson, San Miguel, \& Wilkinson, 1992; Bryant, Schulenberg, Bachman, O’Malley, \& Johnston, 2000; Hussey, Gilchrist, Gillmore, \& Lohr, 1992; Resnick et al., 1997). 
Socioeconomic status and ethnicity ${ }^{2}$ have been considered important moderating factors for differences in both teen pregnancy rates and cigarette smoking behavior (Flay, Phil, Hu, \& Richardson, 1998; Matthews, 2001), and the interrelationship is complex. While cigarette smoking is lower among youths who are non-White, teen pregnancy rates are much higher among minority youth. Rates of teen births in 2000 were 32.6 per 1,000 for non-Hispanic White teens aged 15-19, 79.2 for non-Hispanic Black, 58.3 for American Indian, 20.5 for Asian/Pacific Islander, and 87.3 for Hispanic teens aged 15-19 (Ventura, Hamilton, \& Sutton, 2003). Higher rates of smoking among non-White pregnant adolescents may be because adolescents and women of minority status are over represented in lower socioeconomic levels, which, in tum, is associated with lower quitting rates during pregnancy.

\section{Initiation of Smoking}

Smoking has been associated with multiple demographic, developmental, genetic, psychosocial, cognitive and attitudinal factors. In a review of the literature, Tyas and Pederson (1998) conclude that psychosocial associates with initiation of smoking are evidenced for age, ethnicity/race, family structure, socioeconomic status, personal income, parental/sibling/peer smoking, parental attitudes toward

\footnotetext{
${ }^{2}$ There are significant racial and ethnic disparities in patterns of smoking initiation, progression, and cessation for both pregnant and nonpregnant female adolescents. While these differences are not a focus of this study, they are important. Excellent discussions may be found in Griesler, Kandel \& Davies, (2002); Kaplan, Nápoles-Springer, Stewart and Pérez-Stable (2001); Ma, Shive, Legos and Tan (2003); Kelder et al. (2003), Gritz et al. (1998), USDHHS (1998, 2002).
} 
smoking, peer attitudes and norms about smoking, attachment to family/friends, school connectedness, stress, depression, self-estecm, personal attitudes toward smoking, and personal health concerns. The importance of religion has also been associated with smoking. Both public and private religiosity has been shown to be protective against experimental and regular smoking (Nonnemaker, McNeely, \& Blum, 2003).

A relationship between smoking and other substance use by pregnant teens has been found in several studies (see review in Richardson, 1999). For example, in a study by Barnet, Duggan, Wilson, and Joffe (1995) $83 \%$ of adolescent mothers who reported smoking during pregnancy compared with $30 \%$ of those not smoking during pregnancy were positive for drugs or alcohol in the postpartum period. Archie et al. (1997) found that pregnant adolescent smokers were four times more likely to use alcohol or cocaine than were nonsmokers when controlling for other socio-demographic and economic variables.

Considerable evidence documents a high prevalence of domestic violence and physical and/or sexual abuse among adolescents in the year before or during pregnancy with rates of 20\% (Parker, McFarlane, \& Soeken, 1994), 21.7\% (Parker, McFarlane, Soeken, Torres, \& Campbell, 1993), 29\% (Martin, Clark, Lynch, Kupper, \& Cilenti, 1999), and 33\% (ITPP, 2002). In almost every study in which it has been measured, cigarette smoking is more common among abused than nonabused pregnant teens. Curry, Perrin, and Wall (1998) screened 1,897 women for abuse during pregnancy and found that physical abuse in the past year and/or 
during pregnancy was reported significantly more by adolescent $(37.6 \%)$ than adult women $(22.6 \%)$. Furthermore, abused adolescents were at a significantly greater risk for smoking than abused adults were. McFarlane, Parker, and Soeken (1996) used a prospective cohort design with 1,203 multi-ethnic women from public prenatal clinics in two large cities; approximately $30 \%$ of the sample was aged $13-$ 19. A significant association was found between physical abuse and smoking for African American women (33.7\% of non-abused women smoked compared to $49.5 \%$ for abused women) and White women ( $59.6 \%$ compared to $46.6 \%$, respectively).

An association between smoking and intention to lose weight by female adolescents has been found in numerous studies (see e.g., Crisp et al., 1998; Lowry, Galuska, Fulton, Wechsler, \& Kann, 2002) even for Black and Hispanic girls who have lower smoking rates. In a nationally representative sample of 7,828 high school females, Delnevo, Hrywna, Abatemarco, and Lewis (2003) found that daily smoking was the strongest predictor of practicing extreme weight loss methods for both boys and girls regardless of race. Tomeo, Field, Berkey, Colditz and Frazier (1999) used a SOC acquisition measure and logistic regression in a cross-sectional study of 16,862 children aged 9 to 14 to examine the relationship between weight concerns, weight control behaviors, and early stages of smoking initiation. Progression along the smoking stages was related to having weight concerns. For girls, contemplating smoking was significantly associated with unhappiness with appearance and a tendency to change eating patterns, and experimentation with cigarettes was associated with monthly purging and daily dieting. 
Depression has consistently been associated with smoking, although the directionality remains unclear. Windle and Windle (2001), using data from a fourwave longitudinal study of 1,218 adolescents, found that chronic depressive symptoms were predictors of increased smoking across time. As well, heavy smoking prospectively predicted increases in depressive symptoms. The strong and independent relationship in this study confirms results obtained by Kandel and Davies (1986) where depressive symptoms reported at ages 15-16 predicted the frequency and duration of cigarette smoking nine years later. Wu and Anthony (1999), however, reported that cigarette use prospectively predicted depressive symptoms, but that depressive symptoms did not predict cigarette use.

\section{Progression of Smoking}

The progression from adolescent experimentation to regular smoking evolves through several stages culminating in addiction. Investigators theorize that different factors not only influence this progression but also assume different functions at different times (see review of studies in Mayhew, Flay, \& Mott, 2000). Several recent studies (Flay et al., 1998; Lloyd-Richardson, Papandonatos, Kaqura, Stanton, \& Niaura, 2002; Pederson, Koval, McGrady, \& Tyas, 1998; Scal, Ireland, Borowsky, 2003) have investigated the salience of variables at particular smoking stages and have highlighted factors that appear to vary along the smoking progression continuum.

Pederson et al. (1998) used a self-administered questionnaire with 1,614 Canadian students in the $8^{\text {th }}$ grade to analyze dose-response between psychosocial 
variables and smoking. She classified her sample into groups she labeled as never smokers, experimenters, current smokers, and ex-smokers. Current smoking was associated with poor academic performance, smoking by one or more family members, dissatisfaction with weight, weekly activities with friends, and perceived poor health. Maternal and paternal disapproval of smoking was associated with never smokers.

Flay et al. (1998) employed a longitudinal design and logistic regression to determine predictors of stage membership and movement using categories of never users, triers, experimenters, and regular smokers. A multi-ethnic population of 6,695 students ( $49.6 \%$ female) were interviewed in grade seven, and 2,219 were recontacted when they were in the $12^{\text {th }}$ grade. African-American youths were more likely to stay as never smokers, and White youths were more likely to progress to regular smokers. Important correlates of transition from trial to experimental use included friends' smoking and approval, age, cigarette offers by friends, alcohol and marijuana use, and smoking intentions. Parental approval of smoking was associated with the experimental stage, and parental smoking predicted transition from experimental to regular use.

Lloyd-Richardson et al. (2002) used a multivariate regression medel and examined transitions across six stages she identified as never smoker, experimenter, intermittent, regular established, and ex-smoker. The study included a subsample of 20,747 adolescents originally drawn from the Add Health project, a multi-stage, longitudinal national school survey of 90,000 students in grades $7-12$. Peer smoking 
was the strongest predictor of progression to regular use with low school connectedness, depression, and delinquency also predictive of progression. Age was more likely to differentiate regular smoking from earlier stages, with older teens being four- to five-times more likely to be regular smokers. African American ethnicity and connectedness to school and family were protective of smoking initiation, and alcohol use was most influential on earlier smoking behavior.

Scal et al. (2003) used the same baseline data as Lloyd-Richardson et al. (2002) and as well analyzed the second wave of data on 14,738 adolescents one year later to determine factors predictive of transitioning from non-smoking to smoking. Data were stratified into four gender by grade group categories and logistic regression was used to examine predictive relationships. Across gender and grades, parent-family connectedness and academic achievement as measured by a high grade-point average were significant protective factors. The most powerful predictors of transitioning were other drug use, involvement in violence, learning problems, a history of sexual intercourse, frequent hanging out with friends, and having friends who smoke. A summary of the findings of associates of smoking progression is presented in Table 1.

Among these studies, several factors were uniquely influential and/or showed stronger effects for girls. In the Pederson et al. (1998) study, there was a doseresponse relationship with rebelliousness and depression for females. Flay et al. (1998) found that family conflict was predictive of movement to regular smoking among females only, and offers of cigarettes had stronger effects for females at all 


\section{Table 1}

Associates of Smoking Stage andlor Progression

\begin{tabular}{lc}
\hline Smoking stages and/or transitions & Demographic and psychosocial factors \\
\hline $\begin{array}{l}\text { Protective factors for never } \\
\text { smoling }\end{array}$ & $\begin{array}{c}\text { African American ethnicity, connectedness to } \\
\text { school and/or family, high grade point average } \\
\text { Factors associated with movement } \\
\text { from trial to experimental or }\end{array}$ \\
$\begin{array}{ll}\text { Friends smoking/approval, cigarette offers by } \\
\text { friends, higher grade/older age, alcohol and }\end{array}$ \\
marijuana use, smoking intentions, parental \\
smoking, low school connectedness/ learning \\
problems, depression, delinquency, \\
involvement in violence, history of sexual \\
intercourse, frequent hanging out with friends, \\
Caucasian ethnicity \\
Factors associated with & Poor academic performance, smoking by family \\
current/regular smoking & members, dissatisfaction with weight, weekly \\
& activities with friends, perceived poor health \\
\hline
\end{tabular}

Note. Summary of findings from Lloyd-Richardson et al. (2002), Flay et al. (1998), Pederson et al. (1998), Scal et al. (2003).

levels of use. Lloyd-Richardson et al. (2002) found that maternal smoking had no effect on male offspring but raised the odds ratio for females by $36 \%$. Girls with mothers who did not smoke were $11 \%$ less likely to initiate smoking than males but became $26 \%$ more likely to do so if their own mother smoked. Finally, Scal et al. (2003) found that having friends who smoke increased the likelihood that a girl would transition to smoking more than it did for boys. Significant predictors for both younger and older girls were exposure to and involvement with suicidality, same sex attraction, poor health, and weight dissatisfaction. Absence of depressive symptoms and presence of emotional well-bcing was protective for girls. 


\section{Factors Associated with Quitting Smoking}

The reasons that motivate girls to continue smoking are quite different from those pushing them to start (Aghi et al., 2001). Continued smoking is due both to nicotine dependence and to the difficulties in quitting which stem from multiple biological, psychological and environmental factors. Considerable research suggests that genetic factors account for as much as $60 \%$ of the propensity to smoke and may influence the ability to quit ( $\mathrm{Li}$, Cheng, Ma, \& Swan, 2003).

Significant associations $(p \leq .05)$ for quitting or continuing smoking among female adolescents have been found for nicotine addiction (Woodby, Windsor, Snyder, Kohler, \& DiClemente, 1999), frequency and/or duration of smoking habit (Engels, Knibbe, De Vries, \& Drop, 1998; Zhu, Sun, Billings, Choi, \& Malarcher, 1999; Woodby et al.), length of past quit attempts (Zhu et al.), number of past quit attempts (Engels et al.), self-efficacy (Woodby et al.), readiness/intent to quit (Dijkstra, De Vries, \& Roijackers, 1998; Flay et al., 1998), exposure to environmental tobacco smoke (Severson, Andrews, Lichtenstein, Wall, \& Akers, 1997; Woodby et al.), perceived pros and cons of smoking (Engels et al.), depression

(Covey \& Tam, 1990; Zhu et al.), and peer smoking behavior (Burt \& Peterson, 1998; Covey \& Tam).

Engels et al. (1998), however, did not find a significant effect of peer smoking on motivation to quit among 215 adolescents. The investigators suggest that this could be due to what they call die hards seeking friends who smoke. A longitudinal study by Chassin, Presson, and Sherman (1984) supports this 
hypothesis. They found that psychosocial factors served as antecedents to cessation but the process of quitting itself led to changes in the youths' social environment that further reinforced cessation (e.g., fewer friends who smoked, less positive peer attitudes toward smoking), suggesting that the process of cessation may be bidirectional.

Qualitative studies provide rich information about the personal and social meanings of smoking that make quitting difficult. Nichter, Nichter, Vuckovic, Quintero, and Ritenbaugh (1997) used both qualitative and quantitative methods in a study of 205 girls from two urban high schools in Tucson, Arizona. Themes that emerged for smoking included stress reduction and relaxation, independence in initiation and continuation, and the girls' beliefs that they could control cigarettes rather than having cigarettes control them.

Seguire and Chalmers (2000), reporting on interviews with 25 girls in Canada noted that for regular smokers, smoking became a way to bond with peers and to suppress or cope with feelings. Teens said that smoking always gave them something to do and that cigarettes were like a buddy. Many regretted having started and believed they were addicted, reporting frequent quit attempts and withdrawal effects. They also reported that smoking in their home environment and friends' smoking made it harder to quit.

While further research is needed to differentiate predictors of the onset of smoking from predictors of both continued smoking and smoking cessation, smoking bchavior among female adolescents is a complex interplay of socio-demographic, 
intrapersonal, environmental and behavioral factors that intertwine and become more or less influential at different developmental stages.

\section{Smoking Behavior During and After Pregnancy}

In a review of the literature on smoking cessation before, during, and after pregnancy among adult women, DiClemente, Dolan-Mullen and Windsor (2000) describe four types of smoking behavior by women - pregnancy quitters, spontaneous quitters, pregnant smokers, and postpartum relapsers. Pregnancy quitters are those smokers who have a planned pregnancy and who quit smoking before becoming pregnant. Estimated at approximately $13.6 \%$, these women typically sustain cessation throughout their pregnancy and postpartum period.

Spontaneous quitters quit as soon as they learn they are pregnant, and most maintain cessation throughout their pregnancy. Differences between pregnant smokers and spontaneous quitters have been found for partner smoking and demographics, with rates of quitting lowest for women with low readiness to change (Solomon, Secker-Walker, Skelly \& Flynn, 1996), younger women, women with low levels of education, and those who are either unemployed or in low-skilled jobs (Najman et al., 1998). Ershoff, Solomon, and Dolan-Mullen (2000) note that some studies hypothesize that spontaneous quitters are typically women who are light smokers, better educated, and with less saturated smoking networks. In contrast, those who stay smoking are less motivated and more addicted.

The final group consists of postpartum relapsers. The fact that over $70 \%$ of spontaneous quitters relapse postpartum has led Stotts, DiClemente, Carbonari, \& 
Dolan-Mulien (1996) to perceive their behavior as not truly quitting smoking but rather suspending it for the duration of their pregnancy. Indeed, they suggest that stopping smoking is relatively easy in the context of pregnancy because quitting smoking is imbedded in the context of other life changes. External factors, such as nausea, concern for the health of the baby, social stigma, and pressure from others contribute to successful quitting.

Partner smoking is probably the most influential factor for continued smoking during pregnancy as well as for postpartum relapse (Hakansson, Lendahls \& Petersson, 1999; Olsen, 1993; Nafstad, Botten, \& Hagen, 1996). Other important factors include socializing or living with a smoker (McBride \& Pirie, 1990; Quinn, Mullen \& Ershoff, 1991), heavy smoking prior to pregnancy (Hakansson et al.; Olsen; Severson et al., 1997; Wisborg, Henriksen, Hedegaard, \& Secher, 1996), formula feeding instead of breast feeding ('Campo et al., 1992; Rattner, Johnson, Bottorff, Dahinten, \& Hall, 2000), caffeine intake (Olsen; Wisborg et al.), low maternal and paternal education (Nafstad et al.), skepticism about smoking-related harms (Ockene et al., 2002), absence of encouragement to stay quit (Van't Hof, Wall, Dowler, \& Stark, 2000), taking puffs in late pregnancy (Lelong, Kaminski, Saurel-Cubizolles, \& Bouvier-Colle, 2001), and having more than one child (McLeod, Pullen, \& Cooksun, 2003; Nafstad et al.).

Interviews with pregnant and parenting teens have revealed special themes of the meaning of smoking and the difficulties of cessation for these young women. Dunn, Pirie, \& Lando (1998) conducted focus groups with 57 pregnant and 
parenting, low-income, women and teens and reported that barriers to quitting and/or maintaining cessation included stress and boredom with life, nicotine addiction, not believing smoking is dangerous, and other smokers in the environment.

Lawson (1994) conducted two years of field research that involved in-depth, weekly interviews with 20 pregnant teenagers for two years. Sixty-five percent of the sample reported smoking a pack of cigarettes daily, and 55\% reported no history of quit attempts. Seventy percent began smoking between the ages of 10 and 11 years. Lawson relates that many began smoking to control their weight, noting that the girls believed that weight gain caused peer harassment and also might prevent them from getting another boyfriend. Once pregnant, they said they feared the pain of labor and intentionally smoked to have a lower birth weight baby. Lawson notes that this finding has important implications for cessation programming where the message of quitting smoking to prevent low-birthweight babies is often used. She also suggested that there may be a link between smoking and experiences of abandonment as the girls often grieved the anticipated loss of cigarettes. She noted that this attachment may be profound and a significant factor in cessation efforts. Many youths were aware of the health hazards associated with smoking but feit that smoking was a lesser evil than other drugs.

While the women in these studies appear to be unconvinced or unconcerned about the hazards of smoking, knowledge about the health effects of smoking has been linked to intention and efforts to quit in other studies of pregnant/parenting teens (Albrecht, Higgins, \& Lebow, 2000). Other factors linked to quitting or 
maintaining smoking among pregnant/parenting teens include religiosity (Albrecht, Reynolds, Comelius, Heidinger, \& Armfield, 2002) and friends' cigarette use (Hussey et al., 1992).

The Transtheoretical Model of Change

This discussion is organized into four sections. The first section presents an overview of the constructs and stage effects of the TMC, drawing heavily from seminal works of James Prochaska and Carlo DiClemente, the developers of the model. The second section presents a discussion of the critique of the validity and reliability of the TMC as well as the support for the model. The fourth section presents an overview of research using the TMC and a review of the literature on the TMC as applied to adolescents and adult pregnant women.

\section{Overview of Constructs and Stage Effects}

The TMC (DiClemente \& Prochaska, 1982; Prochaska \& DiClemente, $1983,1984)$ is the dominant model referred to in describing and predicting the processes and stages involved in smoking cessation. Littell and Girvin (2002) in a review of the literature note that the TMC has been the subject of more than 175 empirical studies since 1990.

The transtheoretical model is a framework for "undorstanding, measuring, and intervening in behavior change" (Velasquez et al., 2001, p. 1). Behavior change, such as smoking cessation, is seen as a process involving both volition and motivation that occurs over time as the individual progresses through five distinct stages of change. Movement through the stages is facilitated by ten experiential and 
behavioral processes of change. As one moves through the stages, $\bullet$ ne's decisional balance (i.e., overall weighing of the pros and cons of changing) shifts as does one's self-efficacy and confidence to make the change and resist temptations to smoke.

The TMC originated from a comparative analysis of major theories of psychotherapy conducted by James Prochaska (1979), hence the term transtheoretical. It draws heavily from social learning theory and the concept of self-efficacy (Bandura, 1977), behavior modification (Skinner, 1974), and the decision-making model of Janis and Mann (1977). The stages and processes of change were first identified by Prochaska and DiClemente (1983) from a study that compared smoking self-changers with smokers who had undergone professional treatments. They found that self-changers employed different experiential and behavioral processes of change at particular stages and that the use and timing of these processes were predictive of who would quit and who would not. Stages of Change

The number of stages, definitions, and representations of the stages have evolved since the model was first presented by Prochaska and DiClemente (1983). The initial model identified five stages - Precontemplation, Contemplation, Action, Maintenance, and Relapse - and viewed movement through the stages as unidirectional. In 1991, DiClemente et al. revised the SOC by removing relapse and adding a stage called Preparation between Contemplation and Action, resulting in five stages: Precontemplation, Contemplation, Preparation, Action, and Maintenance. Today, the model is illustrated by a spiral to indicate cyclical 
movement (Prochaska, DiClemente, \& Norcross, 1992). Relapse is still considered an important and normal occurrence of quitting smoking but is viewed as one form of regression to an earlier SOC.

Smokers in the Precontemplation (PC) stage do not perceive smoking as a problem and do not intend to alter their behavior in the foreseeable future, measured as the next six months. Precontemplators commonly have experienced few negative consequences associated with smoking, thus they perceive more advantages than disadvantages to continuing smoking.

Individuals in the Contemplation (C) stage are currently smoking but are considering quitting within the next six months. Contemplators typically indicate that they know they should quit, that they are reevaluating their smoking behavior but are not yet ready to take action. They are characterized by a high level of ambivalence and may stay in this stage for many months. Smokers who intend to quit within the next 30 ays but have not tried to quit within the past year are also classified in the Contemplation stage (compare to Preparation stage described below).

The next three stages involve some behavioral change. Smokers in the Preparation (PR) stage are intending to quit within the next 30 days and have tried, but failed, to quit within the past year. These individuals generally have set goals and commitments to stop smoking. They may demonstrate this commitment to quit by some change in behavior, for example switching to a lighter brand or smoking only at certain times or in certain places. 
Individuals in the Action (Action) and Maintenance (M) stages have quit smoking. Those in the Action stage have quit within the past six months, and those in Maintenance have maintained cessation for over six months. To be classified into these later stages, harm reduction strategies are not considered; only total abstinence counts. Individuals in Action and Maintenance remain susceptible to relapse and must be continually aware of environmental and internal temptations to smoke.

While a variety of staging measures have been used (e.g., Likert scaling measures, continuous measures), Spencer et al. (2002) in their review of the literature note that the revised SOC algorithm (DiClemente et al., 1991; Velicer et al., 1995) that places smokers into five stages of change has been the most frequently used measure. This algorithm codifies smokers into the first three stages according to their intentions to quit combined with the number of past quit attempts. The algorithm, which is detailed in the Methodology chapter, designates smokers into the final two stages by length of time they have maintained cessation.

Processes of change

The ten processes of change were developed and validated by Prochaska, Velicer, DiClemente, and Fava (1988) with an adult sample of 970 smokers. The processes are divided into two higher order factors, with each factor containing five processes. The definition and examples of interventions associated with each process are presented in Table 2 . 
Table 2

Processes of Change

\begin{tabular}{|c|c|}
\hline Process & Definition and interventions \\
\hline \multicolumn{2}{|r|}{ Experiential processes } \\
\hline Consciousness raising (CR) & $\begin{array}{l}\text { Gaining knowledge and self-awareness about } \\
\text { smoking as a problem. Strategies include } \\
\text { education, reframing. }\end{array}$ \\
\hline Dramatic relief (DR) & $\begin{array}{l}\text { Reacting emotionally to smoking messages and } \\
\text { expressing feelings about smoking. Strategies } \\
\text { include eliciting feelings, role-playing, } \\
\text { psychodrama, journaling. }\end{array}$ \\
\hline $\begin{array}{l}\text { Environmental } \\
\quad \text { reevaluation (ER) }\end{array}$ & $\begin{array}{l}\text { Awareness of how smoking affects others/ } \\
\text { environment. Strategies include education about } \\
\text { harm of second hand smoke, empathy training. }\end{array}$ \\
\hline Self-reevaluation (SR) & $\begin{array}{l}\text { Identifying personal values and thinking about } \\
\text { smoking and about continuing the behavior. } \\
\text { Strategies include values clarification, weighing } \\
\text { pros and cons, challenging beliefs. }\end{array}$ \\
\hline Social-liberation (SL) & $\begin{array}{l}\text { Noticing how society is changing to help } \\
\text { nonsmokers; increasing alternatives for policy } \\
\text { change. Strategies include policy interventions, } \\
\text { joining advocacy organizations, educating others. }\end{array}$ \\
\hline \multicolumn{2}{|r|}{ Behavioral processes } \\
\hline Self-liberation (SeL) & $\begin{array}{l}\text { Committing to and believing in ability to stop. } \\
\text { Strategics include making resolutions, increasing } \\
\text { self-efficacy, focusing on cons of smoking. }\end{array}$ \\
\hline $\begin{array}{l}\text { Reinforcement } \\
\text { management (RM) }\end{array}$ & $\begin{array}{l}\text { Rewarding one's self or being rewarded for quitting } \\
\text { and maintaining cessation. Strategies include } \\
\text { contingency contracts, overt reinforcements. }\end{array}$ \\
\hline Helping relationships (HR) & $\begin{array}{l}\text { Talking honestly about feelings; increasing support } \\
\text { through self-help groups or therapy. }\end{array}$ \\
\hline Counterconditioning (CC) & $\begin{array}{l}\text { Substituting alternative behaviors for smoking (c.g., } \\
\text { relaxation techniques, exercise, affirmations) }\end{array}$ \\
\hline Stimulus control (SC) & $\begin{array}{l}\text { Restructuring one's environment to make it easier to } \\
\text { quit, avoiding high-risk cures. }\end{array}$ \\
\hline
\end{tabular}

Adapted from Cancer Prevention Research Center [CPRC] (n.d.a) and from Miller (1999) 
The first factor or group is called the experiential processes and are internal processes that affect one's thoughts and feelings towards smoking. They reflect the individual's exploration and reevaluation of values and priorities and are most germane to the early stages of change. The second factor is called the behavioral processes and focuses on appropriate skills and activities that are helpful in quitting and maintaining cessation.

Certain stages of change are marked by very low or high levels of process activity, and particular processes are more salient in some stages than in other stages. The processes provide both the individual and service providers with a method for stage-matched interventions. For example, to help people move from Precontemplation to Contemplation, processes such as consciousness raising and dramatic relief should be applied. Strategies such as stimulus control or contingency management would be counterproductive but would be important in the later stages as relapse prevention skills. The processes of change have received the most empirical support in the research (see Spencer et al., 2002) as they are the independent variables used in intervention studies to determine stage movement. Further, they have been shown to be good predictors of changes in smoking status at six months into the future (see e.g., DiClemente et al., 1991; Fava, Velicer, \& Prochaska, 1995; Prochaska \& DiClemente, 1984).

\section{Decisional Balance}

Various shifts in motivation are expected to occur as smokers move through the stages. This attitude toward change is operationally defined in terms of a 
decisional balance, where the individual weighs the pros and cons of changing. The Decisional Balance (DB) measure, developed by Velicer, DiClemente, Prochaska and Brandenburg (1985) assesses the relationship between the pros and cons and the stages of change. Decisional balance is derived from the decision-making model of Janis and Mann (1977). The Janis and Mann model suggests that there are four categories of pros (instrumental gains for self and others and approval for self and others) and four of cons (instrumental costs for self and others and disapproval for self and others) that affect behavioral change. Considerable empirical research on the Decisional Balance for Smoking Scale (sce Spencer et al., 2002) has consistently produced only two factors, the pros and cons. The pros represent the pleasurable and anxiety-reducing aspects of smoking and dominate in the first three stages of change. The cons reflect the negative health effects and the perceived social pressures not to smoke. The cons begin to outweigh the pros during the latter part of Preparation and through Maintenance.

\section{Self-efficacy/Temptation}

Self-efficacy is the confidence an individual has that he or she can quit smoking and also refrain from smoking in specific high-risk situations. Temptation is a converse measure and reflects the intensity of urges to smoke. The same items can be used to measure both constructs using different response formats. In considerable research among adults, Prochaska and colleagues (e.g., DiClemente, Prochaska, \& Gilbertini, 1985; Prochaska, Velicer, Guadagnoli, Rossi, \& DiClemente, 1991; Velicer, DiClemente, Rossi, \& Prochaska, 1990) have found 
three factors that reflect the most common types of situations that increase temptations to smoke. These include (a) Negative Affect situations, situations that cause stress, frustration, and boredom; (b) Habit/Addictive situations, situations where the feeling of craving a cigarette is high such as with coffee, at a party, after a meal; and (c) Positive Social situations, for example with friends who smoke or while at a party. The Temptation measure pinpoints the important targets for intervention and addresses the social aspects of use and the negative affects that maintain smoking.

Stage Effects: The Relationships between Constructs

Empirical research has shown that there are significant differences between an individual's temptation and self-efficacy level, his or her weighing of the pros and cons, and the processes used in different stages of change (see e.g., De Vries, Mudde, Dijkstra, \& Willemsen, 1998; DiClemente et al., 1991; Perz, DiClemente, \& Carbona, 1996; Spencer et al., 2002; Velicer et al., 1985). A diagram of the constructs and stage effect for each construct discussed in this section is displayed in Figure 1. In the literature, scores on the Decisional Balance and Selfefficacy/Temptation Scale are often converted to standardized T-scores that have a mean of 50 and a standard deviation of 10 (Wright, 1976) to allow for comparisen between studies.

Stage and processes of change. Certain change processes tend to be used more often or "peak" during particular stages. Each of the processes is related to 
Figure 1. Transtheoretical model of change: Stage effects

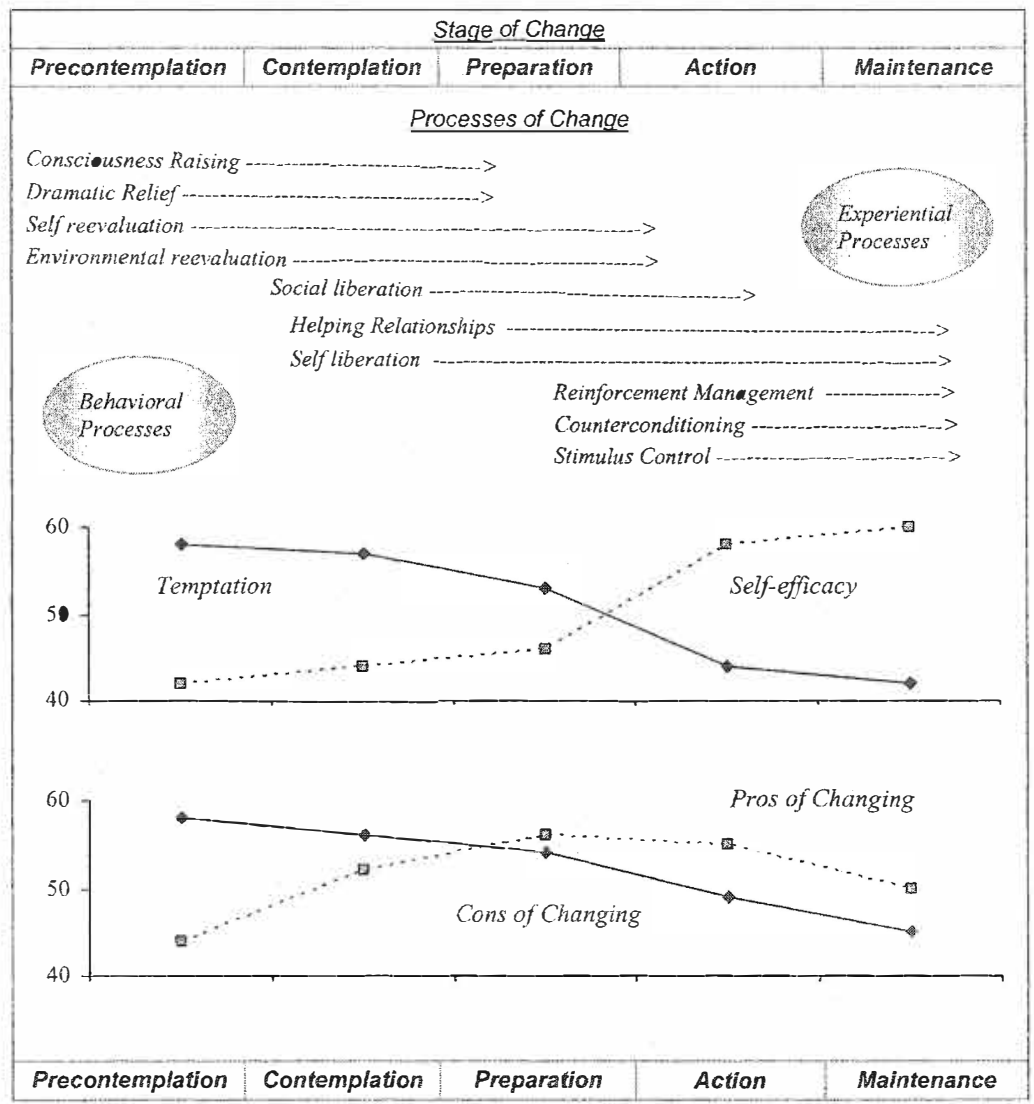

Adapted from CPRC (n.d.a) and from Miller (1999)

the SOC by a curvilinear function, with experiential processes most often used in the movement from Precontemplation to Preparation and peaking in the Contemplation stage. Behavioral processes are typically used to progress through Preparation, Action and Maintenance, peaking somewhere between the Action and 
Maintenance stage. Precontemplators use the processes of change the least, and those in Contemplation and Action use them the most (Prochaska et al., 1992). Evidence from a number of studies indicates that stage status as well as stage transitions are reliably related to the processes of change (see review in Spencer et al., 2002). For example, Perz et al. (1996) examined whether certain processes used during different stages of change influenced quit success. The investigators used a multivariate analysis of covariance at one-month and six-month follow-up with 388 smokers who began in the Contemplation or Preparation stage. Results supported their hypothesis that successful stage transitions involve engaging in experiential process activities during the Preparation and Contemplation stages and shifting to behavioral activities during the Action stage.

Stage and decisional balance. Key relationships have been observed between the stages and the pros and cons of the Decisional Balance Scale (De Vries et al., 1998; Prochaska et al., 1991). Typically, precontemplators report fewer pros and more cons of quitting smoking. However, a crossover occurs around the Contemplation and Preparation stage with the pros of quitting becoming more salient. From Preparation through Maintenance, the pros of quitting continue to outweigh the cons. During the first three stages, the decisional balance is an important predictor of cessation. During the latter stages, as nonsmoking becomes established, both the pros and cons diminish, although the cons continue to remain higher than the pros. 
Prochaska et al. (1994) found that precontemplators weighed the pros of maintaining the behavior more highly than they weighed the cons for 12 different problem behaviors. The authors note that findings suggest strong and weak principles for describing and measuring progression through the stages. Specifically, to progress from Precontemplation to Action, the pros of change increase by one standard deviation (SD); this is called the strong principle. In addition, the cons of changing decrease by one-half SD; this is the weak principle. In other words, the pros of changing increase twice as much as the cons decrease. For intervention purposes, this tells us that focusing on the advantages of quitting is more important in the movement from Precontemplation to Preparation than focusing on the disadvantages of smoking.

Stage and self-efficacy/temptation for smoking. As shown in Figure 1, the stage effect for self-efficacy is typically represented by a monotonically increasing function across the stages. Temptation is a monotonically decreasing function, with both crossing somewhere between the Preparation and Action stage. Because Progression through the stages is associated with higher efficacy levels, selfefficacy measures can provide useful information about stage status. DiClemente et al. (1985) note that in the Precontemplation stage, however, it is difficult to differentiate between unwillingness to change and a true low level of self-efficacy. Changes in temptations to smoke begin to occur in the Preparation stage, with those preparing to quit being least tempted in Positive/Social situations and Habit/Addictive situations and most tempted in Negative/Affective situations, such 
as feeling angry or frustrated. Temptations to smoke decrease steadily through the Action and Maintenance stages. Behavioral measures of smoking (e.g., quantity smoked, length of time smoking, quit attempts) are highly correlated with stage, showing that the Preparation group of smokers is less addicted than both precontemplators and contemplators (Fava et al., 1995). However, because temptations to smoke generally remain high for smokers, significant differences in situational temptations to smoke generally do not occur until the Maintenance stage. Motivation and self-efficacy are known predictors of smoking cessation and relapse (see review of studies by Albrecht, Rosella, \& Patrick, 1994; Quinn, et al. (1991). In a review of smoking cessation studies, Strecher, McEvoy, and Becker (1986) concluded that ratings of self-efficacy were found to discriminate spontaneous quitters from continued smokers, joiners from non-joiners of cessation programs, and successful from unsuccessful participants in cessation programs.

\section{Validity and Reliability of the Model}

There is an emergent critique of the TMC with most criticism centering on three aspects: the staged versus the continuous nature of smoking, the existence of pseudo-stages and/or subtypes within specific stages, and measurement issues of the staging construct. An in-depth discussion of these issues and findings from studies may be found in Davidson (1998), Etter and Sutton (2002), Farkas et al. (1996), Littell and Girvin (2002), Spencer et al. (2002), and Sutton (2000). A brief overview of these issues is presented here. 
Sutton (2000) charges that the stage definitions are logically flawed for two reasons. First, they are defined in such a way that some smokers can not move directly to the next stage. Second, the time frames are arbitrary, which, in turn, casts doubt on whether the stages are qualitatively distinct or may, instead, be pseudo-stages. For example, using the five-stage algorithm, a smoker can never be preparing for his or her first quit attempt because classification into the Preparation stage requires a recent quit attempt. Furthermore, Sutton argues, the stage measures have not shown predictive validity, and the causal relationships among the different TMC constructs are not clearly specified. In stage models, transitions between stages are normally the dependent variables and other constructs are the independent variables. However, according to TMC proponents Martin, Velicer and Fava (cited in Sutton), the processes of change act as independent variables and the pros, cons, self-efficacy, and temptation are dependent variables. Sutton notes that it is not clear if proponents mean that the processes of change influence stage transitions by way of the other constructs. Another criticism is that most research on the TMC involves cross-sectional stulies, and cross-sectional associations of dynamic constructs are open to different causal interpretations. Sutton contends that "problems are compounded in research on the [TMC] because researchers often assume, erroneously, that finding differences between people in different stages supports the model" (p. 223).

Littell and Girvin (2002) in their review of 87 studies (24 of which pertained to smoking) conclude that the stages are not mutually exclusive and that 
studies provide little evidence of either sequential movement through discrete stages or predicted stage effects. For example, studies comparing SOC algorithms and SOC scales to measure an individual's SOC show little concordance between them, and, in fact, some individuals endorse items that reflect nonadjacent stages or items that are thought to reflect different stages. A study by Herzog, Abrams, Emmons and Linnan (2000) found that the experiential processes of change predicted motivation to quit smoking as measured by a continuous measure while Herzog, Abrams, Emmons, Linnan, and Shadel (1999) found that no processes of change predicted motivation when assessed by the SOC algorithm. Further, the investigators suggest that the model oversimplifies the complexities and the continuous process of behavioral change by imposing artificial categories on a continuous process. Noting that no studies have documented movement through the entire stage sequence, they say that while "associations between stage classifications and other variables bave been reported, it is not clear whether these might be better accounted for by continuous measures of readiness for change" ( $p$. 244). Littel and Girvin agree that the model has heuristic value, but they do not support its utility for stage-matched interventions.

The controversy over the staged versus continuous nature of smoking uptake is evidenced as well in the adolescent literature (Mayhew et al., 2000). Lloyd-Richardson et al. (2002) argues for stage categories because they provide the structure for examinations of which variables distinguish various levels of smoking. She states, "Stage conceptualizations reflect the dynamic phenomenon of 
developmental changes taking place and have important implications for controlling smoking among adolescents" (p. 999). Furthermore, she notes that the ability to evaluate whether a particular variable exerts differential influence during progressively different stages has considerable implications for tailoring primary or secondary prevention efforts.

The most recent and most thorough literature review of the TMC was conducted by Spencer et al. (2002) who comprehensively analyzed of 148 peerreviewed studies published prior to March 1, 2001 in order to (a) determine the validity of its constructs, (b) assess the evidence for the use of stage-matched interventions, (c) describe general community and special populations in relation to the TMC constructs, and (d) assess the reliability and validity of methods for determining stage membership. Spencer et al. reviewed 54 construct validation studies, 73 population studies (including 9 with adolescents and 10 with pregnant women), and 37 interventions (either stage-matched interventions or non-tailered programs that were evaluated using the TMC constructs). An overview of findings regarding construct validation, measurement issues and special populations is presented here.

In assessing the construct validity, Spencer et al. (2002) concludes that the TMC is rooted in established theories, that the internal consistency of the constructs has been substantiated by multiple statistical measures in the research and that generalizability across gender, age, socioeconomic, racial/cultural, and international populations has been shown. Overall, studies support the main tenets 
of the TMC - that smokers use different processes across stages, increase in selfefficacy, and experience changes in the perceived pros and cons of smoking. Spencer et al. note that "three studies identified which processes are used in each stage by successful quitters, thus supporting the concept of stage-matched interventions in which specific processes are encouraged" (p. 60). Studies of the Decisional Balance construct, however, have produced mixed results with respect to whether emphasizing the pros of quitting or the cons of smoking in the early stages will move smokers forward.

Spencer et al. (2002) provide a comprehensive review of the construct validity of the stages of change and the evolution of the staging mechanisms. They concur with Littell and Girvin (2002) and Sutton (2000) that the research is mixed regarding the existence of pseudostages. They note, however, that since Sutton's review, two well-designed, prospective studies have validated the SOC construct. Regarding the issue of whether a continuous scale is better than a categorical measure, Spencer et al. maintain that the evidence supporting a fivestage categorization measure is inadequate to date. While one study (Donovan, Jones, Holman, \& Corti, 1998 cited in Spencer et al.) demonstrated good test-retest reliability of the algorithm ( $80 \%$ agreement at measures seven days apart) and high internal consistency $(\alpha=.72)$, findings from other studies suggest that either a seven-stage algorithm with three levels of Precontemplation or a continuous scale might be better measurements. Spencer et al. suggest further research on subtypes 
within stages and the use of more linear methods of staging smokers for individualized interventions.

\section{Types of Research Using the TMC}

Research on the TMC typically includes (a) cross-sectional designs in which individuals are first classified into the SOC and then compared on variables on which they would theoretically be expected to differ; (b) longitudinal designs to determine variables predictive of movement across the stages; and (c) intervention studies of either stage-matched interventions or a tobacco cessation intervention that is evaluated using TMC constructs (see review of the literature in Littell \& Girvin, 2002 \& Spencer et al., 2002).

In studies with three large representative samples of adult smokers, Velicer et al. (1995) demonstrated that the distribution across the first three stages is approximately identical, with about $40 \%$ in Precontemplation, $40 \%$ in Contemplation, and 20\% in Preparation. This $80 \%$ "rule of thumb" (Prochaska \& Velicer, 1997, p. 41) distribution was supported in another study that assessed the SOC for 15 health behaviors with a sample of 10,000 members of an HMO. Spencer et al. (2002) notes that 16 studies, including some conducted outside of the United States, have identified $50 \%$ or more of subjects as being in either the Precontemplation or Contemplation stage.

Several studies using the TMC have involved populations of women, samples from low socioeconomic status, and/or non-White ethnicity (in particular African-American and/or Asian) (Spencer et al., 2002). For example, a study by 
Johnson, Fava, Velicer, Monroe, and Emmons (2002) had a study sample consisting of 296 parents who smoked, with $91.4 \%$ female. Only $20 \%$ had greater than a high school education, and the mean age was 28.4. Since the study involved smokers only, the stage distributions did not include the Action and Maintenance stages. The stage distribution was $25.4 \%$ in Precontemplation, $42.3 \%$ in Contemplation, and $32.3 \%$ in Preparation. Johnson et al. note that perhaps there were less in the Precontemplation stage than the consistent proportions found by Velicer et al. (1995) because women with young children are more apt to be contemplating or preparing to quit. Results indicated stage differences før eight TMC subscales; there were no significant differences, however, for the pros of smoking or for the Habit Strength or Positive Social subscales from the Temptation Scale. While there was nø linear decline across stages as usually found for temptations, there was an overall decrease from Precontemplation to Preparation.

Many studies (see Spencer et al., 2002) have shown that across various samples of smokers, the amount of progress made following an intervention is directly associated with baseline SOC. For example, DiClemente et al. (1991) reported that six months following a smoking cessation intervention, seven times as many smokers in Preparation tried to quit as compared to precontemplators. Needless to say, precontemplators rarely present for treatment or join smoking cessation interventions (Miller \& Rollnick, 1991). Velicer and colleagues note that other theories often characterize smokers in Precontemplation as individuals who are resistant or unmotivated, when, in fact, traditional programs are often not 
matched to their needs (CPRC, n.d.a)

The ineffectiveness of interventions for smokers in the Precontemplation stage has led investigators to examine whether precontemplators are a homogenous group or composed of subtypes that are distinguishable by motivation to quit (see e.g., Dijkstra \& De Vries, 2000; Velicer, Hughes, Fava, Prochaska, \& DiClemente, 1995). Both Velicer, Hughes et al. and Dijkstra and De Vries found a type of precontemplator that looked more like a contemplator and another type who had the they called immotive, who had the lowest motivation to quit. These subtypes did not differ by either the pros of smoking or self-efficacy measures but did differ significantly on the cons of smoking. Norman, Velicer, Fava, and Prochaska (1958) point out that further differentiation of the stages of change will only tend to increase the effectiveness of its use in large-scale interventions.

Studies of the TMC with Adolescents and Adult Pregnant Women The TMC and Adolescents

The thrust of research on the use of the TMC with adolescents has been the development and testing of measures, in particular to determine the number and nature of stages of adolescent smoking acquisition. A secondary area has been on knowledge acquisition regarding tobacco use among adolescents and the use of the stage model as a framework for organizing other variables and processes.

Key construct validation and measurement studies include those by Pallonen, Rossi and Smith (1993), Pallonen (1998), Pallonen, Prochaska, Velicer, Prokhorov and Smith (1998), and Plummer et al. (2001). 
Pallonen et al. (1993) examined stage effects between the processes of change and the SOC using the five-stage of change algorithm with 130 adolescent smokers. Structural equation modeling confirmed the internal consistency of the processes by SOC in adolescents. The 1998 study by Pallonen compared adult data $(n=18,463)$ from three published studies to studies of adolescents $(n=2,087)$ in grades $10-12$, however the vast majority of youths were White and male. Results showed that adolescents were remarkably similar to adults in the distribution across the stages of change, however adolescent smokers appeared to be somewhat less prepared to quit ( $80 \%$ in either Precontemplation or Contemplation stage). Data on quit attempts by SOC revealed significant and theoretically consistent differences, suggesting a strong stage effect. A confirmatory factor analysis showed excellent internal consistency with the Processes of Change Scale, and the overall stage effects of process use lowest in Precontemplation and peaking in Action was observed. Process use, however, was still high in the Maintenance stage, showing that long-term quitters spent almost as much time thinking about smoking as recent quitters. Morever, adolescents rarely used the experiential processes and relied more heavily on the behavioral processes, even at the early stages of the cessation process. Elevated process use in the Maintenance stage along with reliance on behavioral processes in the early stages is consistent with high relapse rates in adolescents.

Stern et al. (1987) were the first to develop a three-stage model of acquisition and a staging instrument, and Pallonen, Prochaska, et al. (1998) 
expanded the use of the stage concept by integrating stages of smoking acquisition and cessation into a single nine-stage measure. The measure was tested with a sample of 700 teens in four vocational schools. This sample was one of the samples used in the study by Pallonen (1998). Pallonen, Prochaska et al. (1998) found three acquisition stages. Sixty-five percent of the total sample were in the acquisition stages, with $93 \%$ of these youths in the stage of never smoking and not considering smoking (i.e., acquisition Precontemplation stage). Thirty-five percent of the sample were in smoking stages, with approximately $81 \%$ of these youths in the first three stages. This study was the first to demonstrate stage effects for demographic and smoking variables found to be associated with smoking. For example, there were statistically significant $(p<.001)$ stage effects for friend's smoking, parental and sibling smoking, exposure to smoking in the environment, and number of quit attempts. The study also confirmed the strong and weak principles of behavior change suggested by Prochaska et al. (1994).

The study is also important because it was the first to test the Decisional Balance measure and Temptation Scale for both adolescent nonsmokers and smokers. Findings show that nonsmokers' positive expectations about smoking as a coping mechanism advanced the acquisition process, indicating smoking is perceived as a means to reduce stress. Further, the anticipated social benefits of starting were less important, contradicting the assumed role of peer pressure in smoking acquisition. The authors found no stage effect for the cons of smoking, which supports research showing that adolescents underestimate and minimize the 
risks of smoking. The study also showed that the coping pros rather than the social pros were more related to adolescents' readiness to quit.

In a study using computer-based interventions with adolescents, Pallonen, Velicer et al. (1998) confirmed a three-factor Decisional Balance Scale for adolescents consisting of social pros, coping pros, and cons of smoking. This scale was confirmed by Plummer et al. (2001) in phase one of a four-year study with 2,808 high school students. These studies are important because they demonstrate that coping with stress is an important factor in smoking for adolescents. The study by Plummer et al. also identified four acquisition stages - Precontemplation, Contemplation, Decision Making/Preparation, and Action - and a Temptation Scale for both smokers and nonsmokers that included a factor for weight control. This work strongly supports the application of the TMC across age and gender groups of adolescents. [Note: Further discussion of these measures is in the Methodology chapter].

The SOC construct has been used in several cross-sectional surveys and prospective studies of adolescents to learn more about adolescent tobacco use or to determine psychosocial variables related to stages (e.g. Hollis, Polen, Lichtenstein, \& Whitlock, 2003; Prokhorov et al., 2001; Siguiera, Rolnitzky, \& Rickert 2001; Tomeo et al., 1999) and as a measure of the effect of intervention studies (Aveyard et̂ al., 1999; Coleman-Wallace, Lee, Montgomery, Blix, \& Wang, 1999; Pallonen, Velicer, et al., 1998; Stevens et al., 2003). 
Tomeo et al. (1999) was the first to find a relationship between smoking acquisition stages and weight concerns among children, and Hollis et al. (2003) found that depression, educational aspirations, smoking among friends and family, and ethnicity were predictive of quitting stages. Prokhorov et al. (2001) used the staging algorithm with 5,624 high school students ( $52 \%$ female) to study the relationship between nicotine addiction, withdrawal symptoms and readiness to quit smoking. Nearly $52.5 \%$ of smokers were in the Precontemplation stage and $16 \%$ were in the Contemplation stage. Nicotine dependence and withdrawal symptom scores were highly correlated with stages $(r=.44, p<.001)$.

Siguiera et al. (2001) also studied the relationship between stage, nicotine addiction, and stress with SOC as the independent measure. The sample was 354 multi-ethnic youth ( $46 \%$ Hispanic and 47\% African American) from an inner-city health clinic; $83 \%$ of the sample was female. This study confirmed the findings of Prokhorov et al. (2001) that smokers in the earlier stages are significantly more likely to report addiction and stress. There was also significant less use of the experiential coping methods by smokers than by quitters, which is contrary to the predicted relationship found in adults but confirms the findings of Pallonen (1998) with adolescents.

Two studies (Aveyard et al., 1999; Pallonen, Velicer, et al., 1998) have examined stage-matched interventions. Aveyard's et al. study with 8,352 British high school students and demonstrated that while the staging mechanism discriminated the stages of acquisition and cessation, their stage-based smoking 
cessation intervention had no effect. Pallonen, Velicer, et al. tested two computerized self-help interventions with 704 high school students, 135 of which were smokers; approximately $41 \%$ were female. This study was important for three reasons. First, it showed high participation rates, almost $90 \%$ in at least two intervention sessions. Second, stage distribution using the algorithm was similar in both interventions, providing support for the measure. Third, quit rates of up to $20 \%$ were observed, but six-month follow-up showed that adolescents were poorly prepared to maintain abstinence. A quasi-experimental study by Coleman-Wallace et al. (1999) found that a stage-based intervention was effective in reducing smoking among high school students. However, there were internal threats to validity having to do with subject sclection, and attrition was not addressed.

In summary, the TMC theory appears to apply to diverse adolescent populations, but there are important differences from studies with adults, and, clearly, further study is warranted. First, the continued development of measures to determine acquisition stages and to validate the TMC tenets is important, in particular with special populations. Second, the studies suggest that there are stage effects for demographic and psychosocial variables that have been identified in the literature as associated with smoking among female adolescents. Third, adolescent acquisition of snoking as well as smoking progression appears to be highly motivated by coping methods to reduce stress. Finally, adolescents appear less likely to use the experiential processes of change than the behavioral processes. 
There is some debate about whether adolescents possess the cognitive and emotional maturity to apply many of the constructs from the TMC. For example, metacognition and self regulation are important processes developed during adolescence and also are important in applying some of the processes of change. Spencer et al. (2002) contends that the experiential processes may require an emotional maturity that adolescents lack and that they may need more assistance during intervention programs in using these processes. However, in a review of the teen smoking cessation literature, Mermelstein (2003) concluded that the evidence is most promising for interventions that follow cognitive-behavioral principles of change, which include training in self management, coping skills, and problem solving combined with specific techniques for enhancing motivation. Pallonen (1998) recommends that eliminating the mismatch between the stage and the process use as well as providing structure and sufficiently long interventions will improve stage-matched interventions to help adolescents quit.

Two recent studies suggest that adolescent substance users and pregnant teens respond positively to social cognitive and behavioral interventions. For example, Dennis et al. (2000) reporting on a multi-site randomized field experiment funded by CSAP using motivational enhancement therapy (MET) and cognitive behavioral therapy (CBT) to reduce marijuana use among adolescents, noted significant reductions in marijuana use and related problems. Koniak-Griffin et al. (2003) reported on the efficacy of an HIV prevention program for adolescent mothers in Los Angeles who were from predominantly poor, Latina backgrounds. 
The program, called Project CHARM, used concepts derived from social cognitive theory and the theory of reasoned action (Ajzen, 1998), whose constructs are not dissimilar from the TMC. The women in the treatment group demonstrated significant improvements in outcomes being measured than the control group.

\section{The TMC and Adult Pregnant Women}

Considerable research has been conducted on the application of the TMC constructs and/or stage-matched interventions with adult pregnant smokers, including those from low-socioeconomic and/or multi-ethnic populations (Bane et al., 1999; Crittenden, Manfredi, Lacey, Warnecke, \& Parons 1994; De Vries \& Backbier, 1994; DiClemente et al., 2000; Dolan-Mullen et al., 1997; Ershoff et al., 2000; Haslam \& Draper, 2000; Hughes et al., 2000; Manfredi, Crittenden, Cho, Engler, \& Warnecke, 2000; Rattner et al., 2000; Ruggiero et al., 1997; Ruggiero et al., 2000; Solomon et al., 1996; Stotts et al., 1996; Stotts, DiClemente, Carbonari, \& Dolan-Mullen, 2000; Stotts et al., 2002; Valanis et al., 2001; Woodby et al., 1999). This section discusses the literature that is most relevant to the proposed research questions.

A study by Bane et al. (1999) showed that pregnant smokers demonstrate the predictive stage effects for the pros and cons of smoking. The investigators developed a Pregnancy-Tailored Decisional Balance measure and tested it with 281 low-income, pregnant young women; $68 \%$ were current smokers. Using the processes of change subscales and the Decisional Balance measure as dependent variables and the SOC as the independent variable, smokers scored significantly 
higher $(p<.001)$ on pregnancy related pros of smoking (e.g., to relax and reduce stress) than nonsmokers. Those in either Action or Maintenance scored higher on the cons (e.g., concern about health effects and disapproval of others).

Stotts et al. (1996) examined process use and self-efficacy/temptations among women who stopped smoking during pregnancy with women in the process of cessation but not pregnant. The sample consisted of 89 pregnant women who had quit smoking, 28 nonpregnant smokers who had recently quit, and 92 nonpregnant smokers in the Preparation stage. Pregnant women differed dramatically in process use and self-efficacy/temptations from nonpregnant women. The level of experiential process use was significantly lower for pregnant quitters as compared with both nonpregnant quitters and nonpregnant smekers. Moreover, pregnant quitters used significantly less behavioral processes than nonpregnant quitters. This lack of experiential and behavioral process use is very unlike the general population of smokers, however the low level use of the experiential processes is similar to adolescents in the early stages of change.

Finally, self-efficacy levels were extremely high and temptation levels uncommonly low among pregnant quitters. Stotts et al. (1996) hypothesize that exaggerated confidence levels result in less temptations to smoke, thus providing a false sense of control over their habit, which results in relapse once the extrinsic motivation of pregnancy is gone. DiClemente et al. (2000) believe that this lack of normal cessation process use may explain the large relapse rates in the first six months, and that the challenge is to shift motivation from baby to self and increase 
process activity during the last trimester and early postpartum. The study by Stotts et al. is important also because it demonstrates that pregnancy itself can be a motivation for change and that change, rather than a progression through stages, can come about quickly as a result of external forces.

Ruggiero et al. (2000) compared 103 low-income, pregnant smokers from a community clinic with a matched group of 103 low-income, nonpregnant smokers. Contrary to the findings by Stotts et al. (1996), pregnancy did not appear to be a strong motivator to quit; further, there was increased use of processes with advanced stages for both pregnant and nonpregnant women. Pregnant smokers, however, were significantly more likely to use consciousness raising, dramatic relief, and environmental reevaluation. There were no differences in either temptations or the pros of smoking between groups; however, pregnant smokers placed less value on the cons compared with nonpregnant smokers. Ruggiero et al. hypothesize that pregnant women may be more tempted in some areas before they quit, but become more confident and less tempted than nonpregnant women once they quit. This is consistent with Stotts et al. hypothesis that pregnant women are able to quit because of external factors.

Given the differences in the cessation process between pregnant and nonpregnant smokers, Stotts et al. (2000) developed and tested a staging algorithm to better predict relapse during postparturn. Subjects were 256 pregnant smokers from an HMO who completed a baseline prenatal interview and follow-up at 3-, 6-, and 12-months postpartum. Sixty-eight percent of women returned to smoking 
postpartum. The rate of return to smoking and how soon a woman would relapse followed the staging pattern, that is, those in Precontemplation at baseline were most likely to relapse and relapse earlier than those in Contemplation, then Preparation, and so on. This study is important not only because it provides important insights into pregnancy/postpartum smoking behavior but also because the staging algorithm successfully predicted smoking status in postpartum period. Stotts et al. note that the revised algorithm was more predictive of relapse than the five-stage standard algorithm, wherein all of these women would have been classified as being in the Action stage.

Two studies have examined the effects of a smoking cessation intervention on low-income, pregnant women (Solomon et al., 1996; Stotts et al., 2002). Solomon et al. did not use the staging algorithm but instead staged pregnant women according to smoking status and motivation to smoke or quit. They hypothesized that brief physician advice to quit and counseling would result in stage progression over time. Findings showed that while the intervention was effective in moving smokers from Precontemplation to Preparation in the early weeks of pregnancy, there was not a sustained effect. Stotts et al studied the efficacy of a late pregnancy smoking cessation intervention for resistant pregnant smokers $(n=269)$ using a stage-matched letter and two phone calls using motivational interviewing strategies. Findings showed a modest effect on smoking outcomes.

DiClemente, Dolan-Mullen, and Carbonari (1999) examined data from several large-scale rials that investigated cessation during pregnancy. DiClemente 
and colleagues advise that interventions should be designed to reach women prior to or early in pregnancy. Reduction in use should be considered as an achievable late pregnancy goal. Helping quitters to make a successful transition through the early postpartum period is important. Innovative approaches involving spouses/partners, motivational interviewing, and stage matched interventions demonstrated promise.

In summary, studies of pregnant smokers have produced mixed results. While the Decisional Balance constructs appear to be consistent with findings for the general population of adult smokers, there are significant differences in stage effects for the processes of change, self-efficacy and temptations. Furthermore, pregnant smokers appear to be different from both the general public and nonpregnant smokers regarding these constructs. Investigators hypothesize that relapse rates are high postpartum because coping strategies and external motivations used during pregnancy to not smoke may not be effective postpartum. Moreover, the pattern of smoking behavior during pregnancy and postpartum and the role of self-efficacy in sustaining cessation has yet to be determined.

\section{Summary of Literature}

There is no unifying model or theory to explain smoking behavior among female adolescents and pregnant/parenting teens. It is due both to nicotine dependence and to a myriad of socio-demographic, psychosocial, biological, and environmental factors. Socioeconomic status and race/ethnicity are key sociodemographic predictors. At the psychosecial and behavioral level, important 
predictors and associates include depression, rebelliousness and impulsivity, maternal smoking, friends' and partner's smoking, body image, attitudes about smoking, healthiness, physical and/or sexual abuse and intimate partner violence, alcohol and illicit drug use, stress, exposure to suicide or suicidality, religiosity, adult and peer support, sexual orientation, and school connectedness.

At the macro level, comprehensive tobacco prevention initiatives, counter advertising strategies, and social control policies have been shown to affect adolescent smoking rates (Forster et al., 1998; Stead \& Lancaster, 2000). Smoking during pregnancy has increasingly become socially stigmatized, and the imperative to stop smoking has been publicly visible since the 1980s. Statistics of reductions in smoking among pregnant teens since 1999 (Martin et al., 2002) suggest that antismoking campaigns and health education programs have been successful, and higher cigarette excise taxes have been shown to reduce smoking among teen mothers (Ringel \& Evans, 2001). Further, pregnancy itself and the transition to motherhood operate as a motivator for many teens to quit smoking. Given these external and internal pressures to stop smoking during pregnancy, the fact that upwards of $27 \%$ of pregnant teens continue to smoke demonstrates the formidable challenges in attaining smoking cessation among this population. Indeed, DiClemente et al. (2000) point out that younger women who decide to smoke "in the context of the current anti-smoking climate and social norms constitute a subgroup of the population that would be more resistant to cessation pressures and needs to be better understood" (p. 17). 
There is a growing body of literature evaluating the effectiveness of stage based interventions, primarily with adult populations, and the evidence is mixed (see for example Riemsma et al., 2003; Spencer et al., 2002). Studies of stagematched interventions need to be conducted with special populations, such as adolescents and pregnant women. As Stotts et al. (1996) note, the atypical smoking patterns in pregnant women present difficulties for staging them and thereby developing stage-matched or other successful interventions. Are similar patterns evident with pregnant/parenting teens? What can TMC measures tell us about the process of quitting/continuing smoking and postpartum relapse among this population? Do pregnant/parenting teens exhibit similar patterns with TMC mediators of change - self-efficacy and process use - as adolescents in general or pregnant adults? It is hoped that the present study, which consists of an examination of stages of change among this population and an examination of variables and measures associated with these stages, will provide helpful information in understanding more about the process of cessation such that appropriate interventions can be developed.

\section{Research Questions}

The rationale for this study and the specific research questions stem from suggestions for future research from the literature review and from studies that have found important relationships among the TMC constructs for adolescents and adult pregnant women. The analytic procedures are modeled after TMC studies in general and those by Stotts et al., (1996) and Johnson et al. (2002) in particular. 


\section{Research Question One}

The aim of the first question was to ascertain whether certain demographic and psychosocial variables noted in the literature as associated with smoking initiation, progression and cessation are associated with never smokers and particular stages of change.

1. What are the similarities and differences among never smokers and the smoking stages of change by the following demographic and psychosocial variables: age, race/ethnicity, pregnancy/parenting status, spirituality, domestic violence, perceived harm of smoking, perceived wrongfulness of smoking, sensation seeking, days used alcohol and marijuana in past 30 days, friends' smoking, partner's smoking, depression, smoking self-efficacy, smoking intention, perceived health, quality of life, peer support, adult support, and adult expectations.

\section{Research Question Two}

The aim of research question two was to examine the stage effects of the TMC.

2. Do the relationships between the stages and the Decisional Balance Scale, Temptation to Smoke Scale, and Processes of Change Scale evidence the theoretically predicted stage effects?

\section{Research Questions Three and Four}

The aim of research questions three and four was to examine the stage effects of the TMC by pregnancy status. 
3. What are the similarities and differences in process activity between pregnant teens who have quit smoking, nonpregnant teens who have quit smoking, and nonpregnant teens who are contemplating or preparing to quit smoking?

4. What are the similarities and differences in self-efficacy and temptation to smoke between pregnant teems who have quit smoking, nonpregnant teems who have quit smoking, and nonpregnant teems who are contemplating or preparing to quit smoking? 


\section{CHAPTER III - METHODOLOGY \\ Sampling and Data Collection Procedures \\ Sampling and Recruitment}

The sample consisted of 245 pregnant and/or parenting females aged 12 through 18 at the time of enrollment into the STAGES study and living in Multnomah County, Oregon. Parental consent was not required for teens aged 18 nor for teens under the age of 18 who had a child; parental/legal guardian consent was required for teens under age 18 who did not have a child. Appendix C provides samples of recruitment materials from the STAGES study.

The STAGES intake manager actively recruited teens into the study by conducting speaking engagements at schools and social service agencies and by distributing STAGES brochures. Teens could self-refer to the study or be referred by staff of local organizations, for example teachers from local and alternative high schools, community health nurses, case managers from public and/or nonprofit organizations serving pregnant and parenting teens. Following referral, the teen was mailed a letter that explained the study, the consent form, and the brochure. This was followed up by a telephone call from the intake manager who explained the study, the confidentiality and consent procedures, and answered any questions the teen and/or her parent or legal guardian might have. The intake manager also queried the teen about reading level and reading difficulties in order to prepare the 
surveyor. Teens who agreed to participate were assigned to a surveyor who contacted the teen to schedule a survey date.

\section{Data Collection and Entry}

The 245 participants were enrolled in three separate groups or cohorts at eight-month intervals. Baseline data were collected on the first cohort of 80 participants between March and June of 2002, the second cohort of 86 between December 2002 and February 2003, and the final cohort of 80 between September and November 2003.

Surveyors were trained in study protocols and survey administration procedures by the author. The surveyor collected the consent form before administering the survey and reiterated the confidentiality procedures of the study. Surveys were self-completed; however teens were stopped at certain questions and provided an explanation. In particular, teens were stopped at the start of the section about drug, alcohol, and tobacco use and reminded that their answers are both voluntary and confidential and that they could skip any questions they felt uncomfortable answering. These procedures have been reported to maximize the validity of self-report (Pallonen, Prochaska et al., 1998). Surveyors read the questions aloud to participants known to have difficulty reading. Survey administrations typically took place in the teen's home and took about one and onehalf hour to complete. Teens were remunerated $\$ 20.00$ upon completion and informed of their group assignment. All forms were then placed in a manila envelope and given directly to this author. 
The cover sheet of the survey contained no identifying information. The author assigned participants a code number linked to her name for follow-up purposes. The consent form and all other personal information were kept apart from the answers to the survey instrument, and only the author had access to this information.

Creation of all data files and entering of all data was done by the author using SPSS 8.0. Quality of the data and reduction in errors were ensured through data cleaning protocols similar to those used in the PAI/CHOICES study (ITPP, 2002) wherein 1) data for an item were considered missing if the teen circled two answers where only one answer was applicable, and 2) logic checks and contingency cleaning were conducted by the author and by the CSAP data coordinating center, who then informed the author. In addition, $70 \%$ of the items of a scale had to be completed, and the scale score was the average of the number of item scores. If the participant failed to complete at least $70 \%$ of the items, the scale score was considered missing data.

\section{Variables and Instruments}

The choice of variables was determined both by the literature review and by data available from the STAGES trial. The survey instrument contained a number of standardized measures of known reliability and validity, many of which were adapted for the PAI and CHOICES study (ITPP, 2002) where reliability and validity were determined for this population. The questions as presented in the 
survey and excluding questions not pertinent to this study may be found in Appendix A.

\section{Constructs from the Transtheoretical Model of Change}

Transtheoretical model-based measures include the Adolescent Stages of Change short form (CPRC, n.d.b), Temptation to Smoke Inventory for smokers ${ }^{3}$ and the Decisional Balance Scale (both from Plummer et al., 2001), and an abbreviated 10-item version of the 20-item Processes of Change Scale (CPRC). These measures, identification of the subscales, and scoring instructions may be found in Appendix B.

The SOC algorithm assesses current smoking with one question, "Are you currently a smoker?" Possible choices and stage classifications are (1) No, I have never smoked regularly (Nonsmoker); (2) No, I used to smoke but I quit more than six months ago (Maintenance stage); (3) No, I used to smoke but I quit within the past six months (Action stage); or (4) Yes, I currently smoke. Smokers are prompted to answer two additional questions. The first assesses whether or not they have had a 24 -bour quit attempt within the past year. The second asks about intentions to quit within the next 6 months or next 30 days. If they report not considering quitting, they are classified into the Precontemplation stage. Those reporting considering quitting within the next six months are classified into the Contemplation stage. Those reporting considering quitting within the next 30 days

\footnotetext{
${ }^{3}$ The STAGES study used both the smokers' and nonsmokers' subscales in the survey; only the smokers' subscales were examined for this study.
} 
who also report at least one 24-hour quit attempt within the past year are classified into the Preparation stage; those not reporting a 24-hour quit attempt are classified into the Contemplation stage.

The Decisional Balance Scale (Plummer et al., 2001) is a 12-item scale and assesses six items that measure the pros of smoking - three items reflecting the coping pros and three reflecting the social pros - and six items measuring the cons of smoking. The items employ a five-point Likert scale rating the importance of the item in making decisions about whether or not to smøke and range from 1 (not at all) to 5 (very much). The measure was adopted from the scale for adult smokers and verified in an adolescent sample (Pallonen, Velicer, et al., 1998). Most recently, Plummer et al. confirmed the three-factor model in a sample of 2,808 adolescents. Coefficient alphas for each construct for both the Pallonen, Velicer, et al. study and the Plummer et al. study are displayed in Table 3.

Table 3

Coefficient Alphas for the Decisional Balance Scale

\begin{tabular}{lcc}
\hline Construct & Pallonen, Velicer, et al. (1998) & Plummer et al. (2001) \\
\hline Social pros & & \\
$\quad$ Smokers & .67 & .79 \\
Nonsmokers & .68 & .68 \\
Coping pros & & \\
$\quad$ Smokers & .75 & .87 \\
Nonsmokers & .81 & .79 \\
Cons & & \\
Smokers & .78 & .88 \\
Nonsmokers & .85 & .86 \\
\hline
\end{tabular}


The Temptation to Smoke measure (sometimes called the Situational Temptation Inventory) is from Plummer et al. (2001). The original measure (Velicer et al., 1990) that identified three factors - Positive Social situations, Negative Affect situations and Habit Strength - was adapted and modified for adolescents by Ding, Pallonen, Migneault, and Velicer (1994) and Ding, Pallonen, and Velicer (1995). This resulted in an eight-item scale for nonsmokers and smokers with four distinct factors and high Coefficient Alphas: Positive Social $(\alpha=$ .68), Negative Affect ( $\alpha=.90)$, Peer Situations ( $\alpha=.75)$, and Curiosity $(\alpha=.80)$. Plummer et al. added two questions that assessed smoking as a means of weight control and determined its psychometric properties with 2,808 high school students.

The result was an eight-item, four-factor model for smokers and a ten-item, fivefactor model for nonsmokers. Coefficient alphas for the scale are presented in Table 4.

Table 4

Coefficient Alphas for the Temptation Scale

\begin{tabular}{lcc}
\hline Subscale & Smoker alpha & Nonsmoker alpha \\
\hline Negative affect & .91 & .83 \\
Positive social & .81 & .77 \\
Habit strength & .72 & na \\
Weight control & .88 & .85 \\
Curiosity & na & .66 \\
Social pressure & na & .77 \\
\hline
\end{tabular}


There is both a long form and short form of the Processes of Change Scale, with the long version consisting of a 40 -item questionnaire with two items each to measure the five experiential processes and the five behavioral processes. The measure was administered to adolescents (cited in Pallonen, 1998) and ten reliable factors were validated with internal consistency of the measures varying between .78 and .91 . A 20-item short form with two questions assessing each process has been found to be both reliable and valid (Fava et al., 1995). For this study, due to survey length and time limitations, only one question instead of two was used to measure each of the ten processes. The measure was administered to current smokers and smokers who had quit within the past year; never smokers and those who had been quit for over a year were instructed not to answer the question.

\section{Standardized Measures}

Standardized measures, their source, and number of items are presented in Table 5 .

The nine-item Depression Scale was adapted from the 20-item Center for Epidemiologic Studies Depression Scale (CES-D) (Radloff, 1977). The shortened version was used in the PAI study and had a reliability coefficient of .82 .

The seven items included in the Peer Social Support Scale were adapted from the Multidimensional Scale of Perceived Social Support (MPSS) (Zimet et al., 1988) whose psychometric properties have been well documented (Corcoran \& Fisher, 2000). In the PAI/CHOICES study (ITPP, 2002), the reliability coefficient was .95 . 
Both the Adult Social Support Scale and Perceived Adult Expectations

Scale were adapted from the California Healthy Kids Survey Resilience

Assessment from the Califomia Department of Education (G. Austin, personal communication, August 5, 2003). The four-item Adult Support Scale had an alpha of .83, and the Adult Expectations Scale had an alpha of .80 .

Table 5

Source of Scales and Number of Items

\begin{tabular}{llc}
\hline \multicolumn{1}{c}{ Name of scale } & \multicolumn{1}{c}{ Source of instrument } & Items \\
\hline Depression & Radloff (1977) & 9 \\
Peer support & MPSS (Zimet, Dahlem, Zimet, \& Farley, 1988) & 7 \\
Adult social support & California Healthy Kids Survey (CHKS), & 4 \\
& California Department of Education (G. Austin, & \\
& personal communication, August 5, 2003) & \\
Adult expectations & CHKS (G. Austin, personal communication, & 4 \\
& August 5, 2003) & \\
Sensation seeking & National Alcohol Survey (Alcohol Research \\
& Group, K. Trocki, personal communication, & 6 \\
TMC measures & August 6, 2003) & \\
Stage of change & & CPRC (n.d.b) \\
Temptation to smoke & Plummer et. al., (2001) & 3 \\
Decisional balance & Plummer et al., (2001) & 8 \\
Processes of change & CPRC (n.d.b) & 12 \\
\hline
\end{tabular}

The Sensation-Seeking Scale is an abbreviated six-item version from the ten-item scale of the National Alcohol Survey, developed in 1964 by the Alcohol Research Group in California (K. Trocki, personal communication, August 6, 2003). The reliability coefficient was .75 in the CHOICES study (ITPP, 2002). 
Demographic and Psychosocial Variables

Variables for analyses include participant age $(1)^{4}$, race/ethnicity $(2,3)$, pregnancy/parenting status (15), and importance of religion (99c) which is a fiveitem ordinal scale. Hispanic ethnicity is considered a separate race/ethnicity in the STAGES study. Also included is a measure of domestic violence/physical abuse (72) that was used in the CHOICES study. Endorsement of any item $1-7$ is scored as "yes" for what is being called domestic violencelabuse and endorsement of item 8 is scored as "no." A question ascertaining perceived health (71) is from the SF-12 Health Survey (Ware, Kosinski, \& Keller, 1996). The question asks, "Overall, how would you rate your health?" with response categories on an ordinal scale ranging from poor (1) to excellent (5). A single quality of life question (96) asks, "Overall, how satisfied are you with your life?" and is from the General Quality of Life Scale (Lehman, 1988). The mean of three questions (98a-c) is considered an honesty check. They ask whether the teen understood the survey questions, answered carefully, and answered honestly.

\section{Smoking and Measures of Substance Use}

Variables include use of alcohol and marijuana within the past 30 days (a dichotomized variable created from questions $78 \mathrm{a}$ and $82 \mathrm{~b}$ which ascertain use of these two substances within past 30 days, number of days smoked in past 30 days (80a), and friend's smoking (101), which is a four-item ordinal scale. These

\footnotetext{
${ }^{4}$ Number in parenthesis refers to question number on STAGES survey.
} 
measures are used in the National Youth Survey and the Monitoring the Future Survey (MTF) (Substance Abuse and Mental Health Data Archive [SAMHDA], n.d.). Partners' smoking is a question with a yes/no response (100) and was developed for STAGES.

Attitudes and beliefs about cigarette smoking are from the MTF survey (SAMHDA, n.d.), and all are ordinal measures with Likert-type response formats. Perceived harm is measured by a question (84) asking, "How much do you think people risk harming themselves physically and in other ways if they smoke one or more packs of cigarettes per day?" Response categories are "no risk," "slight risk," "moderate risk," and "great risk." Perceived wrongfulness is measured by a question (83), which asks, "How wrong do you think it is for someone your age to smoke cigarettes?" Answer categories are "not at all wrong," "a little bit wrong," "wrong," and "very wrong." Smoking self-efficacy is measured by one question (85a), "I believe I am able to not smoke cigarettes over the next six months." A single question assessing the perceived ability to stay quit for the remainder of pregnancy as a self-efficacy measure was used in a study by Woodby et al. (1999) and shown to have good predictive power. Smoking intention is also measured by one question, (85f), "I have decided that I will smoke cigarettes." Answer categories for both questions are "false," "maybe," "true."

\section{Statistical Methods}

Analyses were done using SPSS 8.0, and a significance level of $(p<.05)$ was used as the criterion for deciding whether or not to reject the null hypothesis 
unless otherwise noted. First, socio-demographic characteristics and substance use variables by cohort were examined. Univariate analysis-of-variance (ANOVA) and the chi-square test were used to test for significant differences between cohorts on important variables in order to collapse the cohorts for further analyses.

For question one, subjects were grouped into two categories - never smokers and stage of change (i.e., smokers in the five SOC changes). Descriptive statistics and tests for normality were run on quasi-interval and discrete variables, and reliability tests were conducted on standardized scales. ANOVA, ANCOVA, chi-square tests, and Kruskal-Wailis tests were used to examine similarities and differences of demographic and psychosocial variables among never smokers and stage categories. Post-hoc pairwise comparisons using the Tukey HSD and GamesHowell tests were conducted for significant findings.

The group of never smokers was excluded from the analyses of questions two through four. Reliability coefficients and intercorrelations were determined for the TMC measures, and assumption testing for multivariate analysis-of-variance (MANOVA) was conducted to determine the normality distribution, linearity, and homogeneity of variances and covariances across the stages. Transformations of the data were made when necessary to meet the assumptions. A series of MANOVAs and ANOVAs were employed to assess for stage effects.

For questions three and four, the sample of smokers was divided into three groups - pregnant teens who had quit smoking ( $\mathrm{A}$ and $\mathrm{M}$ stages), nonpregnant teens who had quit smoking, and nonpregnant teens who were contemplating and 
preparing to quit (C and PR stages) - and called pregnantinonpregnant quitters and smokers. For question three, group comparisons using MANOVA were performed with the new variable as the independent variable and the experiential and behavioral processes of change as the dependent variables. Post-hoc tests were performed using Tukey HSD.

Similar procedures were performed for question four with the habit strength, positive social, and negative affect subscales of the Temptation Scale as the dependent variables and pregnant/nonpregnant quitters and smokers as the independent variable. A Kruskal-Wallis test was used to examine smoking selfefficacy across the group of pregnant/nonpregnant quitters and smokers. 


\section{CHAPTER IV - RESULTS \\ Sample and Cohort Description}

The sample consisted of 245 young women - 80 in cohort one, 86 in cohort two, and 79 in cohort three. Demographic and substance use characteristics by cohort are presented in Table 6.

Table 6

Characteristics of Sample by Cohort (\%)

\begin{tabular}{lcccc}
\hline \multicolumn{1}{c}{ Characteristic } & Cohort 1 & Cohort 2 & Cohort 3 & Total \\
\hline Age & & & & \\
$\quad$ 15 and under & 13.8 & 15.1 & 7.6 & 12.2 \\
16-17 & 58.7 & 44.2 & 50.6 & 51.2 \\
$\quad$ 18 and over & 27.5 & 40.7 & 41.8 & 36.6 \\
Pregnant & 28.7 & 29.1 & 38.0 & 31.9 \\
Race/ethnicity & & & & \\
$\quad$ Hispanic & 36.3 & 26.7 & 25.3 & 29.4 \\
$\quad$ White & 31.3 & 36.0 & 36.7 & 34.7 \\
$\quad$ Black & 12.5 & 15.1 & 25.3 & 17.6 \\
2 or more & 13.8 & 15.1 & 7.6 & 12.2 \\
$\quad$ Other & 6.3 & 7.0 & 5.1 & 6.1 \\
Domestic violence & 25.3 & 31.4 & 29.3 & 28.8 \\
Current substance use & & & & \\
Cigarettes & 38.8 & 37.2 & 38.0 & 38.0 \\
$\quad$ Alcohol & 16.3 & 18.3 & 16.9 & 17.2 \\
$\quad$ Marijuana & 12.7 & 15.5 & 13.0 & 13.8 \\
Partner smokes & 43.3 & 50.8 & 42.6 & 45.5 \\
\hline
\end{tabular}

${ }^{5}$ The term current in relation to smoking and other substance use is defined here as it is in national youth surveys as any use within 30 days preceding the survey. 
The mean age of the participants in the study was $17.47 \pm 1.07$. Teens ranged in age from 13.41 to 18.99 years. The majority were under age 18 (63.3\%, $n=155)$, and there were four extreme cases under the age of 15 . Non-Hispanic Whites constituted $34.7 \%$ of the sample followed by Hispanics who comprised 29.5\%; Non-Hispanic Blacks made up 17.6\%. Approximately $12 \%(n=30)$ indicated two or more racial/ethnic combinations, with over half in relatively equal proportions choosing Non-Hispanic White and Non-Hispanic Black or NonHispanic White and American Indian. Approximately 32\% $(n=77)$ of the teens were pregnant, with the majority $(n=41)$ in their third trimester; $30.8 \%$ were in their second trimester. Sixty-seven percent of the sample had one child, and $8.5 \%$ had more than one child. Over $28 \%(n=69)$ said they had taken one or more actions to respond to intimate violence or the threat of intimate violence within the six months prior to taking the baseline survey. The vast majority of teens $(81.6 \%)$ had a partner and/or husband. Of the 200 teens with a partner, 91 (45.5\%) said their partner smoked cigarettes.

With respect to substance use, $37.7 \%(n=92)$ reported being a current smoker (i.e., having smoked within the 30 days preceding the survey), consisting of $32 \%$ of the pregnant teens and $42 \%$ of the nonpregnant teens. For the total sample, the mean number of smoking days within the past month was 8.78 . For teens indicating current smoking, smoking days averaged 23.6, with a median and mode of 30 days. About $67 \%$ of smokers had a daily habit. Quantity smoked was 159.5 cigarettes, an average of 5.7 cigarettes per day. 
Relatively few teens reported having used alcohol (17\%) or marijuana $(13.8 \%)$ over the past 30 days. The average number of days alcohol was used was .48 , with two teens using 15 or more days. Average number of days marijuana was used was slightly higher at .94 , with 6 teens using 15 or more days.

The percentage differences for categorical variables between cohorts were small as well as not statistically significant, as shown in Table 7. Also, findings from a one-way ANOVA demonstrated no significant cohort difference by age, $F(2,241)=1.025, p=.36$. Therefore, the cohorts could be combined for further analyses.

Table 7

Chi-square Results for Categorical Variables by Cohort (\%)

\begin{tabular}{lcccl}
\hline \multicolumn{1}{c}{ Variable } & df & $\mathrm{n}$ & $\chi^{2}$ & $p$ \\
\hline Pregnant & 2 & 245 & 2.02 & .36 \\
Race/ethnicity & 8 & 245 & 8.88 & .35 \\
Domestic violence & 2 & 240 & .761 & .68 \\
Current substance use & & & & \\
$\quad$ Cigarettes & 2 & 244 & .055 & .97 \\
$\quad$ Alcohol & 2 & 239 & .125 & .94 \\
$\quad$ Marijuana & 2 & 240 & .328 & .84 \\
Partner smokes & 2 & 200 & 1.08 & .58 \\
\hline
\end{tabular}

Examination of Variables for Normality and Reliability All 245 participants had valid data for the SOC algorithm. SOC data were compared to responses for the variable current cigarette use for reliability and 
consistency across answers. There were eight inconsistencies, with a total of 160 indicating either never having been a regular smoker $(n=105)$ or having quit $(n=$ 55) to the SOC algorithm but 152 answering 'no' to being a current smoker. Of these eight cases, three were never smokers (NS) and reported smoking 1 to 2 days, two were in the Maintenance (M) stage and indicated smoking 1 to 2 days, and three were in the Action (A) stage with two teens reporting 1 day of smoking and one teen reporting 4 days of smoking. Inconsistencies for those in NS are understandable and non-contradictions as a teen could have experimented with smoking 1 to 2 days of the month and still responded accurately to the algorithm for the NS response item as the wording was "I have never been a regular smoker." An inclusion decision had to be made for the five teens in Action and Maintenance who had smoked. While Prochaska and colleagues count only total abstinence for $\mathrm{A}$ and $\mathrm{M}$ stages (CPRC, n.d.b), sporadic patterns of smoking and unintentional accuracy in reporting are characteristics of adolescent smoking behavior (Mermelstein et al., 2002). Given the exploratory nature of this study, a decision was made to include the four teens who had smoked 1 to 2 days in further analyses and to exclude the one teen in Action who had smoked 4 days. All postulated stages of change were evident and are shown in Table 8.

Most of the teens ( $57 \%$ ) were in one of the five stages of change. Within SOC status, $61.1 \%$ were current smokers (i.e., PC, C, PR stages), and $38.2 \%$ were ex-smokers. Only $18.7 \%$ of smokers were not thinking about quitting. Approximately $33 \%$ were contemplating quitting $(C)$, but only $10.1 \%$ were 
prepared to quit within the next 30 days. Roughly $30 \%$ had quit and maintained cessation for over six months; $8.6 \%$ were recent quitters. Never smokers constituted $43 \%$ of the sample.

Table 8

Distribution of Never Smokers and SOC

\begin{tabular}{cccc}
\hline \multicolumn{1}{c}{ Stage } & $\begin{array}{c}\text { Total sample } \\
(\%)\end{array}$ & $\begin{array}{c}\text { Within } \\
\text { SOC status (\%) }\end{array}$ & $\mathrm{n}$ \\
\hline Never smoker (NS) & 43.0 & & 105 \\
Smoking stages of change & 57.0 & 100.0 & 139 \\
Precontemplation (P) & 10.7 & 18.7 & 26 \\
Contemplation (C) & 18.4 & 32.4 & 45 \\
Preparation (PR) & 5.7 & 10.1 & 14 \\
Action (A) & 4.9 & 8.6 & 12 \\
Maintenance (M) & 17.2 & 30.2 & 42 \\
Total sample & 100.0 & & 244 \\
\hline
\end{tabular}

\section{Reliability of Psychosocial Scales}

Five standardized scales were used to measure depression, sensation seeking, peer support, adult support, and adult expectations. Response values were reversed and recoded when necessary so that the higher value represented the theoretical construct of the scale.

Results from reliability analyses of the psychosocial scales are presented in Table 9, which provides the mean and standard deviation for each scale and item, and Cronbach's alpha for each scale. 
Table 9

Characteristics of Psychosocial Scales - Means, SD, Cronbach's $\propto$

\begin{tabular}{lcccccc}
\hline & \multicolumn{5}{c}{ Mean } & \multicolumn{2}{c}{$\underline{\underline{\text { Mea }}}$} & \\
Scale: (Range = 3) & $\mathrm{n}$ & Scale & Item & Scale & Item & $\alpha$ \\
\hline Depression & 240 & 18.21 & 2.02 & 4.96 & .55 & .80 \\
Sensation seeking & 234 & 12.44 & 2.07 & 3.61 & .60 & .72 \\
Peer social support & 244 & 24.09 & 3.48 & 5.27 & .75 & .95 \\
Adult cxpectations & 244 & 14.51 & 3.62 & 2.22 & .55 & .78 \\
Adult social support & 243 & 14.53 & 3.63 & 2.25 & .56 & .80 \\
\hline
\end{tabular}

All scales demonstrated acceptable to high reliability with coefficients ranging from .72 (sensation seeking) to .95 (peer social support). Mean scores were relatively low on both sensation seeking and depression and were in the high range on all three resiliency scales. The three resiliency scales, however, were not symmetric. All were positively skewed as over $80 \%$ of the teens indicated they had high adult support and expectations as well as considerable peer support. While ANOVA is robust to departures from normality, the data are best if symmetric. Given the departures from normality for the three resiliency scales as well as the lack of variability in each, a decision was made to exclude them from the analyses of question one.

Statistics on the shape and distribution and results from KolmogorovSmirnov (K-S) tests are presented in Table 10. Although the strict K-S test on both 
the Sensation Seeking and Depression Scale showed significant deviations from nonnality, the distributions were symmetrical as demonstrated by their moderate skewness of .51 and .65 , respectively.

Table 10

Shape, Symmetry and Results of K-S test on Psychosocial Scales

\begin{tabular}{lccccc}
\hline \multicolumn{1}{c}{ Scale } & $\mathrm{n}$ & Skewness & Kurtosis & K-S value & $p$ \\
\hline Sensation seeking & 242 & .513 & -.060 & 1.481 & .025 \\
Depression & 244 & .657 & .338 & 1.462 & .028 \\
Adult social support & 244 & -1.989 & 4.229 & 4.180 & .000 \\
Adult expectations & 244 & -2.175 & 5.344 & 4.226 & .000 \\
Peer social support & 244 & -1.778 & 2.707 & 3.875 & .000 \\
\hline
\end{tabular}

\section{Descriptive Statistics of Quasi-interval Measures}

Seven quasi-interval measures with Likert-type responses assessed general health, qualify of life, spirituality, perceived harm of smoking, honesty, perceived wrong of smoking, friends' smoking, smoking self-efficacy, and smoking intention. Table 11 presents the descriptive statistics for these variables.

The distributions of all but perceived harm of smoking approximated normality with only slight to moderate skewness. Overall, teens experienced good to excellent health, with only $10.3 \%$ saying their health was poor to fair; and about $73 \%$ were satisfied to very satisfied with their life. Approximately one-third of teens rated religion/spirituality as fairly important in their lives, with $42 \%$ finding it very to extremely important. The honesty check variable, which was a mean score of three items ascertaining understanding, carefulness, and honesty in answering 
the questions, was slightly skewed with over $93 \%$ of teens responding they understood most to all of the questions and answered them carefully and honestly.

Table 11

Descriptive Statistics for Quasi-interval Variables

\begin{tabular}{lccccccc}
\hline \multicolumn{1}{c}{ Item } & $\mathrm{n}$ & Mean & Median & Mode & SD & Skewness & Kurtosis \\
\hline General health & 241 & 3.79 & 4.00 & 4.00 & .98 & -.326 & -.787 \\
Quality of life & 241 & 4.88 & 5.00 & 5.00 & 1.03 & -1.018 & .929 \\
Spirituality & 213 & 3.33 & 3.00 & 3.00 & 1.05 & -.090 & -.597 \\
Friends' smoking & 242 & 2.34 & 2.00 & 3.00 & .94 & -.087 & -1.031 \\
Smoking & & & & & & & \\
$\quad$ Harm & 244 & 3.53 & 4.00 & 4.00 & .80 & -1.838 & 2.765 \\
$\quad$ Wrong & 242 & 2.66 & 3.00 & 4.00 & 1.13 & -.181 & -1.376 \\
Honesty & 241 & 3.83 & 4.00 & 4.00 & .21 & -1.032 & .459 \\
Smoking self- & 244 & 2.52 & 3.00 & 3.00 & .76 & -1.197 & -.210 \\
$\quad$ efficacy & & & & & & & \\
Smoking intention & 244 & 1.58 & 1.00 & 1.00 & .84 & .928 & -.940 \\
\hline
\end{tabular}

Regarding smoking related variables, $65.3 \%$ had no intention of smoking while $23 \%$ did. Sixty-eight percent had high smoking seif-efficacy, believing they could not smoke over the next six months. The variables of friends' smoking and perceived wrong of smoking were fairly evenly distributed with roughly $50 \%$ saying that most of their friends did not smoke and approximately $55 \%$ believing smoking was wrong to very wrong. Perceived harm of smoking was less symmetric, with $68 \%$ believing there was great risk. Because the question of perceived wrong was related to the age of respondent and to the law prohibiting underage smoking, an ANOVA was conducted to determine if perceptions of the 
wrong of smoking differed by age. There was a significant groups difference, $F(3$, 238) $=5.55, p=.001$. Results of a Tukey post-hoc test are shown in Table 12.

Table 12

Tukey Subsets for Age and Perceived Wrong

\begin{tabular}{lccc}
\hline \multicolumn{3}{c}{ Age } \\
\hline Perceived wrong & $\mathrm{n}$ & \multicolumn{2}{c}{ Subset for alpha $=.05$} \\
\hline Very wrong & 77 & $17.1900_{\mathrm{a}}$ & \multicolumn{2}{c}{} \\
Wrong & 57 & $17.3019 \mathrm{~b}$ & \\
A little & 57 & 17.6037 & 17.6037 \\
Not at all & 51 & & $17.9061_{\mathrm{a}, \mathrm{b}}$ \\
Sig. & & .140 & .398 \\
\hline
\end{tabular}

a compared to ${ }_{\mathrm{a}} p=.001$

$b$ compared to ${ }_{b} p=.015$

As seen, there are two subsets, with those who felt smoking was wrong to very wrong in a younger age group $($ mean $=17.24)$ from those who did not $($ mean $=$ 17.90). This suggests that wrong of smoking be adjusted for age in further analyses.

\section{Testing Assumptions for ANOVA}

Since substance use variables as continuous measures were to be used in an ANOVA procedure, an examination for normality was done with the variables of 'number of days used alcohol', 'number of days used marijuana' and 'number of days smoked' in the past 30 days. As shown in Table 13, both alcohol and marijuana measures exhibited significant departures from normality. 
Table 13

Descriptive Statistics for Substance Use Continuous Variables

\begin{tabular}{ccccccc}
\hline Variable & n & Mean & SD & Median & Skewness & Kurtosis \\
\hline \# days alcohol & 239 & .48 & 1.88 & .00 & 7.280 & 62.725 \\
\# days marijuana & 240 & .95 & 4.23 & .00 & 6.017 & 37.258 \\
\# days smoked & 241 & 8.80 & 13.24 & .00 & .919 & -1.110 \\
\hline
\end{tabular}

Because of the low use of alcohol (17.2\%) and marijuana (13.8\%) and the asymmetrical distribution of the variables when defined as a continuous measure, dichotomous variables for each were created and a test for independence was done using chi-square. Results showed a significant relationship $\chi^{2}(1, \mathrm{n}=235)=$ $25.678, p=.000$. Based on this, the data for each were combined into a new variable called used alcohol and/or marijuana with values and percentages of 'no' (75.3\%) and 'yes' (24.7\%), respectively.

Data were examined for outliers, which resulted in two extreme low values for age being excluded from the analyses, five from spirituality, one from quality of life, one from honesty, and seven from smoking self-efficacy. The Levene Test for constant variance for each variable in Table 11 across the groups of never smokers and stage showed significant differences for quality of life $(p=.002)$, health ( $p=$ $.03)$, smoking harm $(p=.003)$, smoking self-efficacy $(p=.000)$, and smoking intention $(p=.000)$. A power transformation consisting of the square of quality of life and health resulted in a lowering of the Levene significance level to .108 and 
.040 , respectively. Transformations of the data did not result in normality or constant variance for the latter three variables, and all had numerous outliers.

\section{Analyses of Questions}

Question One: Demographic and Psychosocial Variables by SOC

Question one examined the similarities and differences in the six categories of never smokers and stages of change (which will be referred to as never smokers/SOC) by age, race/ethnicity, spirituality, quality of life, honesty, perceived health, perceived wrongfulness of smoking, perceived harm of smoking, sensation seeking, depression, pregnancy status, domestic violence, partner's smoking, current use of alcohol and marijuana, friends' smoking, smoking self-efficacy, and smoking intention. Number of days smoked was assessed for smoking stages (i.e., $\mathrm{PC}, \mathrm{C}, \mathrm{P})$ only. Differences assessed by continuous measures were analyzed using ANOVA for the unbalanced design with Tukey-HSD post-hoc pairwise comparisons for age, spirituality, quality of life, honesty, perceived wrong, sensation seeking, and depression. Tukey HSD was chosen as it is a conservative pairwise comparison test that controls for a Type 1 error when there are a number of group comparisons and when the group variances are equal (Winer, Michels, \& Brown, 1991). Games-Howell was used as a post-hoc test for health as it is recommended when the homogeneity assumption is not met (Toothaker, 1992). The chi-square test was used for discrete measures and the Kruskal-Wallis test as an alternative to ANOVA for perceived harm, friends' smoking, smoking selfefficacy, and smoking intention. Insufficient numbers in the cells required 
collapsing never smokers and stage categories into three groups - never smokers, smokers, and quitters ( $A$ and $M$ stages) for the chi-square analysis of race/ethnicity. Table 14, modeled after the study by Pallonen, Prochaska, et al. (1998) and Stotts et al. (1996), shows that differences among categories of never smokers and stages of change were found for all demographic and psychosocial characteristics except honesty, sensation seeking, and for number of days smoked for smokers only. While the overall $F$ test was significant for quality of life across categories of smoking, follow-up tests did not show any significant difference between pairwise means. Similarly, the $F$ test for age was significant with never smokers younger than contemplators, but it is questionable whether the difference of seven months is that meaningful.

The most consistent difference existed between never smokers and those in one or more of the five stages of change, with the largest and most striking difference occurring with perceived wrong of smoking. Teens who had never smoked reported greater wrong in smoking compared to teens in the stages of change. Also, teens in Maintenance believed smoking was more wrong than teens in the smoking stages. One wonders about the influence or directionality between belief in the wrong of smoking and ability to maintain cessation; that is, to what degree does belief in the wrong of smoking contribute to Maintenance teens being able to stay quit as compared to length of time quit contribute to beliefs about the wrongfulness of smoking? 


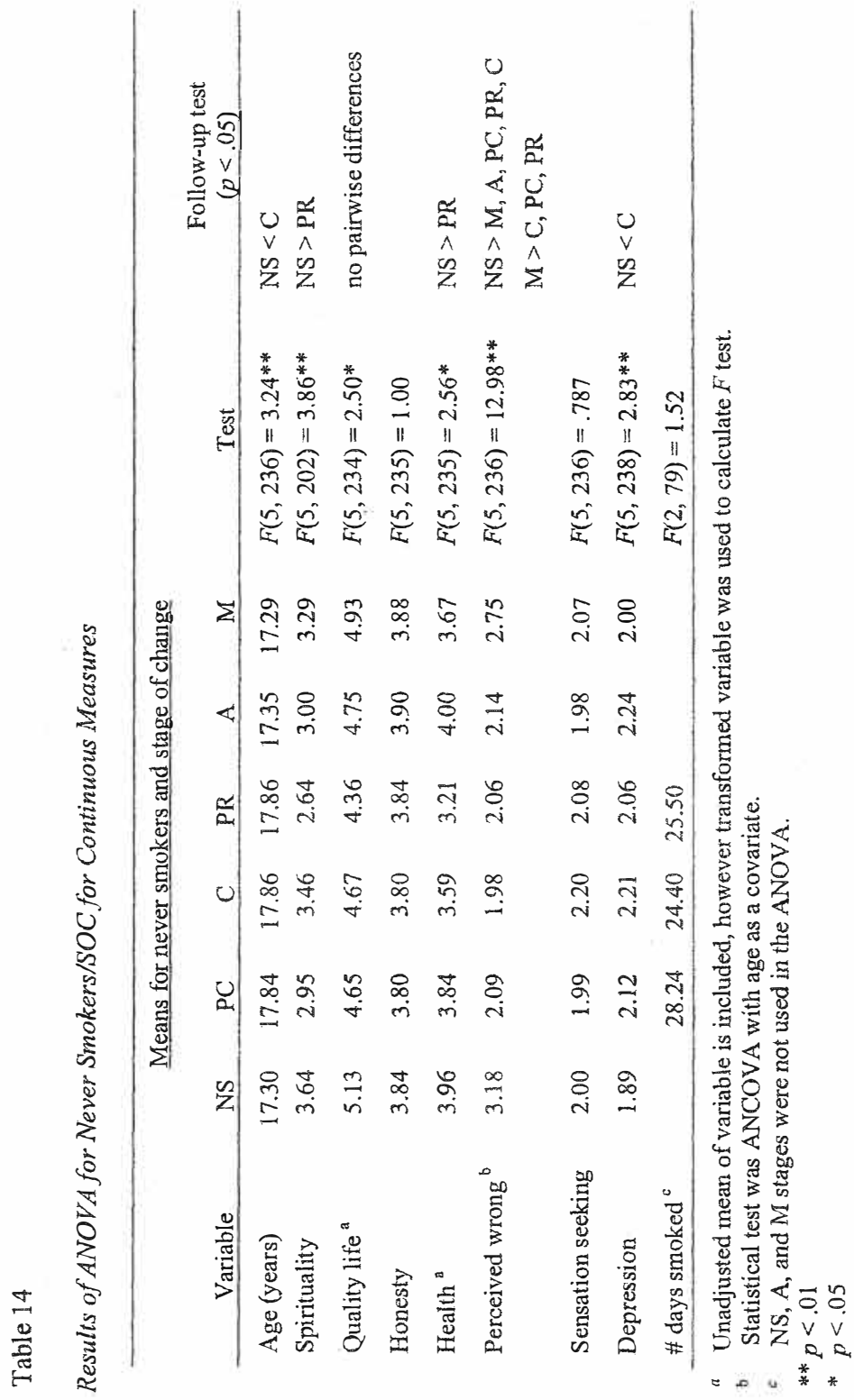


Table 15 presents the results of chi-square tests for analyses of stage differences by pregnancy status, domestic violence, partner's smoking, current aicohol and marijuana use, race/ethnicity, friends' smoking and results of the Kruskal-Wallis tests for perceived harm, friends' smoking, smoking self-efficacy, and smoking intention. All but domestic violence demonstrated significant differences across categories of never smokers/SOC. It is noteworthy, however, that teens in the three smoking stages had the highest percentage of domestic violence among the categories. In particular, approximately one-half of teens contemplating and preparing to quit reported experiencing domestic violence.

Teens in the Action stage were significantly more likely to be pregnant, which is consistent with the literature. The chi-square total cell count for pregnant and nonpregnant in Action was 10.40, which accounts for almost the entire chisquare value. As with the continuous measures, there were differences between never smokers and teens in the stages categories. Never smokers were least likely to have a partner who smoked (25.6\%), while teens in Precontemplation and recent quitters in Action were more likely to have a partner who smoked, $75 \%$ and $73 \%$, respectively. Never smokers also perceived greater harm in smoking than both precontemplators and recent quitters. Worth noting is that teens in Action perceived the least harm in smoking one or more packs a day. 


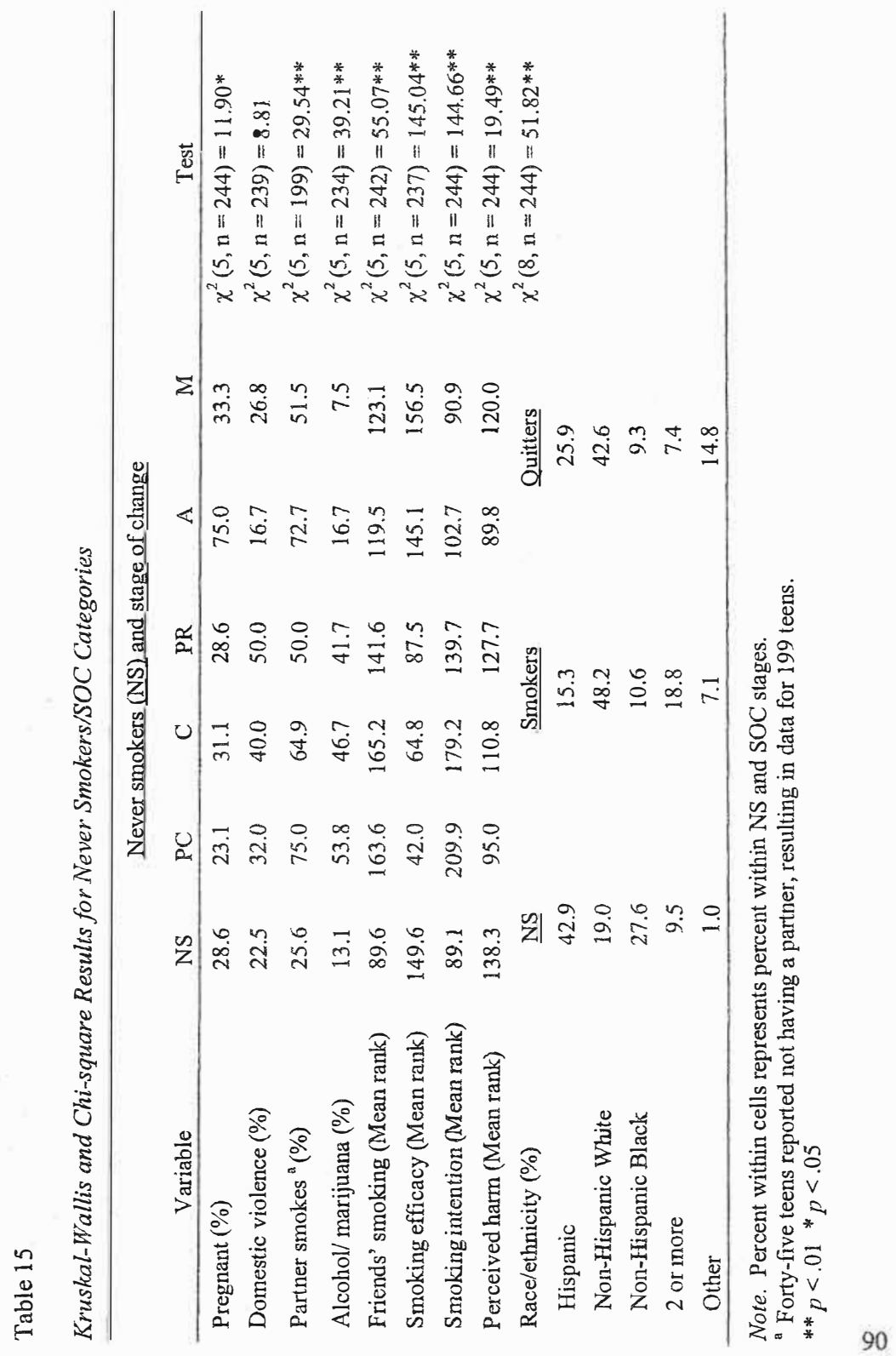


Never smokers and teens who had maintained cessation for over six months were least likely to be current alcohol and marijuana users. In contrast, use of alcohol and marijuana ranged from $41 \%$ to $53 \%$ for smoking stages. Teens who smoked were also more likely to have friends who smoke than were never smokers. Measures of both smoking self-efficacy and smoking intention exhibited stage differences with never smokers and teens in Action and Maintenance showing less intention and higher self-efficacy than those in smoking stages. Moreover, it appears that teens in Preparation had a greater belief that they could refrain from smoking than precontemplators. Interestingly, however, teens in Preparation were not smoking significantly less than teens in either Precontemplation or Contemplation. Since a behavioral characteristic of the Preparation stage is a modification of smoking behavior (e.g., cutting down, changing to a lighter brand), one wonders what, if any, the behavioral change was for the young women in this stage.

Race/ethnicity by smoking categories of never smokers, smokers, and quitters is consistent with the literature showing that Hispanic and Non-Hispanic Black teens were less likely to smoke than non-Hispanic White teens. The group of teens who indicated two or more races also was more likely to be smokers, which is understandable since this group was made up largely of non-Hispanic Whites.

Data were re-analyzed with never smokers excluded and using SOC categories only. Significant differences remained for pregnancy status, $F(4,134)=$ 
2.81, $p=.028$; current alcohol and marijuana use, $F(4,130)=6.46, p=.00$; and for the smoking related variables of friends' smoking, $F(4,132)=14.94, p=.005$; smoking self-efficacy, $F(4,134)=71.57, p=.00$; smoking intention $F(4,134)=$ $76.15, p=.00$; and perceived wrong, $F(4,133)=3.447, p=.01$. Examination of the means suggests that teens in Maintenance had fewer friends who smoked than precontemplators and contemplators. Maintenance stage teens also exhibited greater self-efficacy than teens in the smoking stages. In keeping with the literature, there was a consistent increase in self-efficacy from Precontemplation to Maintenance, with teens preparing to quit most efficacious of the smoking stages. Regarding intention to smoke, it appears that precontemplators had greater intention than teens in the other stages, and contemplators had greater intention than those in Action and Maintenance.

In summary, distribution of the sample by SOC showed that the majority of teens were in one of the five stages of change. Analyses of demographic and psychosocial variables by categories of never smokers/SOC found that significant differences existed between the group of never smokers and one or more of the SOC. In particular, never smokers scored higher on perceived wrong than each SOC stage. Analyses by only SOC categories found differences for pregnancy status and substance use related variables - alcohol and marijuana use, friends' smoking, smoking self-efficacy and intention, and perceived wrong of smoking. 
Question Two: Reliability and Stage Effects

Question two asked whether the theoretically predicted stage effects for the five SOC categories were evidenced for the Decisional Balance Scale, the Temptation Scale, and the Processes of Change Scale. This section is presented in three parts. First, since a chief purpose of this study was to determine the applicability of the TMC constructs for pregnant/parenting adolescent females, the nine TMC measures were examined for internal consistency. The second section describes the examination of all TMC scales across stages of change to determine if the data met the assumptions for a MANOVA procedure and discusses any transformations and adjustments of the data. The final section reports the findings. To facilitate a comparison between different TMC measures both within this study and with the literature, mean scores on the measures were transformed to $\mathrm{T}$-scores using the formula $\mathrm{T}=\mathrm{z}$-score $(10)+50$, and stage effects in tables and figures are reported as T-scores.

Reliability Analysis

Per survey instructions, all teens were to complete both the Decisional Balance Scale and the Temptation Scale; only teens who were current smokers or who had quit within the past year were to complete the Processes of Change Scale. Reliability analysis was performed for teens in the five SOC categories only ( $\mathrm{n}=$ 139). 
Decisional balance scale. Table 16 provides the number of valid cases, mean, standard deviation, and coefficient alpha for each subscale along with the correlations between subscales for the Decisional Balance Scale.

Table 16

Characteristics of Decisional Balance Scale

\begin{tabular}{lccccc}
\hline \multicolumn{1}{c}{ TMC subscale } & Mean & $S D$ & $\alpha$ & \multicolumn{2}{c}{ Interscale corrclations } \\
\hline Decisional balance $(\mathrm{n}=134)$ & 40.20 & 8.43 & .75 & $\underline{\text { Cons }}$ & Coping pros \\
Cons & 24.21 & 6.97 & .92 & & \\
Pros & 11.70 & 3.93 & .65 & -.11 & \\
Social pros & 3.98 & 1.64 & .51 & .01 & .12 \\
Coping pros & 7.72 & 3.40 & .80 & -.13 & \\
\hline
\end{tabular}

The pros scale had a moderate level of reliability $(\alpha=.65)$, principally due to the low intermal consistency of the social pros subscale $(\alpha=.51)$. The mean score on the five-point scale was 1.32 , signifying that pregnant/parenting teens were not motivated to smoke for the social pros included in the measure. This subscale asks whether smoking is important in order to have more friends, get more respect from friends, or go out on more dates. The reliability of the coping pros subscale was fairly high $(\alpha=.80)$. The mean score on this scale (2.57), although higher than the social pros, was below the midpoint for the scale, indicating that perceived advantages of smoking for pleasurable reasons and to relieve unpleasant emotions were rated as somewhat important. For the cons of smoking, the scale had high reliability $(\alpha=.92)$, with a mean inter-item correlation of $r=.68$. Mean scores on 
each of the items of the scale were above the midpoint. This suggests that the cons of smoking (i.e., the messiness, health risks, and bother to other people) were rated as more important by these young women in making decisions about whether or not to smoke than the perceived pros of smoking.

Temptation to smoke scale. Reliability results for the Temptation Scale and subscales are reported in Table 17. The scale and subscales evidenced good to high internal consistency with subscale alphas ranging from a moderate .68 for habit strength to a high of .87 for weight control. As Table 17 shows, intercorrelations among the positive social, negative affect, and habit strength subscales were moderate, ranging from 0.58 to 0.68 . The inter-item mean for each subscale was at or below the midpoint of the scale. In particular, temptation to smoke to control weight was rated low, with a mean of 1.55 . Overall, young women were tempted more in negative affect situations (i.e. to avoid unpleasant emotions), followed by positive social, habit strength, and weight control, respectively.

Table 17

Characteristics of Temptation Scale

\begin{tabular}{ccccccc}
\hline TMC subscale & Mean & \multicolumn{1}{c}{ SD } & $\alpha$ & \multicolumn{2}{c}{ Interscale correlations } \\
\hline Temptation (n=137) & 17.98 & 7.83 & .88 & $\underline{\text { PS }}$ & $\underline{\text { NA }}$ & $\underline{\text { HS }}$ \\
Positive social (PS) & 4.84 & 2.52 & .81 & & & \\
Negative affect (NA) & 6.19 & 2.82 & .86 & $.65^{* *}$ & & \\
Habit strength (HS) & 3.90 & 2.11 & .68 & $.68^{* *}$ & $.58^{* *}$ & \\
Weight control (WC) & 3.10 & 2.18 & .87 & $.42^{* *}$ & $.37^{* *}$ & $.52^{* *}$ \\
\hline$* * p<.01$ & & & & & &
\end{tabular}


Processes of change scale. Table 18 presents the mean, standard deviation, and inter-item correlations for the Processes of Change Scale. The processes are the thoughts, feelings, and skills used to facilitate movement through the stages. As discussed in the Methodology chapter, the study used an abbreviated ten-item version of the scale with one item instead of two measuring each process. The reliability of the scale was good $(\alpha=.84)$ with moderate internal consistency of the subscales, experiential processes $(\alpha=.77)$ and behavioral processes $(\alpha=$ .70). Inter-item correlations for the experiential subscale ranged from 0.25 to 0.58 and for the behavioral subscale from 0.13 to 0.48 , suggesting the subscales are tapping separate domains, as they theoretically should. The correlation between the subscales was moderate $(r=.68, \mathrm{p}=<.01)$.

Item means ranging from 1.7 to 3.36 indicated that the young women were using the processes only seldom to occasionally. Processes used most frequently included the behavioral process of self-liberation (believing in one's ability to stop smoking) and the experiential processes of consciousness raising (awareness of benefits of quitting smoking) and social liberation (noticing how society is changing to help nonsmokers). 
Table 18

Item Means and Inter-item Correlations of the Processes of Change Scale

\begin{tabular}{|c|c|c|c|c|c|c|c|}
\hline Process & Mean & $S D$ & $\alpha$ & & Inter-it & elations & \\
\hline Processes of Change $(n=111)$ & 26.57 & 8.48 & .84 & & & & \\
\hline Experiential processes & 13.79 & 4.66 & .77 & $\underline{\mathrm{SL}}$ & $\underline{\mathrm{CR}}$ & $\underline{E R}$ & $\underline{\mathrm{DR}}$ \\
\hline Social liberation (SL) & 3.07 & 1.30 & & & & & \\
\hline Consciousness raising $(\mathrm{CR})$ & 3.32 & 1.27 & & $.58^{* *}$ & & & \\
\hline Environmental reevaluation (ER) & 2.54 & 1.28 & & $.45^{* * *}$ & $.51 * *$ & & \\
\hline Dramatic relief (DR) & 2.56 & 1.27 & & $.24^{* *}$ & $.41 * *$ & $.39 * *$ & \\
\hline Self reevaluation (SR) & 2.27 & 1.31 & & $.25^{* *}$ & $.47^{* *}$ & $.30 * *$ & $.41^{* *}$ \\
\hline Behavioral processes & 12.79 & 4.51 & .70 & $\underline{\mathrm{CC}}$ & $\underline{\mathrm{SeL}}$ & $\underline{\mathrm{RM}}$ & $\underline{\mathrm{SC}}$ \\
\hline Counter conditioning (CC) & 2.72 & 1.16 & & & & & \\
\hline Self liberation (SeL) & 3.36 & 1.29 & & $.32 * *$ & & & \\
\hline Reinforcement mgmt. (RM) & 2.50 & 1.50 & & .13 & $.32^{* *}$ & & \\
\hline Stimulus control (SC) & 1.70 & 1.15 & & $.32^{* *}$ & $.33^{* *}$ & $.39 * *$ & \\
\hline Helping relationships (HR) & 2.49 & 1.48 & & $.19 * *$ & $.30^{* *}$ & $.47^{* *}$ & $.48^{* *}$ \\
\hline
\end{tabular}

** $p<.01$

$* p<.05$

$\stackrel{-19}{*}$ 


\section{Examination of TMC Data for MANOVA Procedures}

This section describes the examination and transformation of the data to meet the assumptions for use of MANOVA and appropriate post hoc tests. Investigation of the TMC measures included exploring boxplots and stem-and-leaf plots for outliers, determination of homoscedasticity by using the Levene test and Box’s M test, examining spread-versus-level plots, and computing power estimations to transform the data if normality assumptions were not met.

Decisional balance scale. Stem-and leaf plots identified 13 cases with outliers, four in the pros scale and nine in the cons scale. These cases were eliminated from the analyses. The data met the other assumptions for a MANOVA. The Box's test of the equality of the covariances matrices was significant but acceptable, $F(24,8612)=1.526, p=.05$ as was the Levene test for constant variance for both the cons scale, $F(4,118)=.518, p=.71$, and the coping pros scale, $F(4,118)=2.00, p=.09$. The social pros scale, however, did not demonstrate constant variance $F(4,118)=3.42, p=.01$.

Temptation scales. Mean scores on the weight control scale displayed significant departures from normality in both the Action and the Maintenance stage. All 12 teens in the Action stage responded 'not at all' to being tempted to smoke for weight control reasons and 39 of the 42 teens in Maintenance responded likewise. Both the Levene statistic and the K-S test of normality were significant at 
the .00 level. Since the data did not meet the assumptions, the weight control scale was excluded from the MANOVA analyses.

Nine cases with outliers were eliminated from the remaining scales, five from Maintenance, two from action, one from Contemplation, and one from Preparation. Power estimations were used to transform the variables, resulting in equality of covariances, $F(24,7312)=1.53, p=.05$. The error variance for both the positive social scale and the negative affect scale were insignificant, $p=.07$ and $p=.56$, respectively. The habit strength scale did not display equal variance across groups, $F(4,123)=4.82, p=.001$, suggesting that the Games-Howell test be used as a post-hoc test.

Processes of change scales. Three cases with outliers, one for the experiential processes and two for the behavioral processes, were eliminated from the analyses. The homogeneity of variances and covariances assumption was not met for the behavioral processes as indicated by both the Box's test $(p=.001)$ and the Levene test $(p=.000)$. Both variables were transformed using the natural log. While the covariances remained unequal, $F(12,17446)=2.57, p=.002$, the homogeneity of variances was not significantly different across groups (experiential, $F(4,105)=2.45, p=.05$ and behavioral, $F(4,105)=2.27, p=.07$ ), allowing for the use of MANOVA. Analyses of Siage Effects

Three separate MANOVA procedures were conducted with SOC as the independent variable on the dependent variables of (1) the three subscales from the 
Decisional Balance Scale, (2) the habit strength, positive social, and negative affect subscales of the Temptation Scale, and (3) the behavioral and the experiential processes. Tukey HSD test was used as a post-hoc test unless otherwise indicated. All analyses used a listwise deletion procedure to eliminate subjects with missing data. Follow-up univariate ANOVAs were conducted on the behavioral processes using a pairwise deletion for missing values, thus the sample sizes differ.

Results of the MANOVA for the Decisional Balance scale and the Temptation Scale are shown in Table 19, which presents the mean T-scores, standard deviations, Wilks' lambda $F$ value, pairwise comparisons, and the effect size for significant $F$ values at the .01 level. Eta squared $\left(\eta^{2}\right)$ was used as the measure of the effect size and represents the degree of association between SOC and the dependent variable. 
Table 19

Decisional Balance and Temptation Scale by SOC

\begin{tabular}{|c|c|c|c|c|c|c|c|c|}
\hline Scale & $\mathrm{PC}$ & $\mathrm{C}$ & PR & A & M & Wilks' lambda & $\begin{array}{c}\text { Pairwise } \\
\text { comparisons }\end{array}$ & $\eta^{2}$ \\
\hline & & & \multicolumn{6}{|l|}{$\mathrm{T}$-score / SD } \\
\hline \multicolumn{6}{|c|}{ Decisional balance $(n=123)$} & \multicolumn{3}{|c|}{$F(12,307)=6.91^{* *}$} \\
\hline Cons & $52.1 / 5.6$ & $51.1 / 7.5$ & $53.0 / 4.9$ & $54.2 / 5.8$ & $52.9 / 6.9$ & $F(4,118)=.638$ & & \\
\hline Social pros ${ }^{a}$ & $47.9 / 7.5$ & $52.0 / 9.60$ & $47.7 / 8.1$ & $54.5 / 11.9$ & $48.2 / 6.4$ & $F(4,118)=2.34$ & & \\
\hline Coping pros & $57.7 / 5.6$ & $52.8 / 8.1$ & $51.9 / 10.0$ & $47.3 / 6.9$ & $41.4 / 6.1$ & $\begin{array}{c}F(4,118)= \\
20.9^{* *}\end{array}$ & $\begin{array}{l}\mathrm{M}<\mathrm{PR}, \mathrm{C}, \mathrm{PC} \\
\mathrm{A}<\mathrm{PC}\end{array}$ & .415 \\
\hline \multicolumn{6}{|c|}{ Temptation $(n=128)$} & \multicolumn{2}{|c|}{$F(12,320)=15.1 * *$} & .242 \\
\hline Habit strength ${ }^{a}$ & $55.8 / 11.2$ & $53.4 / 8.7$ & $48.5 / 7.3$ & $44.7 / 6.6$ & $41.7 / 2.1$ & $\begin{array}{c}F(4,123)= \\
27.64 * *\end{array}$ & $\begin{array}{l}\mathrm{M}<\mathrm{PR}, \mathrm{C}, \mathrm{PC} \\
\mathrm{A}<\mathrm{C}, \mathrm{PC}\end{array}$ & .473 \\
\hline Positive social & $55.8 / 9.2$ & $54.0 / 7.2$ & $51.7 / 10.4$ & $41.8 / 4.1$ & $40.4 / 3.6$ & $\begin{array}{c}F(4,123)= \\
35.96^{* *}\end{array}$ & $\begin{array}{l}\mathrm{M}<\mathrm{PR}, \mathrm{C}, \mathrm{PC} \\
\mathrm{A}<\mathrm{C}, \mathrm{PC}\end{array}$ & .539 \\
\hline Negative affect & $56.6 / 6.6$ & $54.2 / 7.5$ & $53.8 / 7.7$ & $47.1 / 7.5$ & $38.8 / 4.9$ & $\begin{array}{c}F(4,123)= \\
40.32 * *\end{array}$ & $\begin{array}{c}\mathrm{M}<\mathrm{A}, \mathrm{PR}, \mathrm{C} \\
\mathrm{PC} \\
\mathrm{A}<\mathrm{C}, \mathrm{PC}\end{array}$ & .567 \\
\hline
\end{tabular}

" Games-Howell test was used for the pairwise comparisons.

$* * p<.01$ 
Decisional balance scale. Findings are clearly seen in Figure 2, which presents the T-scores of the three scales within the five stages.

Figure 2. Decisional balance t-scores.

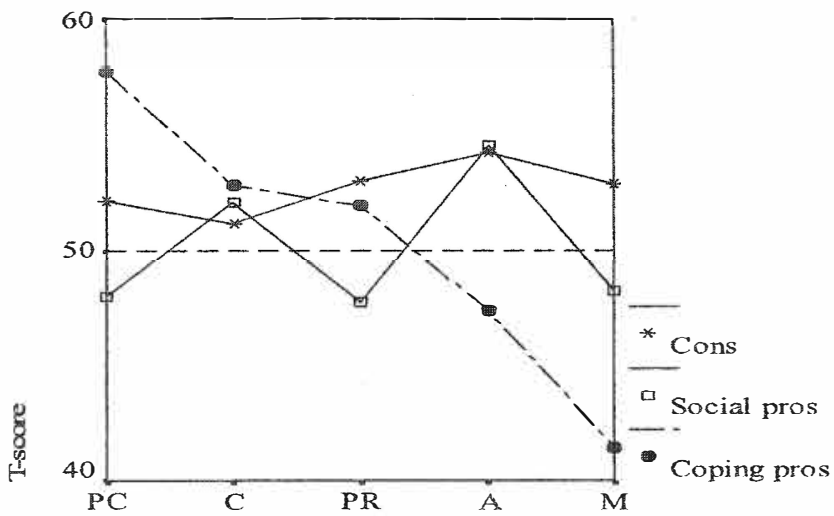

Only the coping pros subscale showed significant stage effects, with mean scores decreasing significantly from Precontemplation to Maintenance. For example, teens in Precontemplation had a mean T-score of 57.7 while Maintenance teens had a score of 47.3 . The effect size was fairly large and suggests that stage of change accounts for $42 \%$ of the variance in the coping pros scores. Post hoc tests showed that smoking for pleasure and/or to avoid negative feelings was significantly more important for teens in the smoking stages than it was for teens who had maintained cessation for over six months. The coping pros were also more important for Precontemplators than for recent quitters in Action. Neither the social pros nor the cons scales evidenced a significant stage effect. Noteworthy, 
however, is that the cons of smoking were rated important in making decisions about whether or not to smoke regardless of stage.

Temptation to smoke. All three subscales displayed stage effects. As shown in Table 19 and displayed in Figure 3, mean scores decreased fairly consistently from Precontemplation to the Maintenance stage.

Figure 3. Temptation to smoke t-scores.

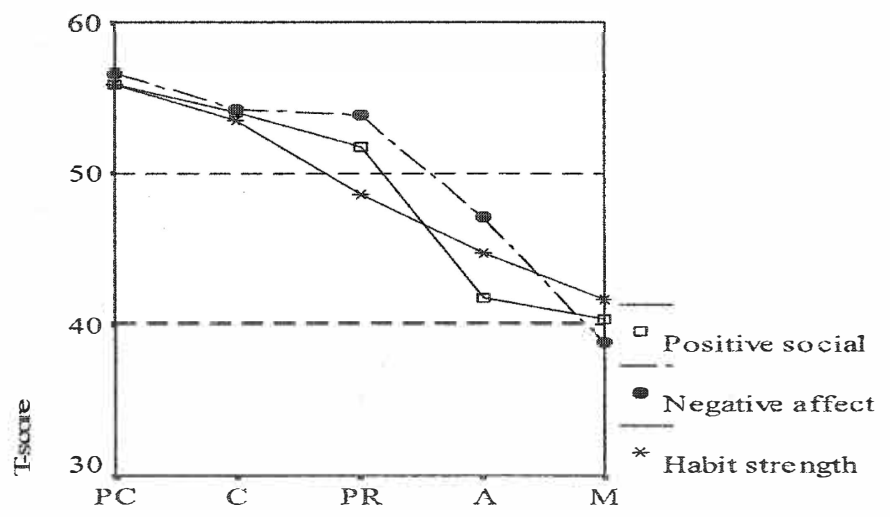

The pattern is most evident with the negative affect and positive social scales, where there was a sharp decline in temptations to smoke once teens had bccome prepared to quit (PR stage). Teens in Maintenance who had maintained cessation for over six months displayed significantly less temptation to smoke on all three scales than did smokers. In addition, teens in Maintenance were less tempted than teens in Action to smoke to control unpleasant emotions. Recent quitters in the Action stage also had lower scores on all three temptation scales than did 
precontemplators and contemplators. The association between SOC and the temptation subscales were $33 \%$ for habit strength, $54 \%$ for positive social, and $56 \%$ for negative affect, suggesting a large proportion of variance in temptations to smoke due to SOC.

Processes of change. Results from the MANOVA are displayed in Figure 4 and reported in Table 20. As noted in the discussion on reliability and clearly seen in Figure 4, teens used the processes relatively little but used the behavioral processes more, even in the early stages. The increase in the mean scores from Precontemplation to Preparation suggests that the young women who had quit and maintained cessation had higher process use.

Figure 4. Processes of change t-scores.

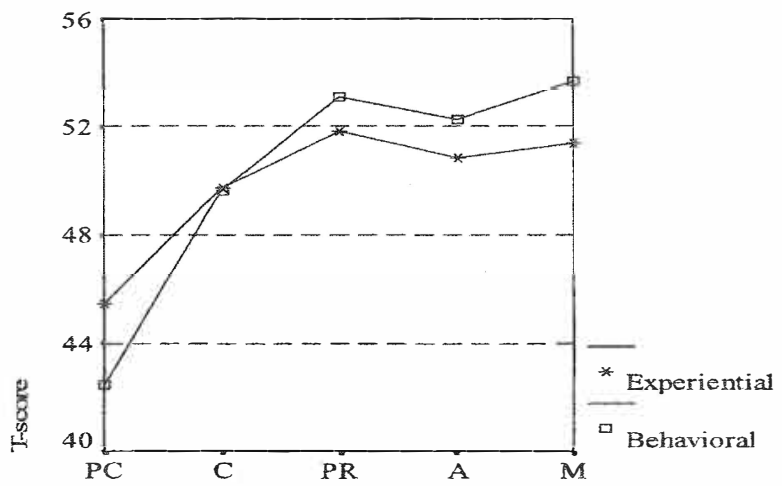

As seen in Table 20, only the behavioral processes showed significant stage effects. 
Table 20

Behavioral Processes by SOC

\begin{tabular}{|c|c|c|c|c|c|c|c|c|}
\hline \multicolumn{6}{|c|}{ Stage of Change } & \multirow[b]{2}{*}{ Wilks Lambda } & \multicolumn{2}{|l|}{ Pairwise } \\
\hline Scale & PC & $\mathrm{C}$ & PR & $\mathrm{A}$ & M & & comparisons & $\eta^{2}$ \\
\hline \multicolumn{2}{|c|}{ Processes of Change $(n=110)$} & & Mean / SD & & & $F(8,208)=2.59 *$ & & \\
\hline Experiential & $45.4 / 9.1$ & $49.7 / 8.1$ & $51.8 / 8.9$ & $50.8 / 11.4$ & $51.4 / 12.5$ & $F(4,105)=1.39$ & & \\
\hline Behavioral & $42.4 / 5.1$ & $49.6 / 8.3$ & $53.1 / 7.6$ & $52.2 / 9.9$ & $53.6 / 13.5$ & $F(4,105)=5.17^{* *}$ & $\mathrm{PC}<\mathrm{C}, \mathrm{A}, \mathrm{PR}, \mathrm{M}$ & .165 \\
\hline Behavioral & & & & & & $\underline{F \text { test }}$ & & \\
\hline $\begin{array}{l}\text { Counter- } \\
\text { conditioning }\end{array}$ & $46.0 / 9.2$ & $47.8 / 8.4$ & $52.0 / 7.9$ & $55.8 / 10.3$ & $54.4 / 12.3$ & $F(4,105)=3.73^{* *}$ & $\mathrm{PC}<\mathrm{M}, \mathrm{A}$ & $: 124$ \\
\hline Self liberation & $45.9 / 8.7$ & $50.3 / 9.6$ & $51.5 / 8.4$ & $50.7 / 12.1$ & $52.6 / 11.5$ & $F(4,105)=1.41$ & & \\
\hline $\begin{array}{l}\text { Reinforcement } \\
\text { management }{ }^{a}\end{array}$ & $43.8 / 5.3$ & $50.4 / 9.3$ & $54.8 / 10.6$ & $51.4 / 11.4$ & $52.1 / 11.8$ & $F(4,111)=3.62^{* *}$ & $\mathrm{PC}<\mathrm{C}, \mathrm{PR}$ & .120 \\
\hline Stimulus control ${ }^{a}$ & $44.7 / 3.6$ & $46.4 / 9.8$ & $50.7 / 8.4$ & $53.4 / 9.8$ & $54.5 / 13.3$ & $\mathrm{~F}(4,113)=3.40^{* *}$ & $\mathrm{PC}<\mathrm{M}$ & .112 \\
\hline $\begin{array}{l}\text { Helping } \\
\text { relationships }\end{array}$ & $45.1 / 7.8$ & $51.5 / 9.6$ & $52.3 / 9.8$ & $49.4 / 11.2$ & $50.9 / 11.4$ & $F(4,113)=1.94$ & & \\
\hline
\end{tabular}

${ }^{a}$ Games-Howell test was used for the pairwise comparisons.

$* * p<.01$

* $p<.05$ 
Of these processes, significant differences were found for counterconditioning, reinforcement management, and stimulus control. This is depicted in Figure 5. The effect sizes were relatively small, however, with stage of change accounting for only about $12 \%$ of the variance in these behavioral processes.

Figure 5. Significant behavioral processes t-scores.

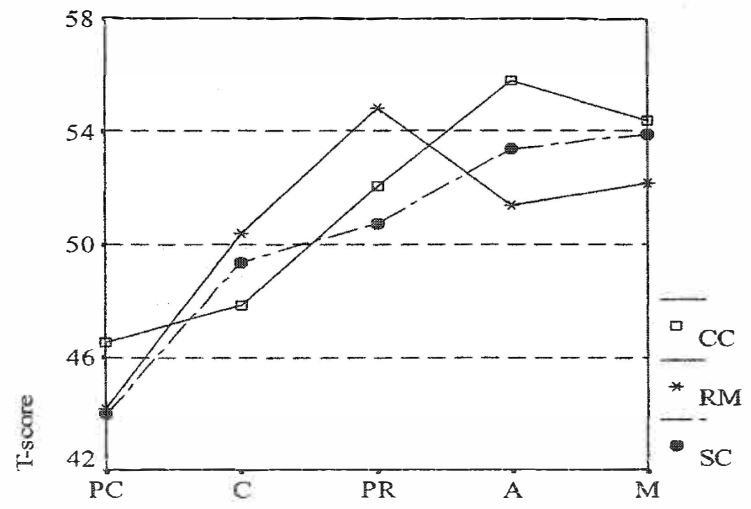

Post hoc tests showed that young women who had quit smoking (A and M stages) used the process of counterconditioning (substituting alternative behaviors for smoking) significantly more than precontemplators. Maintenance teens also used stimulus control (avoiding high risk situations and restructuring their environment) more than precontemplators. Another stage difference was found for reinforcement management (rewarding self or being rewarded by others for not 
smoking), with teens contemplating and preparing to quit using this process more than precontemplators.

While no significant stage effects were found for the experiential processes, examination of the means showed that consciousness raising (thinking about information on the benefits of quitting smoking) and social liberation (noticing how nonsmokers are stating their rights) were used fairly equally and the most frequently across the stages. The experiential process used the least across the stages was self reevaluation (identifying values about smoking and being upset about one's smoking).

In summary, the TMC scales exhibited moderate to good reliability. Analyses using MANOVA and post-hoc tests showed stage effects for the coping pros scale of the Decisional Balance Scale, the three subscales of the Temptation Scale, and the behavioral Processes of Change Scale. For the behavioral processes, the processes of counterconditioning, reinforcement management, and stimulus control exhibited stage effects, although the effect size for each was moderate. Question Three: Processes by Pregnancy and Smoking Status Question three was suggested from findings of the study by Stotts et al. (1996) wherein pregnant women in Action displayed lower process activity and temptation but higher self-efficacy than nonpregnant women in Action and nonpregnant women in Preparation. Question three examined the differences in process activity between pregnant tcens who had quit smoking ( $A$ and $M$ stages), 
nonpregnant teens who had quit smoking ( $\mathrm{A}$ and $\mathrm{M}$ stages), and nonpregnant smokers who were contemplating or preparing to quit smoking.

Exploration of the data for MANOVA showed that the covariances matrices were not different across the groups, $F(6,14310)=1.86, p=.08$. Levene's test of the error variance across groups was insignificant for the experiential processes, $F(2,68)=2.66, p=.07$, but significant for the behavioral processes, $F(2,68)=$ $7.23, p=.001$. The results of a MANOVA for the experiential and behavioral processes across the three groups, as shown in Table 21 , showed no significant differences.

Table 21

Processes of Change by Pregnancy and Smoking Status

\begin{tabular}{ccccc}
\hline Scale & $\begin{array}{c}\text { Pregnant } \\
\text { Quitters } \\
(\mathrm{n}=18)\end{array}$ & $\begin{array}{c}\text { Nonpregnant } \\
\text { Quitters } \\
(\mathrm{n}=13)\end{array}$ & $\begin{array}{c}\text { Nonpregnant } \\
\text { Smokers } \\
(\mathrm{n}=40)\end{array}$ & Wilks' lambda \\
\hline & & $\underline{\text { T-score } / \mathrm{SD}}$ & & \\
$\begin{array}{c}\text { Processes of Change } \\
\text { Experiential }\end{array}$ & $49.8 / 11.8$ & $53.0 / 12.4$ & $50.2 / 8.3$ & $F(2,68)=.47$ \\
Behavioral & $51.7 / 10.2$ & $55.2 / 14.7$ & $49.7 / 8.1$ & $F(2,68)=1.53$ \\
\hline
\end{tabular}

Although the differences between groups did not reach statistical significance, nonpregnant quitters used both types of processes more than did pregnant quitters and nonpregnant smokers, as seen in Figure 6. This suggests that maintaining cessation may require greater use of the processes by nonpregnant teens than by 
pregnant teens who have the external motivator of 'quitting for the baby' to encourage them.

Figure 6. Processes by pregnancy and smoking status

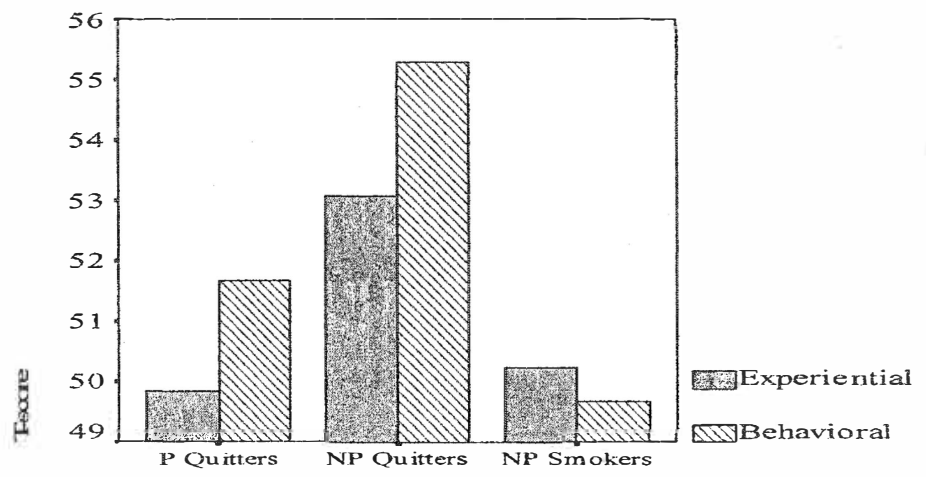

Question Four: Temptation/Self-efficacy by Pregnancy and Smoking

Question four examined the similarities and differences in temptation to smoke and self-efficacy between pregnant teems who had quit smoking, nonpregnant teems who had quit smoking, and nonpregnant teens who were contemplating or preparing to quit smoking.

The four subscales of the Temptation Scale were examined for normality and homogeneity of variances across the three groups of pregnant/nonpregnant quitters and smokers. As with question two, the weight control subscale exhibited departures from normality with both the pregnant and nonpregnant quitters displaying no variance; consequently, it was excluded from the analyses. 
Neither the habit strength nor the positive social scale exhibited normality or homogeneity of variance. Both were transformed using power estimations. The negative affect scale displayed equality of variance $(p=.27)$, although the $\mathrm{K}-\mathrm{S}$ test for nomality was significant for all three groups at the 01 level. A MANOVA with the three subscales as dependent variables showed no significant difference for covariances, $F(12,26255)=.733, p=.72$, and all variables demonstrated equality of variance across groups; habit strength, $F(2,91)=.03, p=.97$; positive social, $F(2,91)=1.27, p=.28$; negative affect, $F(2,91)=1.32, p=.27$.

The MANOVA was significant as was each subscale for between-subjects effects. Table 22 provides the $\mathrm{T}$-scores for each group along with the SD, $F$ values, and effect size.

Table 22

Temptation Subscales by Pregnancy and Smoking Status

\begin{tabular}{|c|c|c|c|c|c|}
\hline Scale & $\begin{array}{c}\text { Pregnant } \\
\text { Quitters } \\
(n=23)\end{array}$ & $\begin{array}{l}\text { Nonpregnant } \\
\text { Quitters } \\
(\mathrm{n}=31)\end{array}$ & $\begin{array}{l}\text { Nonpregnant } \\
\text { Smokers } \\
(n=40)\end{array}$ & Wilks' lambda & $\eta^{2}$ \\
\hline \multicolumn{6}{|c|}{ T-score / SD } \\
\hline Temptation & & & & $F(6,178)=13.9 * *$ & \\
\hline Habit strength & $43.8 / 5.3$ & $43.6 / 5.5$ & $54.0 / 9.7$ & $F(2,91)=1.05 * *$ & .383 \\
\hline Positive social & $44.3 / 8.1$ & $41.7 / 6.7$ & $54.8 / 9.1$ & $F(2,91)=30.02 * *$ & .398 \\
\hline Negative affect & $41.0 / 7.5$ & $42.8 / 8.8$ & $55.4 / 7.4$ & $F(2,91)=33.02 * *$ & .422 \\
\hline
\end{tabular}


Tukey post-hoc tests confirmed that for each subscale, the group of nonpregnant smokers had higher mean scores and differed significantly from the other two groups. The effect size was large for each subscale, ranging from $38 \%$ for habit strength to $42 \%$ for negative affect. There were no significant pairwise differences between the pregnant quitters and nonpregnant quitters. This pattern is clearly visible in Figure 7, which displays the T-scores for each subscale across groups. Figure 7. T-scores of temptation subscales by pregnancy and smoking status

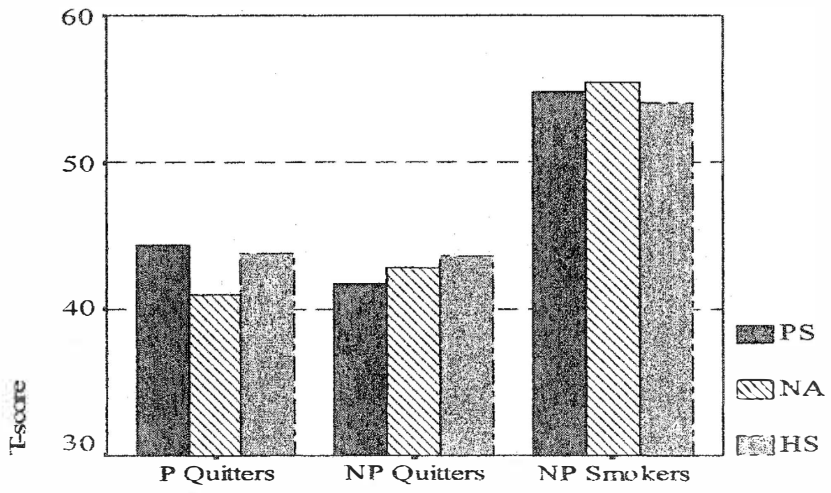

The second examination for question four involved the mean scores of selfefficacy across the three groups. The data displayed significant departures from normality as 51 of the 54 teens within the combined groups of pregnant/nonpregnant quitters reported the maximum score of ' 3 '; this suggested a nonparametric test be used. Findings from the Kruskal-Wallis test of self-efficacy across groups are provided in Table 23. Non-pregnant smokers were different from 
both of the non-smoking groups, $\chi^{2}(2, n=94)=45.6, p=.00$. Teens who had quit smoking, regardless of pregnancy status, reported significantly greater self-efficacy to refrain from smoking.

Table 23

Kruskal-Wallis Test of Self-efficacy by Pregnancy and Smoking Status

\begin{tabular}{lcc}
\hline \multicolumn{1}{c}{ Groups } & n & Mean rank \\
\hline Pregnant Quitters & 23 & 59.96 \\
Nonpregnant Quitters & 31 & 63.68 \\
Nonpregnant Smokers & 41 & 29.44 \\
\hline
\end{tabular}

In summary, there were no significant differences between pregnant teens who had quit smoking and non-pregnant teens who had quit smoking on either the Temptation Scale or smoking self-efficacy. Nonpregnant smokers, however, were different from both groups of teens who had quit smoking, regardless of pregnancy status. No significant differences were found between the groups for the use of the processes of change; however, nonpregnant quitters use the processes more than did pregnant quitters and nonpregnant smokers. 


\section{CHAPTER V - DISCUSSION}

The objectives of this dissertation were threefold: (1) to investigate whether factors identified in the literature as associated with initiating and quitting smoking were related to never smokers and stage of change; (2) to determine the applicability of the TMC constructs with this population by examining the reliability of the measures and ascertaining whether the theoretically predicted stage effects were evidenced; and (3) to examine the use of the experiential and behavioral processes of change, self-efficacy, and temptation to smoke between pregnant and nonpregnant teens within different stages of smoking. Data were from the baseline survey of 245 pregnant and parenting female adolescents aged 18 years and younger who were participating in a randomized control trial of a substance use prevention intervention through a teen parent program in P•rtland, Oregon.

\section{Principal Findings \\ Stage of Change}

The findings show that the majority of pregnant'parenting teens were in one of the five stages of change with respect to smoking, with $38.8 \%$ in the cessation stages and $42.5 \%$ either contemplating or preparing to quit smoking. It is encouraging that they enrolled in a study involving a smoking cessation intervention. Since this is the first study to classify pregnant/parenting teens within 
SOC, it is not known to what degree this distribution is representative of the population. The smoking rate for the total sample is high in comparison to the rate for $12^{\text {th }}$ grade females of $22.1 \%$ from the 2003 MTF study (Johnston, O'Malley, \& Bachman, 2003b). Further, the rate of $32 \%$ smoking in this study by pregnant teens was higher than the 2001 rate of $22 \%$ reported for Oregon pregnant adolescents (Oregon Department of Human Services, 2003). The sample rate, however, resembles findings from cross-sectional studies of smoking by pregnant/parenting teens (Albrecht et al., 1999; Cornelius, Geva, Day, Cornelius, \& Taylor, 1994; Gilchrist, Hussey, Gillmore, Lohr, \& Morrison, 1996; O'Campo, Faden, Brown, \& Gielen, 1992).

Demographic and Psychosocial Associates with Stage of Change Findings suggest that teens both understood the $\mathrm{SOC}$ algorithm and reported honestly, as the responses of only two teens were not cross-validated by other measures of smoking behavior.

Consistency with studies on demographic and psychosocial constructs associated with smoking provides additional support for the use of the SOC measure. Several of the factors associated with never smokers, smokers, and quitters (see e.g., Aghi et al., 2001; Flay et al., 1998; Lloyd-Richardson et al., 2002; Pederson et al., 1998; Scal et al., 2003; Tyas and Pederson, 1998) were found in question one of this study. For example, never smokers and quitters were significantly more likely to perceive smoking as wrong. Never smokers were also least likely to have a partner or friends who smoked and more likely to perceive 
smoking as harmful. Findings of SOC differences with smokers reporting more alcohol and drug use, more friends who smoked, less wrongfulness in smoking, less self-efficacy, and higher smoking intention than teens in Action and Maintenance are generally consistent with the literature on adolescents cited above as well as with the literature from TMC studies with adolescents (Pallonen, Prochaska et al., 1998) and studies with adult pregnant women (c.g., Burt \& Pederson, 1998; Covey \& Tam, 1990; Hakansson et al., 1999; McBride \& Pirie, 1990; Ockene et al., 2002). Self-efficacy has been shown to differentiate between stages and to be associated with preparing to quit and maintaining cessation (Dijkstra et al., 1998; Engels, et al., 1998). Findings of stage differences for smoking self-efficacy, with teens showing increased beliefs of being able to refrain from smoking from Precontemplation through Maintenance is also consistent with the literature.

\section{Reliability and Stage Effects of TMC Scales}

The measures of decisional balance and temptation to smoke came from the study by Plummer et al. (2001) and had been developed and tested with a sample of 2,808 high school students, the majority being non-Hispanic White and one-half male, in Rhode Island. There is not an adolescent version of the processes of change measure; a modified tem-item version of the adult scale was used.

\section{Decisional Balance}

The cons scale exhibited higher internal consistency $(\alpha=.92)$ as compared to $(\alpha=.88)$ in Plummer et al. (2001) but showed no stage effects. Rather than following a linear upward across the stages as with Plummer et al.'s sample, 
the cons scores were relatively constant with a $T$-score range from 52 to 54 . In the study by Pallonen, Prochaska et al. (1998), the authors found no stage effect for the cons of smoking and concluded that this supported research showing that adolescents underestimate and minimize the risks of smoking. This conclusion is not borne out with the present study; the cons of smoking were rated high (mean = 4.04) regardless of stage.

The coefficient alphas for the pros of the Decisional Balance Scale (.51 for social pros and .80 for coping pros) were lower than the alphas obtained by Plummer et al. (2001), .79 and .87 , respectively. Findings indicate that smoking for peer acceptance, or at least for the items included in this scale, did not resonate as important with this population. Findings here, however, are consistent with the study by Pallonen, Prochaska et al. (1998) where the social pros of smoking were less important than the coping pros. Thus, the influence of the role of peer pressure and peer acceptance for smoking is contradicted in both this study and the Pallonen, Prochaska et al. study.

It is speculative but possible that because Plummer et al.'s (2001) scale included 50\% males that the social pros scale is not reliable and valid for this population of adolescent females. Moreover, the biological fact of pregnancy and/or status of teen parent may place teens in a subculture where the social and peer-related reasons for smoking are different than they are for the general high school population of teens. Bane et al. (1999) suggest that approval from others is extremely important during pregnancy because women want to be perceived as 
being a good parent. One would assume this approval is even more important for teen parents because of their developmental stage as well as the stigma associated with teen pregnancy. Further research to develop a quality measure of the pros of smoking for this population might explore the Pregnancy-Tailored Decisional Balance measure developed by Bane et al. (1999), which showed significant stage effects for pregnancy related pros of smoking. Information related to social approval and disapproval and reflecting pros that are salient during pregnancy may be particularly important in tailoring intervention programs to help pregnant/parenting teens move forward through the stages.

The coping pros, however, scale displayed both good validity and stage effects consistent with both the Plummer et al. (2001) and the Pallonen, Prochaska et al. (1998) studies, thus it may remain useful as a measure in further studies with teen parents. Smoking for pleasure and to avoid negative feelings was significantly more important for teens in the three smoking stages than for teens in Maintenance and more important for precontemplators than for teens in Action, signifying that the coping pros rather than the social pros were more connected to readiness to quit. The $\mathrm{T}$-scores ranging from 54 in $\mathrm{PC}$ to 41 in $\mathrm{M}$ were similar to those in Plummer et al.'s (2001) study, 56 to 41, respectively.

\section{Temptation to Smoke}

The results of this study generally supported the Plummer et al. (2001) study. The reliability coefficients for the positive social, negative affect, and habit strength scales were similar to those reported by Plummer et al. As well, the inter- 
scale correlations were relatively high, except for weight control. As with the Plummer et al. study, there was a linear trend of decreasing temptation scores from Precontemplation through Maintenance. T-scores were similar as well, ranging from 40 to 55. Interestingly, habit strength, which represents nicotine addiction, was not as strong a motivator to smoke as was negative affect. These results support the findings from the decisional balance construct of the importance of the coping pros. Smoking as a perceived means to deal with stress and frustration and to avoid umpleasant emotions is a significant factor for this population.

The weight control scale demonstrated little variability. There is not enough information to know the cause. It could be attributable to the scale items not being salient to this population or to pregnant/parenting teens not being concerned about weight control or to them not viewing smoking as a means to control weight. However, given considerable findings of the association of smoking as a means of weight control with both pregnant adult women and adolescents (Albrecht et al., 1994; USDHHS, 2001), it is more probable that the scale items failed to capture this construct with this sample.

Processes of Change

The processes of change subscales were moderately reliable and displayed almost a parallel linear trend from Precontemplation through Maintenance, suggesting one of two things - either the two subscales were not distinguishable from each other within this sample of teens or the young women were using both the experiential and behavioral processes equally. Perhaps the abbreviated scale 
that used one item as a measure of each construct instead of two did not capture the difference between the two domains. It is also conceivable that either the adult concepts operationalized in the scale and/or the cognitive developmental stage of the teens made this particular measure not as appropriate for this population.

Nevertheless, some of the theoretically predicted stage effects were evidenced. Process use was lowest in Precontemplation $(\mathrm{T}<45)$ and peaked in Preparation ( $T>51$ ). Additionally, stage effects for the behavioral processes of counter-conditioning (substituting alternative behaviors) peaking in Action, reinforcement management (rewarding oneself or being rewarded by others) peaking in Preparation, and stimulus control (changing the environment, avoiding triggers) peaking in Action and Maintenance are congruent with the model. This pattern is also consistent with the Pallonen (1998) study which showed high behavioral process use from Preparation through Maintenance. The high use of the experiential processes in the latter stages and the low use of the behavioral processes in the early stages contradicts the findings by Pallonen. The elevated use of both processes through the Maintenance stage is of concern as it is considered an indicator of potential relapse (Pallonen).

High risk for relapse is also indicated by the fact that no stage effects were found for the experiential processes. As noted in studies with pregnant adult women who have relapsed (DiClemente, et al., 2000), this might signify a more externally driven than an internally driven process of change. Moreover, not finding a stage effect for self liberation (making a commitment to change) may also 
indicate lack of internal motivation to change, as this process is associated with forward movement from the Preparation stage.

\section{Stage Effects by Pregnancy and Smoking Status}

As discussed in the literature review, studies that have examined process use and temptation to smoke with pregnant and nonpregnant women have had contradictory findings. Stotts et al. (1996) found that pregnant women showed low process use and low temptation but high self-efficacy, whereas Ruggiero et al. (2000) found increased use of processes for both pregnant and nonpregnant women as they advanced through the stages but no differences in temptation. This study examined these patterns with pregnant quitters, nonpregnant quitters, and nonpregnant teens in Contemplation and Preparation.

In this study, process use, self-efficacy, and temptation to smoke were not affected by pregnancy status. Self-efficacy and temptation to smoke were affected by smoking status. In other words, both pregnant and nonpregnant teens who had quit smoking displayed high self-efficacy and low temptation to smoke as compared with nonpregnant teens who smoked. However, there were no significant differences in the use of the processes of change. While this finding can not be compared to the finding by Stotts et al. (1996) due to differences in group composition, it suggests that pregnant/parenting teens who have quit smoking may be at high risk for relapse due to the lack of stage-appropriate coping methods. 
Strengths and Limitations

There were several strengths of the current study. The sample size was large and consisted of diverse racial and cultural representation. The methodolegy incorporated validity checks and approaches to encourage honesty of reporting. For example, responses to the SOC algorithm were cross-validated using standard questions about current smoking. Three factors encouraged hønest self-reporting. Participants were assured strict confidentiality, informed about the voluntary nature and the right to refuse or skip questions, and the surveys were administered in an individual format (Klebanoff et al., 2001; Pallonen, Prochaska et al., 1998).

The study nevertheless had limitations. Although the sample was diverse, it was nonetheless limited to an urban, geographical area in the Northwest, which would affect the generalizability of the results. Second, recruitment procedures may have missed the most substance-using teens because they tend not to be involved with school or with social service agencies. Third, there was no biochemical validation of smoking.

Another limitation is the use of single items with only three response formats to measure both smoking intention and smoking self-efficacy. Also, the measure of domestic violence was indirect, inquiring about actions taken to avoid violence or the threat of violence rather than more direct questions such as those used in the Abuse Assessment Screen (McFarlane, Parker, Soeken \& Bullock, 1992). Consequently, some of the young women who had experienced intimate partner and/or family violence may have been missed. 
Finally, findings involving the Processes of Change scale need to be interpreted judiciously. The sample of 245 was sufficiently large for many of the analyses; however, it became drastically reduced to a subsample of 110 smokers for analyses involving the processes. Specifically, while the reliability of .77 for the experimental subscale and .70 for the behavioral subscale is acceptable for an exploratory study, there is too much error in the instrument itself, which weakens the power of any statistical analyses. In addition, since the error is randomly distributed, it could be washing out the distinction between the scales, resulting in either a Type I or Type II error.

Implications for Research, Policy and Practice

\section{Research}

This is the first study to apply the constructs and measures from the TMC to smoking among this population. Thus, there are significant areas for research, some of which already have been suggested in this chapter. Findings here are mixed and need to be replicated in a longitudinal study with a more representative sample. There is mixed evidence for the effectiveness of stage-based interventions in smoking cessation. However, as Riemsma et al. (2003) note, this could be due in part to problems with the way programs have been implemented rather than to problems with the model. We have just begun to examine this evidence with pregnant/parenting teens. Six- and twelve-month follow-up data from the STAGES randomized controlled study will be available in March 2005. Findings should 
provide valuable information on the efficacy of a stage-matched approach and factors associated with stage movement.

Rigorous evaluation depends on valid and reliable measures of TMC constructs within this population. Measures for general populations of adolescents are currently being evaluated, however, as found in this study, measures that work for a mixed-gender high school population may not be suitable for pregnant/parenting female adolescents. As noted previously, the Pregnancy Tailored Decisional Balance measure (Bane et al., 1999) should be tested with an adolescent population.

There are no adolescent measures of the processes of change. The interrelationship of the stages and the processes of change provide avenues for important new research. The pattern found here of almost parallel use of both higher order processes across the stages is not evident in other studies. A reliable and valid measure for this construct is critical since it is these processes that are used both to facilitate stage movement and to tailor interventions. We need to conduct further analyses on the links between processes and intermediate outcomes. Specifically, how do specific strategies and coping mechanisms promote quitting and maintaining cessation?

We know very little about the process of smoking cessation among this population. We also need to know more about how to improve access and delivery of programs that are developmentally and culturally appropriate. These young women may have multiple issues and problems that interact with their smoking. 
Information from qualitative methodologies involving pregnant/parenting teens and their partners could contribute significantly to research and to the design of interventions. An important question is how successful teens quit and maintain cessation postpartum. Findings could enhance our knowledge about how to apply the TMC framework to understand the general principles, specific processes, and intermediate steps underlying successful behavior change with pregnant/parenting teens who are addicted to tobacco as well as to other drugs.

\section{Policy}

The only way to affect cigarette smoking during pregnancy and postpartum is to establish a national, state and local commitment to do so, to fund it substantially, and to encourage and assist community organizations in developing programs. This underscores the importance of raising the consciousness of social workers regarding smoking as a social work issue and emphasizes the value of policy within and by the profession. Social werkers and social service providers within local agencies must take up the issue of cigarette smoking by pregnant/parenting teens as one they can affect. This will require education, consciousness raising and training in best practices.

Local non-profit agencies need help with finding funding for smoking cessation programs and with establishing protocols and fiscal policies regarding acceptance of tobacco company money. A major funder of research and interventions has been the Legacy Foundation, but they will have a reduced portion of funding in 2004 as tobacco companies cease payments from the tobacco 
settlement fund (Campaign for Tobacco Free-Kids, 2004). At the same time, the Phillip Morris Company is approaching non-profit agencies and offering them funding. Many agencies do not know that acceptance of money from tobacco companies may cause loss of revenue from other funding sources.

Financing for primary and secondary prevention with accompanying evaluation is essential. A recent report on state funding of tobacco prevention and cessation states that "tobacco companies spend more in three weeks marketing their products than all 50 states spend over a full year trying to prevent tobacco use" (Campaign for Tobacco-Free Kids, 2004, p. ii). Over the past few years most states have cut funding for their tobacco prevention and cessation programs to less than $35 \%$ of the CDC's minimum recommendations. For example, appropriated revenue for fiscal year 2004 in the state of Oregon is only $13.72 \%$ of the recommended amount due to funds being reallocated to fill budget gaps. As budgets for funding public and social services become more constricted, it will be important for social workers to develop a policy stance regarding adequate funding for programs.

\section{Practice}

This study found that a high percentage of pregnant and parenting teens in this sample smoked. It also found that they displayed both readiness to quit and willingness to participate in both research and interventions involving smoking cessation. The need for cessation programs for this population is clear. 
cessation), they also reported a high risk factor for relapse, that is, having a partner who smoked $-73 \%$ of teens in Action and $53 \%$ of teens in Maintenance. Teens in Action, as well as precontemplators, reported the lowest scores for perceived harm of smoking one or two packs of cigarettes a day. At the same time, their scores on the Decisional Balance Scale showed they considered the health risks of smoking as important. Clearly, there must be extreme ambivalence about smoking within this population. Stage-based interventions using client-centered approaches such as motivational interviewing (Miller, 1999) to decrease ambivalence and tap into their motivation to quit may hold promise for this group of young women. In addition, groups for couples and/or techniques for dealing with partner's continued smoking are warranted across all the stages of change.

Findings demonstrate that coping with stress is an important factor in smoking for pregnant/parenting teens, in particular for teens in the smoking stages. Individualized stage-based interventions focusing on stress reduction skills and alternative coping strategies to smoking are important. Assessing levels $\bullet$ domestic violence and use of other substances may also prove important for designing interventions with teens in the smoking stages.

We know that strategies that work for women who spontaneously quit upon becoming pregnant may not work for a subgroup of "hard-core" pregnant smokers (Goldenberg, Klerman, Windsor, \& Whiteside, 2000). Both smoking rates and relapse rates are high for subgroups such as teen parents who are in lower socioeconomic classes, have less support and resources, and less residential 
stability. A very informative study by Wakschlag, et al. (2003) shows that "smoking appears to be not merely a single health-compromising behavior but rather a manifestation of a long-standing behavioral style" (p. 2457) that involves a pattern of psychosocial risk-compromising behaviors in multiple domains. This suggests the importance of supplementing TMC strategies with skill development that promotes changes across multiple social and bealth systems. Ideally, support for smoking cessation interventions tailored to the issues of teen parents could be provided as part of a network of community services concerned with improving their overall quality of life.

As Goldenberg et al. (200) so simply state, "There is no obvious powerful anti-smoking intervention appropriate for pregnant women [and pregnant/parenting teens] on the horizon" (p. 85). We need to do all we can to ensure there is. 


\section{REFERENCES}

Aghi, M., Asma, S., Yeong, C., \& Vaithinathan, R. (2001). Initiation and maintenance of tobacco use. In J. Samet \& S. Yoon (Eds.), Women and the tobacco epidemic: Challenges for the $21^{\text {st }}$ century (pp. 49-68). Geneva, Switzerland: World Health organization. Retrieved February 23, 2003, from http://www5.who.int/tobacco/repository/tpc49/ WomenMonograph.pdf

Ajzen, I. (1998). Attitudes, personality and behavior. Chicago: The Dorsey Press.

Albrecht, S., Comelius, M., Braxter, B., Reynolds, M., Stone, C., \& Cassidy, B. (1999). An assessment of nicotine dependence among pregnant adolescents. Journal of Substance Abuse Treatment, 16(4), 337-344.

Albrecht, S., Higgins, L., \& Lebow, H. (2000). Knowledge about the deleterious effects of smoking and its relationship to smoking cessation among pregnant adolescents. Adolescence, 35(140), 709716.

Albrecht, S., Reynolds, M., Cornelius, M., Heidinger, J., \& Arnfield, C. (2002). Connectedness of pregnant adolescents who smoke [Electronic version]. Journal of Child \& Adolescent Psychiatric Nursing, 15(1), 16-23.

Albrecht, S., Rosella, J., \& Patrick, T. (1994). Smoking among low-income, pregnant women prevalence rates, cessation interventions, and clinical implications. BIRTH, 21(3), 155-162.

Archie, C., Anderson, M., \& Gniber, E. (1997). Positive smoking history as a preliminary screening device for substance use in pregnant adolescents. Journal of Pediatric Adolescent Gynecology, 10(1) 1317.

Aveyard, P., Cheng, K., Almond, J., Sherratt, E., Lancashire, R., Lawrence, T., Griffin, C., \& Evans, L. (1999). Cluster randomised controlled trial of expert system based on the transtheoretical model for smoking prevention and cessation in schools [Electronic version]. British Medical Journal, 319(7215), 948-953. 
Bandura, A. (1977). Social learning theory. Englewood Cliffs, NJ: Prentice Hall.

Bane, C., Ruggiero, L., Dryfoos, J., \& Rossi, J. (1999). Development of a pregnancy-tailored decisional balance measure for smoking cessation. Adaictive Behaviors, 24, 795-799.

Barber, J. (1995). Working with resistant drug abusers. Social Work, $40(1)$, 17-23.

Barnet, B., Duggan, A., Wilson, M., \& Joffe, A. (1995). Association between postpartum substance use and depressive symptoms, stress, and social support in adolescent mothers. Pediatrics, 96, 659-666.

Berenson, A., San Miguel, V., \& Wilkinson, G. (1992). Violence and its relationship to substance use in adolescent pregnancy. Journal of Adolescent health, 13(6), 470-474.

Bogolub, E. (1990). Tobacco: The neglected addiction. Social Work, 35(1), 77-78.

Boyd, N., Windsor, R., Perkins, L., \& Lowe, J. (1998). Quality of measurement of smoking status by self-report and saliva cotinine among pregnant women. Maternal and Child Health Journal, 2(2), 77-83.

Brogan, M., Prochaska, J. O., \& Prochaska, J. M. (1999). Predicting termination and continuation status in psychotherapy using the transtheoretical model. Psychotherapy, 36(2), 105-113.

Brook, J., Brook, D., \& Whiteman, M. (2000). The influence of maternal smoking during pregnancy on the toddler's negativity. Archives of Pediatric \& Adolescent Medicine, 154, 381-385.

Brown, J. (1997). Working toward freedom from violence: The process of change in battered women. Violence Against Women, 3(1), 5-26.

Bryant, A., Schulenberg, J., Bachman, J., O'Malley, P. \& Johnston, L. (2000). Understanding the links among school misbehavior, academic achievement, and cigarette use: A national panel study of adolescents [Abstract]. Prevention Science, 1(2), 78-87. 
Burt, R., \& Peterson, A. (1998). Smoking cessation among high school seniors. Preventive Medicine, 27, 319-327.

Campaign for Tobacco-Free Kids. (2004). Complete report: State tobacco settlement. Retrieved February 28, 2004 from http://www. tobaccofreekids.org/reports/settlements/2004/fullreport.pdf

Cancer Prevention Research Center. (n.d.a). Detailed overview of the transtheoretical model. Retrieved May 6, 2003, from http://www.uri.edu/research/cprc/index-old.htm

Cancer Prevention Research Center. (n.d.b) Measures of the transtheoretical model of change. Retrieved November 1, 2003, from http://www.uri.edu/research/cprc/measures.htm

Chassin, L., Presson, C., \& Sherman, C. (1984). Cognitive and social influence factors in adolescent smoking cessation. Addictive Behaviors, 9(4), 383-390.

Chen, X., Unger, J., Palmer, P., Weinter, M., Johnson, C., Wong, M., et al. (2002). Prior cigarette smoking initiation predicting current alcohol use: Evidence for a gateway drug effect among California adolescents from eleven ethnic groups. Addictive Behaviors, 27(5), 799-817.

Cnattingius, S., Haglund, B., \& Meirik, O. (1988). Cigarette smoking as risk factor for late fetal and early neonatal death. BMJ, 297(6643), 258261.

Coleman-Wallace, D., Lee, J., Montgomery, S., Blix, G., \& Wang, D. (1999). Evaluation of developmentally appropriate programs for adolescent tobacco cessation. Journal of School Health, 69(9), 314-319.

Colman, G., \& Joyce, T. (2003). Trends in smoking before, during, and after pregnancy in ten states. American Journal of Preventive Medicine, 24(1), 29-36.

Connors, G., Donovan, D., \& DiClemente, C. (2001). Substance abuse treatment and the stages of change: Selecting and planning interventions. New York: The Guilford Press.

Corcoran, K., \& Fischer, J. (2000). Measures for clinical practice: A sourcebook (3rd ed., Vol. 2). New York: The Free Press. 
Cornelius, M., Geva, D., Day, N., Cornelius, J., \& Taylor, P. (1994). Patterns and covariates of tobacco use in a recent sample of pregnant teenagers. Journal of Adolescent Health, 15(7), 528-535.

Cornelius, M., Leech, S., Goldschmidt, L., \& Day, N. (2000). Prenatal tobacco exposure: Is it a risk factor for early tobacco experimentation? Nicotine \& Tobacco Research, 2(45-52), 45-52.

Comelius, M., Taylor, P., Geva, D., \& Day, N. (1995). Prenatal tobacco and marijuana use among adolescents: Effects on offspring gestational age, growth, and morphology. Pediatrics, 95(5), 738-743.

Covey, L., \& Tam, D. (1990). Depressive mood, the single-parent home, and adolescent cigarette smoking [Electronic version]. American Journal of Public Health, 80(11), 1330-1333.

Crisp, A, Stavrakaki, C., Halek, C., Williams, E., Sedgwick, P., \& Kiossis, I. (1998). Smoking and pursuit of thinness in schoolgirls in London and Ottawa. Postgraduate Medical Journal, 74, 473-479.

Crittenden, K., Manfredi, C., Lacey, L., Warnecke, R., \& Parons, J. (1994). Measuring readiness and motivation to quit smoking among women in public health clinics. Addictive Behaviors, 19(5), 497-507.

Curry, M., Perrin, N., \& Wall, E. (1998). Effects of abuse on maternal complications and birth weight in adult and adolescent women. Obstetrics \& Gynecology, 92, 530-534.

Dallow, C., \& Anderson, J. (2003). Using self-efficacy and a transtheoretical model to develop a physical activity intervention for obese women. American Journal of Health Promotion, 17(6), 373-381.

Davidson, R. (1998). The transtheoretical model: A critical overview. In W. Miller \& N. Heather (Eds.), Treating addictive behaviors (pp. 25-38). New York: Plenum.

Delnevo C., Hrywna, M., Abatemarco, D., \& Lewis, M. (2003). Relationships between cigarette smoking and weight control in young women. Family \& Community Health, 26(2), 140-146. 
Dennis, M. L., Babor, T. F., Diamond, G., Donaldson, J., Godley, S. H., Titus, J. et al. (2000). The cannabis youth treatment (CYT) experiment: Preliminary findings. Rockville, MD: Center for Substance Abuse Treatment. Retrieved August 10, 2003, from http://www.samhsa.gov/centers/csat/content/Recoverymonth/0900can nabis.PDF

De Vries, H., \& Backbier, E. (1994). Self-efficacy as an important determinant of quitting among pregnant women who smoke: The phipattern. Preventive Medicine, 23(2), 167-174.

DiClemente, C., Dolan-Mullen, P., \& Carbonari, J. (1999, March). Smoking cessation: The problems and promise of pregnancy and postpartum. Poster session presented at the 1999 annual meeting of the Society for Research on Nicotine and Tobacco. Retrieved May 6, 2003, from http://www.smt.org/events/abstracts99/index.htm

DiClemente, C., Dolan-Mullen, P., \& Windsor, R. (2000). The process of pregnancy smoking cessation: Implications for interventions [Electronic version]. Tobacco Control, 9(3), 16-21.

DiClemente, C. C. \& Prochaska, J. O. (1982). Self-change and therapy change of smoking behavior: A comparison of processes of change in cessation and maintenance. Addictive Behaviors, 7, 133-142.

DiClemente, C., Prochaska, J. O., Fairhurst, S., Velicer, W., Rossi, J., \& Velas uez, M. (1991). The process of smoking cessation: An analysis of precontemplation, contemplation, and preparation stages of change. Journal of Consulting \& Clinical Psychology, 59, 295-304.

DiClemente, C., Prochaska, J. O., \& Gilbertini, M. (1985). Self-efficacy and the stages of self-change of smoking. Cognitive Therapy and Research, 9(2), 181-200.

Dijkstra, A., \& De Vries, H. (2000). Subtypes of precontemplating smokers defined by different long-term plans to change their smoking behavior. Health Education Research, 15(4), 423-434.

Dijkstra, A., De Vries, H., \& Roijackers, J. (1998). Targeting smokers with low readiness to change with tailored and nontailored self-help materials. Preventive Medicine, 28(2), 203-211. 
Ding, L., Pallonen, U., Migneault, J., \& Velicer, W. (1994). Development of a measure to assess adolescents' temptation to smoke [Abstract]. Annals of Behavioral Medicine, 16, S175.

Ding, L., Pallonen, U., \& Velicer, W. F. (1995). Temptations to smoke and stages of change among adolescent smokers [Abstract]. Annals of Behavioral Medicine, 17, S087.

Dolan-Mullen, P., Richardson, M., Quinn, V., \& Ershoff, D. (1997). Postpartum return to smoking: Who is at risk and when. American Journal of Health Promotion, 1I(5), 323-330.

Dunn, C., Pirie, P., \& Lando, H. (1998). Attitudes and perceptions related to smoking among pregnant and postpartum women in a low-income, multiethnic setting. American Journal of Health Promotion, 12, 267 274.

Engels, R., Knibbe, R., De Vries, H., \& Drop, M. (1998). Antecedents of smoking cessation among adolescents: Who is motivated to change? Preventive Medicine, 27, 348-357.

Ernster, V. (2001). Impact of tobacco use on women's health. In J. Samet \& S. Yoon (Eds.), Women and the tobacco epidemic: Challenges for the $21^{\text {st }}$ century (pp. 1-16). Geneva, Switzerland: World Health Organization. Retrieved February 3, 2003, from http://www5. who.int/tobacco/repository/tpc49/WomenMonograph.pdf

Ershoff, D., Solomon, L., \& Dolan-Mullen, P. (2000). Predictors of intentions to stop smoking early in prenatal care [Electronic version]. Tobacco Control, $9(3), 41-45$.

Etter, J., \& Sutton, S. (2002). Assessing 'stage of change' in current and former smokers [Electronic version]. Addiction, 97(9), 1171-1182.

Farkas, A., Pierce, J., Zhu, S., Rosbrook, B., Gilpin, E., Berry, C., et al. (1996). Addiction versus stages of change models in predicting smoking cessation [Electronic version]. Addiction, 91(9), 1271-1292.

Fava, J., Velicer, W., \& Prochaska, J. O. (1995). Applying the transtheoretical model to a representative sample of smokers. Addictive Behaviors, 20(2), 189-203. 
Finnell, D. (2003). Use of the transtheoretical model for individuals with cooccurring disorders. Community Mental Health Journal, 39(1), 3-15.

Flanagan, P., \& Kokotailo, P. (1999). Adolescent pregnancy and substance use. Clinics in Perinatology, 26(1), 185-200.

Flay, B., Phil, D., Hu, F., \& Richardson, J. (1998). Psychosocial predictors of different stages of cigarette smoking among high school students. Preventive Medicine, 27(5, Part 2), 9-18.

Forster, J., Murray, D., Wolfson, M., Blaine, T., Wagenaar, A., \& Hennrikus, D. (1998). The effects of community policies to reduce youth access to tobacco. American Journal of Public Health, 88(8), 1193-1198.

Gilchrist, L., Hussey, J., Gillmore, J., Lohr, J., \& Monison, D. (1996). Drug use among adolescent mothers: Prepregnancy to 18 months postpartum [Electronic version]. Journal of Adolescent Health, 19(5), 337-344.

Goldenberg, R., Klerman, L., Windsor, R., \& Whiteside, H. (2000). Smoking in pregnancy: final thoughts. Tobacco Control, 9(Suppl. 3), iii85-iii86.

Gorin, S. (2001). Inequality and health: Implications for social work [Electronic version]. Health \& Social Work, 25(4), 270-275.

Griesler, P., Kandel, D., \& Davies, M. (2002). Ethnic differences in predictors of initiation and persistence of adolescent cigarette smoking in the National Longitudinal Survey of Youth. Nicotine \& Tobacco Research, 4(1), 79-93.

Gritz, E., Prokhorov, A., Hudmon, K., Chamberlain, R., Taylor, W., DiClemente, C., et al. (1998). Cigarette smoking in a multiethnic population of youth: Methods and baseline findings. Preventive Medicine, 27, 365-384.

Hakansson, A., Lendahls, L., \& Petersson, C. (1999). Which women stop smoking? A population-based study of 403 pregnant smokers. Acta Obstetricia et Gynecologica Scandinavica, 78(3), 217-224. 
Haslam, C., \& Draper, E. (2000). Stage of change is associated with assessment of health risks of maternal smoking among pregnant women. Social Science \& Medicine, 5I(8), 1189-1196.

Herzog, T., Abrams, D., Emmons, K., \& Linnan, L. (2000). Predicting increases in readiness to quit smoking: A prospective analysis using the Contemplation ladder [Electronic version]. Psychology \& Health, 15(3), 369-381.

Herzog, T., Abrams, D., Emmons, K., Linnan, L. \& Shadel, W. (1999). Do processes of change predict smoking stage movements? A prospective analysis of the transtheoretical model. Health Psychology, 18(4), 369-375.

Hollis, J., Polen, M., Lichtenstein, E., \& Whitlock, E. (2003). Tobacco use patterns and attitudes among teens being seen for routine primary care. American Journal of Health Promotion, 17(4), 231-239.

Hughes, E., Lamont, D., Beecroft, M., Wilson, D., Brennan, B., \& Rice, S. (2000). Randomized trial of a "stage-of-change" oriented smoking cessation intervention in infertile and pregnant women. Fertility and Sterility, 74(3), 498-503.

Hussey, J., Gilchrist, L., Gillmore, M., \& Lohr, M. (1992). Factors related to cigarette smoking during adolescent pregnancy. Journal of Youth and Adolescence, 21(4), 409-420.

Insights Teen Parent Program. (2002). Final report of the choices in-home counseling program for pregnant and parenting teens. (Available from Insights Teen Parent Program, 2020 SE Powell, Portland, OR, 97202)

Janis, I. \& Mann, L. (1977). Decision making: A psychological analysis of conflict, choice, and commitment. New York: Collier Macmillan.

Johnson, J. L., Fava, J., Velicer, W., Monroe, A., \& Emmons, K. (2002). Testing stage effects in an ethnically diverse sample. Addictive Behaviors, 27(4), 605-617. 
Johnston, L., O'Malley, P., \& Bachman, J. (2003a). Monitoring the future national survey results on drug use, 1975-2002. Vol 1: Secondary school students (NIH Publication No. 03-5375). Bethesda, MD: NIDA. Retrieved June 6, 2003, from http://www. monitoringthefuture.org/pubs/monographs/vol1_2002.pdf

Johnston, L., O'Malley, P., \& Bachman, J. (2003b, December 19). Teen smoking continues to decline in 2003, but declines are slowing. Ann Arbor: University of Michigan News and Information Services. Retrieved February 7, 2004, from http://www. monitoringthefuture.org.

Kandel, D., \& Davies, M. (1986). Adult sequelae of adolescent depressive symptoms. [Abstract]. Archives of General Psychiatry, 43, 255-262.

Kandel, D. \& Udry, R. (1999). Prenatal effects of maternal smoking on daughters smoking: Nicotine or testosterone exposure? American Journal of Public Health, 89(9), 1377-1383.

Kaplan, C., Nápoles-Springer, A., Stewart, S., \& Pérez-Stable, E. (2001). Smoking acquisition among adolescents and young Latinas: The role of socioenvironmental and personal factors. Addictive Behaviors, 26, 531-550.

Kaplan, M., \& Weiler, R. (1997). Social patterns of smoking behavior: Trends and practice implications [Electronic version]. Health $d$ Social Work, 22(1), 47-53.

Kaufman, J. (1996). Teenage parents and their offspring. Annals of the New York Academy of Science, 789, 17-30.

Keigher, S., \& Taylor-Brown, S. (2001). Women's health needs special treatment. Health \& Social Work, 26(2), 67-71.

Kelder, S., Prokhorov, A., Barroso, C., Murray, N., Orpinas, P., \& McCormick, L. (2003). Smoking differences among African American, Hispanic, and White middle school students in an urban setting [Electronic version]. Addictive Behaviors, 28(3), 513-522.

King, C., \& Siegel, M. (2001). The master settlement agreement with the tobacco industry and cigarette marketing in magazines. New England Journal of Medicine, 345(7), 504-511. 
Klebanoff, M., Levine, R., Clemens, J., DerSimonian, R., \& Wilkins, D. (1998). Serum cotinine concentration and self-reported smoking during pregnancy. American Journal of Epidemiology, 148(3), 259. 262.

Klebanoff, M., Levine, R., Morris, C., Hauth, J., Sibai, B., Curet, L., et al. (2001). Accuracy of self-reported cigarette smoking among pregnant women in the 1990s [Electronic version]. Paediatric and Perinatal Epidemiology, 15(2), 140-143.

Kohlendorfer, U., Kiechl, S., \& Sperl, W. (1998). Sudden infant death syndrome: Risk factor profiles for distinct subgroups. American Journal of Epidemiology, 147, 960-968.

Koniak-Griffin, D., Lesser, J., Nyamathi, A., Uman, G., Stein, J., \& Cumberland, W. (2003). Project CHARM: An HIV prevention program for adolescent mothers. Family \& Community Health, 26(2), 94-107.

Lai, S., Lai, H., Page, J., McCoy, C. (2000). The association between cigarette smoking and drug abuse in the United States. Journal of Addictive Diseases, 19(4), 11-24.

Lawson, E. (1994). The role of smoking in the lives of low-income pregnant adolescents: A field study. Adolescence, 29(113), 61-79.

Lehman, A. (1988). A quality of life interview for the chronically mentally ill. Evaluation and Program Planning, 40, 369-373.

Lelong, N., Kaminski, M., Saurel-Cubizolles, M., \& Bouvier-Colle, J. (2001). Postpartum return to smoking among usual smokers who quit during pregnancy. European Journal of Public Health, 11(3), 334339.

Li, M., Cheng, R., Ma, J., \& Swan, G. (2003). A meta-analysis of estimated genetic and environmental effects on smoking behavior in male and female adult twins [Abstract]. Addiction, 98(1), 23-31.

Littell, J., \& Girvin, H. (2002). Stages of change: A critique. Behavior Modification, 26(2), 223-273. 
Lloyd-Richardson, E., Papandonatos, G., Kaqura, A., Stanton, C., \& Niaura, R. (2002). Differentiating stages of smoking intensity among adolescents: Stage-specific psychological and social influences [Electronic version]. Journal of Consulting and Clinical Psychology, 70(4), 998-1009.

Lowry, R., Galuska, D., Fulton, J, Wechsler, H., \& Kann, I. (2002). Weight management goals and practices among U.S. high school students: Associations with physical activity, diet, and smoking. Journal of Adolescent Health, 31(2), 133-144.

Lu, Y., Tong., S., \& Oldenburg, B. (2001). Determinants of smoking and cessation during and after pregnancy [Electronic version]. Health Promotion International, 16(4), 355-365.

Ma, G., Shive, S., Legos, P., \& Tan, Y. (2003). Ethnic differences in adolescent smoking behaviors, sources of tobacco, knowledge and attitudes toward restriction policies [Electronic version]. Addictive Behaviors, 28(2), 249-268.

Manfredi, C., Crittenden, K., Cho, Y., Engler, J., \& Warnecke, R. (2000). Minimal smoking cessation interventions in prenatal, family planning, and well-child public health clinics. American Journal of Public Health, 90(3), 423-427.

Martin, J., Hamilton, B., Ventura, S., Menacker, F. \& Park, M. (2002, February 12). Births: Final data for 2000 [Electronic version]. National Vital Statistics Reports 50(5), 1-102. Retrieved May 16, 2003, from http://www.cdc.gov/nchs/data/nvsr/nvsr50/nvsr50_05.pdf

Martin, S., Clark, K., Lynch, S., Kupper, L., \& Cilenti, D. (1999). Violence in the lives of pregnant teenage women: Associations with multiple substance use. American Journal of Drug Alcohol Abuse, 25(3), 425440 .

Matthews, T. (2001). Smoking during pregnancy in the 1990s [Electronic version]. National Vital Statistics Reports, 49(7), 1-15. Retrieved May 10, 2003, from http://www.cdc.gov/nchs/data/nvsr/ nvsr49/nvsr49_07.pdf

Mayhew, K., Flay, B., \& Mott, J. (2000). Stages in the development of adolescent smoking. Drug and Alcohol Dependence, 59(Suppl. 1), 61-81. 
McBride, C., \& Pirie, P. (1990). Postpartum smoking relapse. Addictive Behaviors, 15(2), 165-168.

McFarlane, J., Parker, B., \& Soeken, K. (1996). Physical abuse, smoking, and substance use during pregnancy: Prevalence, interrelationships, and effects on birth weight. Journal of Obstetric, Gynecologic, \& Neonatal Nursing, 25, 313-320.

McFarlane, J., Parker, B., Soeken, K., \& Bullock, L. (1992). Assessing for abuse during pregnancy. Journal of the American Medical Association, 267, 3176-3178.

McLeod, D., Pullon, S., \& Cookson, T. (2003). Factors that influence changes in smoking behaviour during pregnancy. New Zealand Medical Journal, 116(1173). Abs ract retrieved May 13, 2003, from PubMed database.

Mermelstein, R. (2003). Teen smoking cessation. Tobacco Control, I2(Suppl. 1), 125-134.

Mermelstein, R., Colby, S., Patten, C., Prokhorov, A., Brown, R., Myers, M., et al. (2002). Methodological issues in measuring treatment outcome in adolescent smoking cessation studies. Nicotine \& Tobacco Research, 4(4), 395-403.

Miller, W. (1999). Enhancing motivation for change in substance abuse treatment: Treatment improvement protocol (TIP) series 35. (DHHS Publication No. SMA 99-3354). Rockville, MD: U.S. Department Of Health And Human Services, Public Health Service, Substance Abuse and Mental Health Services Administration, Center for Substance Abuse Treatment.

Miller, W., \& Rollnick, S. (1991). Motivational interviewing: Preparing people to change addictive behavior. New York: The Guilford Press.

Milunsky, A., Carmella, S., Ye, M., \& Hecht, S. (2000). A tobacco-specific carcingen in the fetus. Prenatal Diagnosis, 20(4), 307-310. Abstract retrieved May 6, 2003, from PubMed database.

Nafstad, P., Botten, G., \& Hagen, J. (1996). Partner's smoking: A major determinant for changes in women's smoking behaviour during and after pregnancy. Public Health, 110(6), 379-385. 
Najman, J., Lanyon, A., Andersen, J., Williams, G., Bor, W., \& O'Callaghan, M. (1998). Socioeconomic status and maternal cigarette smoking before, during and after a pregnancy [Electronic version]. Australian and New Zealand Journal of Public Health, $22(1), 60-66$.

Nichter, M., Nichter, M., Vuckovic, N., Quintero, G., \& Ritenbaugh, C. (1997). Smoking experimentation and initiation among adolescent girls: Qualitative and quantitative findings [Electronic version]. Tobacco Control, 6(4), 285-295.

Nonnemaker, J., McNeely, C., \& Blum, R. (2003). Public and private domains of religiosity and adolescent health risk behaviors: Evidence from the National Longitudinal Study of Adolescent Health. Social Science \& Medicine, 57(11), 2049-2054.

Norman, G., Velicer, W., Fava, J., \& Prochaska, J. O. (1998). Dynamic typology clustering within the stages of change for smoking cessation. Addictive Behaviors, 23(2), 139-153.

Oaks, L. (2001). Smoking and pregnancy: The politics of fetal protection. New Brunswick, NH: Rutgers University Press.

O'Campo, P., Faden, R., Brown, H., \& Gielen, A. (1992). The impact of pregnancy on women's prenatal and postpartum smoking behavior. American Journal of Preventive Medicine, 8(1), 8-13.

Ockene, J., Ma, Y., Zapka, J., Pbert, L., Valentine Goins, K., \& Stoddard, A. (2002). Spontaneous cessation of smoking and alcohol use among low-income pregnant women [Electronic version]. American Journal of Preventive Medicine, 23(3), 150-159.

O'Hare, T. (1996a). Court-ordered versus voluntary clients: Problem differences and readiness for change. Social Work, 41(4), 417-422.

O'Hare, T. (1996b). Readiness for change: Variation by intensity and domain of client distress. Social Work Research, 20(1), 13-17.

Olsen, J. (1993). Predictors of smoking cessation in pregnancy. Scandanavian Journal of Social Medicine, 21(3), 197-202. Abstract retrieved July 15, 2000, from PubMed database. 
Oregon Department of Human Services. (2003). Oregon Tobacco Facts [Electronic version]. Retrieved February 7, 2004, from http://www.healthoregon.org/tobacco

Pallonen, U. (1998). Transtheoretical measures for adolescent and adult smokers: Similarities and differences. Preventive Medicine, 25(5 Pt 3), 29-38.

Pallonen, U., Prochaska, J. O., Velicer, W., Prokhorov, A., \& Smith, N. (1998). Stages of acquisition and cessation for adolescent smoking: An empirical integration. Addictive Behaviors 23, 303-324.

Pallonen, U., Rossi, J. S., \& Smith, N. F. (1993). Applying the stages of change and processes of adolescent smoking cessation [Abstract]. Annals of Behavioral Medicine, 15, S131.

Pallonen, U., Velicer, W., Prochaska, J. O., Rossi, J., Bellis, J., Tsoh, J., et al. (1998). Computer-based smoking cessation interventions in adolescents: Description, feasibility, and six-month follow-up findings. Substance Use \& Misuse, 33(4), 935-965.

Parker, B., McFarlane, J., \& Soeken, K. (1994). Abuse during pregnancy: Effects on maternal complications in adult and teenage women. Journal of Obstetrics \& Gynecology, 84, 323-328.

Parker, B., McFarlane, J., Soeken, K., Torres, S., \& Campbell, D. (1993). Physical and emotional abuse in pregnancy: A comparison of adult and teenage women. Nursing Research, 42(3), 173-178.

Pederson, L., Koval, J., McGrady, G., \& Tyas, S. (1998). The degree and type of relationship between psychosocial variables and smoking status for students in grade 8: Is there a dose-response relationship? Preventive Medicine, 27, 337-347.

Perz, D., DiClemente, C., \& Carbona, J. (1996). Doing the right thing at the right time? The interaction of stages and processes of change in successful smoking cessation. Health Psychology, 15(6), 462-468.

Plummer, B., Velicer, W., Redding, C., Prochaska, J. O., Rossi, J., Pallonen, U., et al. (2001). Stage of change, decisional balance, and temptations for smoking: Measurement and validation in a large, school-based population of adolescents. Addictive Behaviors, 26, 551-571. 
Polacsek, M., Celentano, D., O'Campo, P., \& Santelli, J. (1999). Correlates of condom use stage of change: Implications for intervention. AIDS Education and Prevention, 11(1), 38-52.

Prochaska, J.O. (1979). Systems of psychotherapy: A transtheoretical analysis. Pacific, CA: Brooks-Cole.

Prochaska, J. O., \& DiClemente, C. (1983). Stages and processes of selfchange of smoking: Toward an integrative model of change. Journal of Consulting and Clinical Psychology, 51, 390-395.

Prochaska, J. O. \& DiClemente, C. (1984). Self change processes selfefficacy and decisional balance across five stages of smoking cessation. In A.R. Liss (Ed.), Advances in cancer control: Epidemiology and research. New York: Alan R. Liss.

Prochaska, J. O., DiClemente, C., \& Nercross, J. (1992). In search of how people change: Applications to addictive behaviors. American Psychologist, 47(9), 1102-1114.

Prochaska, J. O., \& Velicer, W. (1997). The transtheoretical model of health behavior change. American Journal of Health Promotion 12(1), 3848.

Prochaska, J. O., Velicer, W., DiClemente, C., \& Fava, J. (1988). Measuring processes of change: Applications to the cessation of smoking. Journal of Consulting \& Clinical Psychology, 56, 520-528.

Prochaska, J. O., Velicer, W., Guadagnoli, E., Rossi, J., \& DiClemente, C. (1991). Patterns of change: Dynamic typology applied to smoking cessation. Multivariate Behwieral Research, 26(1), 83-107.

Prochaska, J. O., Velicer, W., Rossi, J., Goldstein, M., Marcus, B., Rakowski, W., et al. (1994). Stages of change and decisienal balance for 12 problem behaviors. Health Psychology, 13(1), 39-46.

Prokhorov, A., Hudmon, K., de Moor, C., Kelder, S., Conroy, J., \& Ordway, N. (2001). Nicotine dependence, withdrawal symptoms, and adolescents' readiness to quit smoking. Nicotine \& Tobacco Research, 3, 151-155. 
Quinn, V., Mullen, P., \& Ershoff, D. (1991). Women who stop smoking spontaneously prior to prenatal care and predictors of relapse before delivery. Addictive Behaviors, 16(1-2), 29-40.

Radloff, L.S. (1977). The CES-D scale: A self-report depression scale for research in the general population. Applied Psychological Measurement, 1, 385-401.

Rattner, P., Johnson, J., Bottorff, J., Dahinten, S., \& Hall, W. (2000). Twelve-month follow-up of a smoking relapse prevention intervention for postpartum women. Addictive Behaviors, 25(1), 8192.

Resnick, M., Bearman, P., Blum, R., Bauman, K., Harris, K., Jones, J., et al. (1997). Protecting adolescents from harm: Findings from the national longitudinal study on adolescent health. JAMA, 278(10), 832-832.

Richardson, K. (1999). Adolescent pregnancy and substance use. Journal of Obstetric, Gynecologic, \& Neonatal Nursing, 28, 623-627.

Ricmsma, R., Pattenden, J., Bridle, C., Sowden, A., Mather, L., Watt, I., \& Walker, A. (2003). Systematic review of the effectiveness of stage based interventions to promote smoking cessation. BMJ, 326(7400), 1175-1177.

Ringle, J., \& Evans, W. (2001). Cigarette taxes and smoking during pregnancy. American Journal of Public Health, 91(11), 1851-1856.

Ruggiero, L, Redding, C., Rossi, J., \& Prochaska, J. O. (1997). A stagematched smoking cessation program for pregnant smokers. American Journal of Health Promotion, 12(1), 31-33.

Ruggiero, L., Tsoh, J., Everett, K., Fava, J., \& Guise, B. (2000). The transtheoretical model of smoking: Comparison of pregnant and nonpregnant smokers. Addictive Behaviors, 25(2), 239-251.

Rush, D. (1992). Exposure to passive cigarette smoking and child development: An updated critical review. In D. Poswillo and E. Alberman (Eds.), Effects of smoking on the fetus, neonate, and child (pp. 150-170). New York: Oxford University Press. 
Ryan, H., Wortley, P., Easton, A., Pederson, L., \& Greenwood, G. (201). Smoking among lesbians, gays, and bisexuals: A review of the literature. American Journal of Preventive Medicine, 21(2), 142-149.

Samet, J. \& Yang, G. (2001). Passive smoking, women and children. In J. Samet \& S. Yoon (Eds.), Women and the tobacco epidemic: Challenges for the $21^{\text {st }}$ century (pp. 17-48). Geneva, Switzerland: World Health Organization. Retrieve February 3, 2003, from http: //www5.who.int/tobacco/repository/tpc49/WomenMonograph.pdf

Scal, P., Ireland, M., \& Borowsky, I. (2003). Smoking among American adolescents: A risk and protective factor analysis [Electronic version]. Journal of Community Health, 28(2), 79-97.

Scholl, T., Hediger, M., \& Belsky, D. (1994). Prenatal care and maternal health during adolescent pregnancy: A review and meta-analysis. Journal of Adolescent Health, 15(6), 444-456.

Seguire, M., \& Chalmers, K. (2000). Late adolescent female smoking. Journal of Advanced Nursing, 31(6), 1422-1429.

Severson, H., Andrews, J., Lichtenstein, E., Wall, M., \& Akers, L. (1997). Predictors of smoking during and after pregnancy: A survey of mothers of newborns. Preventive Medicine, 24(1), 23-28.

Siguiera, L., Rolnitzky, L., \& Rickert, V. (2001). Smoking cessation in adolescents: The role of nicotine dependence, stress, and coping methods. Archives of Pediatrics \& Adolescent Medicine, 155(4), 489-495.

Skinner, B. F. (1974). About behaviorism. New York: Random House.

Snow, M., Prochaska, J., \& Rossi, J. (1991). Stages of change for smoking cessation among former problem drinkers: A cross-sectional analysis. Journal of Substance Abuse, 4(2), 107-116.

Solomon, L., Secker-Walker, R., Skelly, J., \& Flynn, B. (1996). Stages of change in smoking during pregnancy in low-income women. Journal of Behavioral Medicine, 19(4), 333-344.

Spencer, L., Pagell, F., Hallion, M., \& Adams, T. (2002). Applying the transtheoretical model to tobacco cessation and prevention: A review of literature. American Journal of Health Promotion, 17(1), 7-71. 
Stead, L., \& Lancaster, T. (2000). A systematic review of interventions for preventing tobacco sales to minors. Tobacco Control, 9(2), 169-176.

Stern, R., Prochaska, J. O., Velicer, W., \& Elder, J. (1987). Stages of adolescent cigarette smoking acquisition: Measurement and sample profiles. Addictive Behaviors, 12(4), 319-329.

Stevens, S., Colwell, B., Miller, K., Sweeney, D., McMillan, D., \& Smith, D. (203). Differences in evaluations of a tobacco awareness and cessation program by adolescents in four stages of change. Addictive Behaviors, 28(3), 471-482.

Stotts, A., DiClernente, C., Carbonari, J., \& Dolan-Mullen, P. (1996). Pregnancy smoking cessation: A case of mistaken identity. Addictive Behaviors, 2I(4), 459-471.

Stotts, A., DiClemente, C., Carbonari, J., \& Dolan-Mullen, P. (2000). Postpartum return to smoking: Staging a "suspended" behavior. Health Psychology, 19(4), 324-332.

Stotts, A., DiClemente, C., \& Dolan-Mullen, P. (2002). One-to-one: A motivational intervention for resistant pregnant smokers. Addictive Behaviors, 27(2), 275-292.

Strecher, V., McEvoy, D., \& Becker, M. (1986). The role of self-efficacy in achieving health behavior change. Health Education Quarterly, 15, 75-91.

Substance Abuse and Mental Health Data Archive. (n.d.). Substance Abuse and Mental Health Services Administration, Office of Applied Studies website. Retrieved November 1, 2003, from http:/t www.icpsr.umich.edu/SAMHDA/archive.html

Sutton, S. (2000). A critical review of the transtheoretical model applied to smoking cessation. In P. Norman, C. Abraham, \& M. Conner (Eds.), Understanding and changing health behaviour: From health beliefs to self-regulation (pp. 207-225). Reading, PA: Harwood Academic Press.

Tomeo, C. A., Field, A. E., Berkey, C. S., Colditz, G., \& Frazier, L. (1999). Weight concerns, weight control behaviors and smoking cessation [Electronic version]. Pediatrics, 104, 918-924. 
Toothaker, L. E. (1992). Multiple comparison procedures: Quantitative applications in the social sciences series (Vol. 89). Thousand Oaks, CA: Sage Publications.

Tyas, S., \& Pederson, L. (1998). Psychosocial factors related to adolescent smoking: A critical review of the literature. Tobacco Control, 7, 409420 .

U.S. Department of Health \& Human Services. (1964). Smoking and health: Report of the advisory committee to the Surgeon General of the public health service [Electronic version]. Retrieved March 12, 2003, from http://www.cdc.gov/tobacco/sgr/sgr_ 1964/sgr64.htm

U.S. Department of Health \& Human Services. (1994). Preventing tobacco use among young people: A report of the Surgeon General [Electronic version] Retrieved May 1, 2003 from http://www.cdc. gov/tobacco/sgr/sgr_1994/index.htm

U.S. Department of Health and Human Services. (1998). Tobacco use among U.S. racial/ethnic minority groups-African Americans, American Indians and Alaska natives, Asian Americans and Pacific Islanders, and Hispanics: A report of the Surgeon General [Electronic version]. Retrieved July 8, 1999, from http://www. cdc.gov/tobacco/sgr/sgr_1998/index.htm

U.S. Department of Health and Human Services. (2001). Women and smoking: A report of the Surgeon General [Electronic version]. Retrieved May 10, 2003, from http://www.cdc.gov/tobacco/ sgr/sgr_forwomen/index.htm

U.S. Department of Health \& Human Services (2002). Changing adolescent smoking prevalence: where it is and why (National Cancer Institute Monograph No. 14, NTIS No. PB2002105520) [Electronic version]. Retrieved May 20, 2003, from http://cancercontrol.cancer.gov/ tcrb/monographs/14/index.html

Valanis, B., Lichtenstein, E., Mullooly, J., Labuhn, K., Brody, K., Severson, H., \& Stevens, N. (201). Maternal smoking cessation and relapse prevention during health care visits. American Journal of Preventive Medicine, 20(1), 1-8.

Valentich, M. (1994). Social work and the development of a smoke-free society [Electronic version]. Social Work, 39(4), 439-450. 
Van't Hof, S., Wall, M., Dowler, D., \& Stark, M. (2000). Randomized controlled trial of a pestpartum relapse prevention intervention [Electronic version]. T'obacco Control, 9(3), 64-66.

Velasquez, M., Maurer, G., Crouch, C., \& DiClemente, C. (2001). Group treatment for substance abuse: A stages of change therapy manual. New York: Guilford Press.

Velicer, W., DiClemente, C., Prochaska, J. O., \& Brandenburg, N. (1985). Decisional balance measure for assessing and predicting smoking status. Journal of Personality and Social Psychology, 48, 12791289.

Velicer, W., DiClemente, C., Rossi, J., \& Prochaska, J. O. (1990). Relapse situations and self-efficacy: An integrative model. Addictive Behaviors, 15, 271-283.

Velicer, W., Fava, J., Prochaska, J. O., Abrams, D., Emmons, K., \& Pierce, J. (1995). Distribution of smokers by stage in three representative samples. Preventive Medicine, 24, 401-411.

Velicer, W., Hughes, S., Fava, J., Prochaska, J. O., \& DiClemente, C. (1995). An empirical typology of subjects within stage of change. Addictive Behaviors, 20(3), 299-320.

Velicer, W., Norman, G., Fava, J., \& Prochaska, J. (1999). Testing 40 predictions from the transtheoretical model. Addictive Behavior, 24(4), 455-469.

Ventura, S., Hamilton, B., \& Sutton, P. (2003, February 6). Revised birth and fertility rates for the United States, 2000 and 2001 [Electronic version]. National Vital Statistics Reports 51(4), 1-19.. Retrieved June 10, 2003 from http://www.cdc.gov/nchs/data/nvsr/nvsr51/ nvsr51_04.pdf

Ventura, S., Mosher, W., Curtin, S., \& Abma, J., (2001, June 6). Trenđ̊s in pregnancy rates for the United States, 1976-1997: An update [Electronic version]. National Vital Statistics Reports 49(4), 1-10. Retrieved June 10, 2003 from http://www.cdc.gov/nchs/data/nvsr/ nvsr49/nvsr49_04.pdf 
Von Kries, R., Toschke, A., Koletzko, B., \& Slikker, W. (2002). Maternal smoking during pregnancy and childhood obesity. American Journal of Epidemiology, 156, 954-961.

Wakschlag, L., Pickett, K., Middlecamp, M., Walton, L., Tenzer, P., \& Leventhal, B. (2003). Pregnant smokers who quit, pregnant smokers who don't: Does history of problem behavior make a difference? Social Science \& Medicine, 12, 2449-2460.

Ware, J., Kosinski, M., \& Keller, S. (1996). A. 12-item short-form health survey: Construction of scales and preliminary tests of reliability and validity. Medical Care, 34(3), 220-233.

Weissman, M., Warner, V., Wickramaratne, P., \& Kandel, D. (1999). Maternal smoking during pregnancy and psychopathology in offspring followed to adulthood. Journal of the American Academy of Child and Adolescent Psychiatry, 38(7), 892-899.

Wilcox, A. (1993). Birth weight and perinatal mortality: The effect of maternal smoking. American Journal of Epidemiology, 137(10), 109114.

Windle, M., \& Windle, R. (2001). Depressive symptoms and cigarette smoking among middle adolescents: Prospective associations and intrapersonal and interpersonal influences [Electronic version]. Journal of Consulting and Clinical Psychology, 69(2), 215-226.

Windsor, R., \& Orleans, T. (1986). Guidelines and methodological standards for smoking cessation intervention research among pregnant women: Improving the science and art. Health Education Quarterly, 13(3), 131-161.

Winer, B., Brown, D., \& Michels, K. (1991). Statistical principals in experimental design. (3rd ed.). New York: McGraw-Hill.

Wisborg, K., Henriksen, R., Hedegaard, M., \& Secher, N. (1996). Smoking among pregnant women and the significance of sociodemographic factors on smoking cessation. Ugeskrifi for Leger, 158(26), 37843788. Abstract retrieved July 15, 2000, from PubMed database.

Woodby, L, Windsor, R., Snyder, S., Kohler, C., \& DiClemente, C. (1999). Predictors of smoking cessation during pregnancy. Addiction, 94(2), 283-292. 
Wright, R. (1976). Understanding statistics. New York: Harcourt Brace Jovanovich.

Wu, L. T., \& Anthony, J. C. (1999). Tobacco smoking and depressed mood in late childhood and early adolescence. American Journal of Public Health, 89, 1837-1840.

Wunschel, S., \& Rohsenow, D. (1993). Coping strategies and the maintenance of change after inpatient alcoholism treatment. Social Work Research \& Abstracts, 29(4), 18-22.

Zhu, S., Sun, J., Billings, S., Choi, W., \& Malarcher, A. (1999). Predictors of smoking cessation in U.S. adolescents [Electronic version]. American Journal of Preventive Medicine, 16(3), 202-207.

Zimet, G., Dahlem, N., Zimet, S., \& Farley, G. (1988). The multidimensional scale of perceived social support. Journal of Personality Assessment, 52, 30-41. 


\section{APPENDICES}

\section{Appendix A - Questions from Stages Survey}

\section{ABOUT YOU}

1. What is your date of birth?

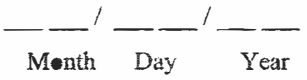

2. Are you Hispanic or Latina?

1. Yes

2. No

3. What is your race? (Circle all that apply)

1. Black or African American

2. Asian

3. American Indian / Native American

4. Native Hawaiian or Other Pacific Islander

5. Alaska Native

6. White

7. Other (Specify)

\section{PREGNANCY/PARENTING}

15. Are you pregnant now? (Circle one answer.)

$$
\begin{array}{ll}
1 & \text { Yes } \\
2 & \text { No } \\
3 & \text { Don't know }
\end{array}
$$

\section{HOW YOU FEEL}

How true are the following statements for you?

\begin{tabular}{|l|l|c|c|c|c|}
\hline \multicolumn{2}{|c|}{ (Circle one answer for each statement below.) } & $\begin{array}{c}\text { Very } \\
\text { true }\end{array}$ & $\begin{array}{c}\text { Fairly } \\
\text { true }\end{array}$ & $\begin{array}{c}\text { A little bit } \\
\text { true }\end{array}$ & $\begin{array}{c}\text { Not at all } \\
\text { true }\end{array}$ \\
\hline 29. & $\begin{array}{l}\text { I often act on the spur-of-the moment } \\
\text { without stopping to think. }\end{array}$ & 1 & 2 & 3 & 4 \\
\hline 33. & $\begin{array}{l}\text { Some people might say I act without } \\
\text { thinking first. }\end{array}$ & 1 & 2 & 3 & 4 \\
\hline 36. & $\begin{array}{l}\text { I like to test myself every now and then } \\
\text { by doing something a little risky }\end{array}$ & 1 & 2 & 3 & 4 \\
\hline
\end{tabular}




\begin{tabular}{|l|l|c|c|c|c|}
\hline 4. & $\begin{array}{l}\text { I don't let the risk of getting hurt a little } \\
\text { stop me from having a good time. }\end{array}$ & 1 & 2 & 3 & 4 \\
\hline 42. & $\begin{array}{l}\text { I get a real kick out of doing things that } \\
\text { are a little dangerous. }\end{array}$ & 1 & 2 & 3 & 4 \\
\hline 45. & $\begin{array}{l}\text { Many of my actions seem to be hasty } \\
\text { (without much thought). }\end{array}$ & 1 & 2 & 3 & 4 \\
\hline
\end{tabular}

In my life there is an adult (either in my home, neighborhood, community or school) who. . .

\begin{tabular}{|c|c|c|c|}
\hline $\begin{array}{l}\text { Very } \\
\text { true }\end{array}$ & $\begin{array}{c}\text { Fairly } \\
\text { true }\end{array}$ & $\begin{array}{c}\text { A little bit } \\
\text { true }\end{array}$ & $\begin{array}{l}\text { Not at all } \\
\text { true }\end{array}$ \\
\hline 1 & 2 & 3 & 4 \\
\hline 1 & 2 & 3 & 4 \\
\hline 1 & 2 & 3 & 4 \\
\hline 1 & 2 & 3 & 4 \\
\hline 1 & 2 & 3 & 4 \\
\hline 1 & 2 & 3 & 4 \\
\hline 1 & 2 & 3 & 4 \\
\hline 1 & 2 & 3 & 4 \\
\hline
\end{tabular}

In my life I have a friend (someone my age, Very Fairly A little bit Not at all could be a relative or family member) who... true

54. Is around when I need a friend.

55. Is a real source of comfort for me.

56. Really tries to help me.

57. I can count on when things go wrong.

58. I can share my jøys and sorrows with.

59. Really cares about my feelings.

60. I can talk with about my problems.

$\begin{array}{llll}1 & 2 & 3 & 4 \\ 1 & 2 & 3 & 4 \\ 1 & 2 & 3 & 4 \\ 1 & 2 & 3 & 4 \\ 1 & 2 & 3 & 4 \\ 1 & 2 & 3 & 4 \\ 1 & 2 & 3 & 4\end{array}$

\section{$\rightarrow$ FAITH \& RELIGION}

We're interested in the role that faith and religion play in your life. We want to remind you that you do not have to answer any questions you don't want to. 
99c. How important is religion in your life today?

1. Extremely important

2. Very important

3. Fairly important

4. Not very important

5. Not important at all

98. Don't know

100. Don't want to answer

During the past week, how often did you feel the following things? (Circle one answer for each statement below.).)

\section{During the past week...}

$\begin{aligned} & \text { None of } \\ & \text { the time ome of }\end{aligned}$ Most of All of the
the time time

61. I was bothered by things that usually

\section{don't bother me.}

62. I felt depressed.

1

2

3

4

63. I felt hopeful about the future.

\section{2}

3

4

64. My sleep was restless.

1

2

3

4

65. I was happy.

1

2

3

4

66. I talked less than usual.

\section{1}

\section{2}

3

4

67. I felt lonely.

\section{1}

\section{2}

3

4

68. I enjoyed life.

\section{1}

2

3

4

69. If felt sad.

$\begin{array}{llll}1 & 2 & 3 & 4 \\ 1 & 2 & 3 & 4\end{array}$

\section{YOUR HEALTH}

71. In general, how would you say your health is? (Circle one answer.)
1 Excellent
2 Very good
3 Good
4 Fair
5 Poor 


\section{$\rightarrow$ YOUR SAFETY}

72. In the past six months, has violence or the threat or fear of violence with your current partner/ past partner or the father of your child resulted in any of the following? (Circle all that apply).

1 I avoided the violent/threatening person as much as possible.

2 I spent the night out of the house. If so, how many nights total did you spent out of the house during the past six months?

3 The threatening person spent the night out of the house. How many nights total did this person spend out of the house during the past six months?

4 I called the police. How many times did you call the police in the past six months?

5 I called someone/someplace else for help. How many times have you called someone/someplace else in the past six months?

6 I ended or left the relationship.

7 I did something other than what is listed above.

8 None of the above.

The following sections are about drug, alcohol, and tobacco use. Please remember that your answers are confidential. We would appreciate your answering all questions honestly. If you do not feel comfortable answering a question or are tempted to be dishonest with your answer, please skip the question. Thank you.

78. During the past $\mathbf{3 0}$ days how many days did you .....

Number of Days

78a Use any alcohol

79. During the past $\mathbf{3 0}$ days, have you.....?

\begin{tabular}{|c|l|c|c|}
\cline { 2 - 3 } \multicolumn{2}{l|}{} & Yes & No \\
\hline $79 \mathrm{a}$ & Smoked part or all of a cigarette & 1 & 2 \\
\hline $82 \mathrm{~b}$ & Used marijuana/hashish & 1 & 2 \\
\hline
\end{tabular}

If you did smoke part or all of a cigarette during the past 30 days.....

80a. about how many days did you smoke? (Enter \# of days you smoked or " 0 " if you didn't) (number of days smoked in last 30 days)

80b. about how many cigarettes a day did you have? (Enter \#of cigarettes you smoked per day or " 0 " if you didn't) (number of cigarettes smoked per day) 
100. If you have a partner or boyfriend/husband, does he/she smoke cigarettes?

(1) Yes

(2) No

(99) Not applicable / I don't have a partner

101. Which of the following statements most closely describes smoking by your friends?

1. None of my close friends smoke

2. Most of my close friends don't smoke

3. Most of my close friends smoke

4. All of my close friends smoke

83. How wrong do you think it is for someone your age to...

\begin{tabular}{|c|c|c|c|c|c|}
\hline & & Very wrong & Wrong & A little bit & Not at all \\
\hline & & & & & \\
\hline $83 \mathrm{~b}$ & Smoke cigarettes? & 1 & 2 & 3 & 4 \\
\hline
\end{tabular}

84. How much do people risk harming themselves physically and in other ways when they. .

(Circle one answer for each

\begin{tabular}{|c|c|c|c|c|c|}
\hline & statement.) & No risk & $\begin{array}{l}\text { Slight } \\
\text { risk }\end{array}$ & $\begin{array}{l}\text { Moderate } \\
\text { risk }\end{array}$ & Great risk \\
\hline $84 a$ & $\begin{array}{l}\text { Smoke one or more packs } \\
\text { of cigarettes per day? }\end{array}$ & 1 & 2 & 3 & 4 \\
\hline
\end{tabular}

85. How true are the following statements for you?

(Pick one answer for each statement)

\begin{tabular}{|c|c|c|}
\hline False & Maybe & True \\
\hline 1 & 2 & 3 \\
\hline 1 & 2 & 3 \\
\hline
\end{tabular}




\section{$\rightarrow$ CIGARETTE SMOKING}

90. Are you currently a smoker? (Circle one answer, then follow the arrow if you circle \#4)

1 No, I have never smoked regularly

2 No, 1 used to smoke but I quit more than 6 months ago

3 No, I used to smoke but I quit within the last 6 months

4 Yes, I currently smoke

91. In the last year, how many times have you quit smoking for at least 24 hours? (Circle one answer)

$1 \quad$ None

2 One or more times

92. Are you seriously thinking of quitting smoking? (Circle one answer)

1 Yes, within the next 30 days

2 Yes, within the next 6 months

3 No, not thinking of quitting

$\rightarrow 93$. Listed below are situations that lead some people to start smoking or to return to smoking when they're trying to quit. We would like to know HOW TEMPTED you might be to smoke in each situation.

\begin{tabular}{|c|c|c|c|c|c|c|}
\hline & & $\frac{\text { Not at all }}{\text { tempted }}$ & $\frac{\frac{\text { Not }}{\text { very }}}{\text { tempted }}$ & $\begin{array}{l}\text { Some- } \\
\text { what } \\
\text { tempted }\end{array}$ & $\frac{\text { Very }}{\text { tempted }}$ & $\begin{array}{l}\text { Extremely } \\
\text { tempted }\end{array}$ \\
\hline $93 a$ & $\begin{array}{l}\text { When I realize I haven't } \\
\text { smoked for a while. }\end{array}$ & 1 & 2 & 3 & 4 & 5 \\
\hline $93 b$ & $\begin{array}{l}\text { When I want to know how } \\
\text { a cigarette tastes. }\end{array}$ & 1 & 2 & 3 & 4 & 5 \\
\hline $93 c$ & $\begin{array}{l}\text { When my friends offer me } \\
\text { a cigarette. }\end{array}$ & 1 & 2 & 3 & 4 & 5 \\
\hline $93 d$ & While talking and relaxing. & 1 & 2 & 3 & 4 & 5 \\
\hline $93 e$ & With friends at a party. & 1 & 2 & 3 & 4 & 5 \\
\hline $93 \mathrm{f}$ & $\begin{array}{l}\text { When I want to be part of } \\
\text { the crowd. }\end{array}$ & 1 & 2 & 3 & 4 & 5 \\
\hline $93 \mathrm{~g}$ & $\begin{array}{l}\text { When others are talking } \\
\text { about how much they like } \\
\text { smoking. }\end{array}$ & 1 & 2 & 3 & 4 & 5 \\
\hline
\end{tabular}




\begin{tabular}{|c|c|c|c|c|c|c|}
\hline $93 \mathrm{~h}$ & $\begin{array}{l}\text { When I am very anxious } \\
\text { and stressed. }\end{array}$ & 1 & 2 & 3 & 4 & 5 \\
\hline $93 \mathrm{i}$ & $\begin{array}{l}\text { When I am afraid I might } \\
\text { gain weight. }\end{array}$ & 1 & 2 & 3 & 4 & 5 \\
\hline $93 \mathrm{j}$ & $\begin{array}{l}\text { When I am very angry } \\
\text { about something or } \\
\text { someone. }\end{array}$ & 1 & 2 & 3 & 4 & 5 \\
\hline $93 \mathrm{k}$ & $\begin{array}{l}\text { When I am having a good } \\
\text { time. }\end{array}$ & 1 & 2 & 3 & 4 & 5 \\
\hline 931 & $\begin{array}{l}\text { When it is difficult to } \\
\text { refuse a cigarette. }\end{array}$ & 1 & 2 & 3 & 4 & 5 \\
\hline $93 m$ & When I feel I need a lift. & 1 & 2 & 3 & 4 & 5 \\
\hline $93 n$ & $\begin{array}{l}\text { When things are not going } \\
\text { my way and I am } \\
\text { frustrated. }\end{array}$ & 1 & 2 & 3 & 4 & 5 \\
\hline 930 & When I want to get thinner. & 1 & 2 & 3 & 4 & 5 \\
\hline
\end{tabular}

$\rightarrow 94$. The following statements represent different opinions about smoking. Please rate HOW IMPORTANT each statement is to your decision to smoke.

\begin{tabular}{|c|c|c|c|c|c|c|}
\hline & & $\frac{\text { Not }}{\text { at all }}$ & $\frac{\text { Not }}{\underline{\text { much }}}$ & $\frac{\text { Some }}{\text { what }}$ & Alot & $\frac{\text { Very }}{\underline{\text { much }}}$ \\
\hline $94 a$ & $\begin{array}{l}\text { Smoking cigarettes relieves } \\
\text { tension }\end{array}$ & 1 & 2 & 3 & 4 & 5 \\
\hline $94 b$ & $\begin{array}{l}\text { Smoking makes you get } \\
\text { more respect from others }\end{array}$ & 1 & 2 & 3 & 4 & 5 \\
\hline $94 c$ & $\begin{array}{l}\text { Smoking helps people to } \\
\text { cope better with frustrations }\end{array}$ & 1 & 2 & 3 & 4 & 5 \\
\hline $94 \mathrm{~d}$ & $\begin{array}{l}\text { Tcens who smoke have } \\
\text { more friends }\end{array}$ & 1 & 2 & 3 & 4 & 5 \\
\hline $94 \mathrm{e}$ & Smoking is a messy habit & 1 & 2 & 3 & 4 & 5 \\
\hline $94 \mathrm{~g}$ & Smoking stinks & 1 & 2 & 3 & 4 & 5 \\
\hline $94 \mathrm{~h}$ & $\begin{array}{l}\text { Smoking cigarettes is } \\
\text { pleasurable }\end{array}$ & 1 & 2 & 3 & 4 & 5 \\
\hline $94 \mathrm{I}$ & $\begin{array}{l}\text { Smoking can affect the } \\
\text { health of others }\end{array}$ & 1 & 2 & 3 & 4 & 5 \\
\hline $94 j$ & $\begin{array}{l}\text { Cigarette smoking bothers } \\
\text { other people }\end{array}$ & 1 & 2 & 3 & 4 & 5 \\
\hline $94 \mathrm{k}$ & $\begin{array}{l}\text { Teens who smoke go out on } \\
\text { more dates }\end{array}$ & 1 & 2 & 3 & 4 & 5 \\
\hline $94 \mathrm{~m}$ & $\begin{array}{l}\text { Smoking cigarettes is } \\
\text { hazardous to peoples health }\end{array}$ & 1 & 2 & 3 & 4 & 5 \\
\hline $94 n$ & $\begin{array}{l}\text { Smoking makes teeth } \\
\text { yellow }\end{array}$ & 1 & 2 & 3 & 4 & 5 \\
\hline
\end{tabular}


IF YOU CURRENTLY SMOKE OR HAVE QUIT SMOKING WITHIN THE PAST YEAR, ANSWER THIS NEXT QUESTION, then continue on to finish the survey.

IF YOU HAVE NEVER BEEN A SMOKER OR QUTT MORE THAN A YEAR AGO, skip \#95 and go on to $\# 96$ and finish the survey.

$\rightarrow 95$. Plcase indicate how often these thoughts or feelings have happened for you over the past few months.

(Circle one answer for each statement.)

\begin{tabular}{|c|c|c|c|c|c|c|}
\hline \\
\hline $95 a$ & $\begin{array}{l}\text { When } 1 \text { am tempted to } \\
\text { smoke, I think about } \\
\text { something eise. }\end{array}$ & 1 & 2 & 3 & 4 & 5 \\
\hline $95 b$ & $\begin{array}{l}\text { I tell myself I can quit if I } \\
\text { want to. }\end{array}$ & 1 & 2 & 3 & 4 & 5 \\
\hline $95 c$ & $\begin{array}{l}\text { I notice that nonsmokers are } \\
\text { stating their rights. }\end{array}$ & 1 & 2 & 3 & 4 & 5 \\
\hline $95 \mathrm{~d}$ & $\begin{array}{l}\text { I think about information } \\
\text { people have given me on the } \\
\text { benefits of quitting } \\
\text { smoking. }\end{array}$ & 1 & 2 & 3 & 4 & 5 \\
\hline $95 \mathrm{e}$ & $\begin{array}{l}\text { I can expect to be rewarded } \\
\text { by others if I don't smoke. }\end{array}$ & 1 & 2 & 3 & 4 & 5 \\
\hline $95 f$ & $\begin{array}{l}\text { I stop to think that smoking } \\
\text { is polluting the } \\
\text { environment. }\end{array}$ & 1 & 2 & 3 & 4 & 5 \\
\hline $95 \mathrm{~g}$ & $\begin{array}{l}\text { Warnings about the health } \\
\text { hazards of smoking move } \\
\text { me emotionally. }\end{array}$ & 1 & 2 & 3 & 4 & 5 \\
\hline $95 \mathrm{~h}$ & $\begin{array}{l}\text { I get upset when I think } \\
\text { about my smoking. }\end{array}$ & 1 & 2 & 3 & 4 & 5 \\
\hline $95 \mathrm{i}$ & $\begin{array}{l}\text { I remove things from my } \\
\text { home or place of work that } \\
\text { remind me of smoking. }\end{array}$ & 1 & 2 & 3 & 4 & 5 \\
\hline $95 \mathrm{j}$ & $\begin{array}{l}\text { I have someone who listens } \\
\text { when I need to talk about } \\
\text { my smoking. }\end{array}$ & 1 & 2 & 3 & 4 & 5 \\
\hline
\end{tabular}

96. How satisfied are you with your life as a whole?
1 Very satisfied
2 Satisfied
3 Slightly satisfied
4 Slightly dissatisfied
5 Dissatisfied
6 Very dissatisfied 
YOUR ANSWERS

98. For how many of your answers are the following statements true?

(Circle one answer for each statement below.)

98 a I understood the questions in this

All Most Some Hardly
any

survey.

$98 \mathrm{~b}$ I answered the questions carefully.

$98 \mathrm{c}$ I answered the questions honestly.

12

3

4

YOU ARE DONE. THANK YOU. 


\section{Appendix B - TMC Measures}

Smoking Stage of Change Algorithm

90. Are you currently a smoker? (Circle one answer, then go to \#92 if you circle \#4)

1. No, I have never smoked regularly (NONSMOKER)

2. No, I used to smoke but I quit more than 6 months ago (MANNTENANCE)

3. No, I used to smoke but 1 quit within the last 6 months (ACTION STAGE)

4. Yes, I currently smoke (Go to \#92)

91. In the last year, how many times have you quit smoking for at least 24 hours? (Circle one answer and go to \#92)
$1 \quad$ None
2 One or more times

92. Are you seriously thinking of quitting smoking? (Circle one answer)

1 Yes, within the next 30 days (PREPARATION STAGE if they have one 24hour quit attempt in the past year - refer to $\$ 1$ - if no quit attempt then

CONTEMPLATION STAGE)

2 Yes, within the next 6 months (CONTEMPLATION STAGE)

3 No, not thinking of quitting (PRECONTEMPLATION STAGE) 


\section{Processes of Change Subscales}

\begin{tabular}{|c|c|c|}
\hline & Question & Process \\
\hline $95 \mathrm{a}$ & When I am tempted to smoke, I think about something else & Counterconditioning \\
\hline $95 b$ & I tell myself I can quit if I want to. & Self-liberation \\
\hline $95 \mathrm{c}$ & I notice that nonsmokers are stating their rights. & Social Liberation \\
\hline $95 d$ & $\begin{array}{l}\text { I think about information people have given me on the } \\
\text { benefits of quitting smoking. }\end{array}$ & Consciousness Raising \\
\hline $95 \mathrm{e}$ & I can expect to be rewarded by others if I don't smoke. & Reinforcement Management \\
\hline $95 f$ & I stop to think that smoking is polluting the environment. & Environmental Reevaluation \\
\hline $95 \mathrm{~g}$ & $\begin{array}{l}\text { Warnings about the health hazards of smoking move me } \\
\text { emotionally. }\end{array}$ & Dramatic Relief \\
\hline $95 \mathrm{~h}$ & I get upset when I think about my smoking. & Self Reevaluation \\
\hline $95 \mathrm{i}$ & $\begin{array}{l}\text { I remove things from my home or place of work that } \\
\text { remind me of smoking. }\end{array}$ & Stimulus Control \\
\hline $95 \mathrm{j}$ & $\begin{array}{l}\text { I have someone who listens when I need to talk about my } \\
\text { smoking. }\end{array}$ & Helping Relationships \\
\hline
\end{tabular}

Experiential Processes $=c, d, f, g, h$

Behavioral Processes $=a, b, e, i, j$ 


\section{Temptation to Smoke Measure Subscales Smokers (S) Nonsmoker (NS)}

\begin{tabular}{|c|c|c|}
\hline & Question & Subscale \\
\hline $93 a$ & When I realize I haven't smoked for a while. & S - Habit Strength \\
\hline $93 c$ & When my friends offer me a cigarette. & S-Positive Social \\
\hline $93 \mathrm{i}$ & When I am afraid I might gain weight. & S \& NS - Weight Control \\
\hline $93 j$ & $\begin{array}{l}\text { When I am very angry about something or } \\
\text { someone. }\end{array}$ & S-Negative Affect \\
\hline 931 & When it is difficult to refuse a cigarette. & S - Positive Social \\
\hline $93 \mathrm{~m}$ & When I feel I need a lift. & S - Habit Strength \\
\hline $93 n$ & $\begin{array}{l}\text { When things are not going my way and I am } \\
\text { frustrated. }\end{array}$ & S \& NS - Negative Affect \\
\hline 930 & When I want to get thinner. & S \& NS - Weight Control \\
\hline
\end{tabular}

\section{$\underline{\text { Smoker Subscales }}$}

Positive Social - 93c, 931

Negative Affect - 93j, 93n

Habit strength - 93a, 93m

Weight Control - 93i, 930 


\section{Decisional Balance Scale}

\begin{tabular}{lll}
\hline & \multicolumn{1}{c}{ Question } & Subscale \\
\hline $94 \mathrm{a}$ & Smoking cigarettes relieves tension & Coping Pro \\
$94 \mathrm{~b}$ & Smoking makes you get more respect from others & Social Pro \\
$94 \mathrm{c}$ & Smoking helps people to cope better with frustrations & Coping pro \\
$94 \mathrm{~d}$ & Teens who smoke have more friends & Social Pro \\
$94 \mathrm{e}$ & Smoking is a messy habit & Con \\
$94 \mathrm{~g}$ & Smoking stinks & Con \\
$94 \mathrm{~h}$ & Smoking cigarettes is pleasurable & Coping pro \\
$94 \mathrm{i}$ & Smoking can affect the health of others & Con \\
$94 \mathrm{j}$ & Cigarette smoking bothers other people & Con \\
$94 \mathrm{k}$ & Teens who smoke go out on more dates & Social Pro \\
$94 \mathrm{~m}$ & Smoking cigarettes is hazardous to peoples health & Con \\
$94 \mathrm{n}$ & Smoking makes teeth yellow & Con \\
\hline
\end{tabular}




\section{Appendix C - Description of the STAGES Intervention}

In September 2001, Insights Teen Parent Program of Portland, Oregon received a threeyear grant from the Center for Substance Abuse Prevention for the purpose of field testing an intervention to prevent or reduce substance use by pregnant and parenting teen women. The STAGES (Strong Teens Achieving Goals, Efficacy, and Sufficiency) project is a randomized field trial of a nine-month intervention consisting of weekly, in-home counseling sessions coupled with five, two-hour, weekly educational/support groups for pregnant and parenting female adolescents. Counselors trained in the TMC and motivational interviewing provide the in-home counseling, and a counselor and teen parents recruited from former CHOICES participants deliver the group intervention. STAGES is an addition to the standard services teen parents receive in Portland (e.g., case management, school groups, parenting classes.) Both the intervention group and the control group may receive standard community services; only the intervention group receives STAGES, which consists of the following two components.

\section{In-Home Counseling using Motivational Interviewing}

The counseling component uses motivational interviewing tailored to the teen's stage of change (per the Transtheoretical Model of Change.) Motivational interviewing (MI) blends principles drawn from client-centered therapy (Rogers, 1959), cognitive therapy, and research on self-regulation (Miller \& Brown, 1991). Home-based counseling occurs weekly to bi-weekly for 45 minutes to 1 hour. The focus of the counselor is on increasing self-efficacy and motivation to make changes in behaviors through their use of $\mathrm{MI}$ and educating about major constructs from the TMC - decisional balance, temptations, and processes of change. While participants can receive services for nine months, the focus and frequency of services may change depending on the needs and desires of each. participant.

\section{Educational and Support Groups}

Approximately two months following enrollment, the teen begins the group component, which consists of weekly, two-hour educational groups for five consecutive weeks. Childcare and transportation are provided. The groups are interactive in nature, concentrating on teaching skills as well as providing peer support and role modeling. The goal is to empower teens by teaching them how to succeed in sclf-change efforts and by using peer role models for support and promotion of positive behavioral change. Make up groups are built into the design in case teens miss any of the scheduled group sessions. Topics include:

- Session One: Making Changes. The first session focuses on helping teens understand the steps involved in making life changes and identifying significant changes they have made in their life. They are also encouraged to explore the possibility of other changes they may want to make in the future. 
- Session Two: Siages of Change. This session introduces the stages of change model and how one moves through the stages. Teens are encouraged to identify use of the stages with any significant change they have made and are taught some of the defenses used in the earlier stages.

- Session Three: Healthy and Unhealthy Relationships. Teens learn the qualities of healthy and unhealthy relationships. They identify the quality and characteristics of important relationships in their life and rate these relationships in terms of healthiness.

- Session Four: Being Your Own Best Friend and Self-Sabotage \& Refusal Skills. This session helps teens identify self-defeating behavior and teaches them a model of refusal skills. They learn how to apply these skills in various high-risk situations and how to replace self-sabotage thoughts with positive statements.

- Session Five - Problem Solving Skills provides teens with a skill-based model of how to identify and solve problems. Teens identify a problem and various approaches to solving it as well as the consequences associated with each approach.

\section{Description of the STAGES Study}

The research design is a classical, pretest posttest experimental design using random assignment to the experimental condition and a control group. Research participants are enrolled over three cohorts with each cohort comprised of 82 pregnant and/or parenting teens and randomly assigned either to the STAGES experimental condition or to a control group. Participants are exposed to the experimental condition and control for nine months, with follow-up assessments administered at 6 months and 12 months. The unit of analysis is the individual pregnant and/or parenting teen, and indirectly her child. Data are self-report by the teen and are collected through pen and paper surveys; the instrument is administered in individual format, typically at the teen's home. Teens are remunerated for each survey administration, and teens in the experimental condition are remunerated for group attendance as well.

Participants are recruited directly from local and altemative high schools and social service agencies and through coordination with community health nurses and case managers from a variety of public and nonprofit agencies. The majority of participants have self-referred to the study because of hearing a presentation of the project by the STAGES intake manager. Community healtb nurses and Insights' case managers are also a major referral source. A STAGES brochure was developed for the project and was distributed with every speaking engagement as well as placed at local high schools and social service agencies. Teens are informed that the study is voluntary and confidential and is funded by the federal govemment for the purposes of preventing and/or substance use. An example of a first-person scenario for a teen who self-referred is presented here. 
A woman from Insights Teen Parent Program gave a presentation at my school and passed out a brochure and referral form about a study called STAGES. I was interested and so I filled out the referral form and gave it to the woman. A few days later I received a packet of materials in the mail. I looked these over with my mom. A few days later the woman from Insights called to see if I was interested in participating. She went over the Consent Form with me. I had a lot of questions about the two groups, random assignment, and the money I would get. I also wanted to know about confidentiality of my answers on the surveys. She was very nice and answered all my questions. I said I wanted to participate. She asked me about my reading level, whether English was my spoken language and other questions about the best time to reach mc. She said a woman would be calling me soon to set up a time for my first survey. She also said the woman could come to my home or school to do it. I said okay. The surveyor called me the next day after school and we scheduled a time. She came to my home, went over the consent form again with me. I signed two copies. She kept one, and I kept one. Then I took the survey. It took about an hour and a half. She paid me $\$ 20$ in cash. Then she teld me that I had been assigned to the STAGES program group and that my counselor would be \{name\} and that she would be calling me soon. She also gave me a schedule for the groups. A few days later my counselor called. We arranged to meet at my school over lunch. We did. I was nervous, but she was very nice. We set up a schedule for home visits for the next few weeks. She said that groups would start in about a month and that we could talk about these the next time we met. She also said that I could get transportation and child care for the groups. That made me feel better about going. 


\section{YOU ARE BEING ASKED TO TAKE PART IN A RESEARCH STUDY}

Insights Teen Parent Program has received a grant from the federal government to provide a new program, called the STAGES program, to pregnant and parenting teen mothers 12 to 18 years of agc. The intent of the new program is to prevent and/or reduce substance use and to help teen parents make positive changes in their lives. Since the STAGES program is new and it is not known whether this program is more effective than other local programs, a study of its effectiveness is being conducted by the evaluator at Insights and by staff from Portland State University.

\section{WHAT WILL I HAVE TO DO?}

1. You will fill out a survey 3 times over the next year - when you start the study, at 6 months, and at 12 months. The surveys will ask you about background information and have questions about drug, tobacco and alcohol use and your attitudes about using substances; relationship with partners, family and friends; work and school experience; and how you feel about yourself. The survey takes about an hour and a half. We can do the survey in your home, at school, or any other place convenient for you.

2. Everyone taking the first survey will be randomly assigned to one of two groups (explained below). You will leam what group you are in at the end of the first survey.

Comparison Group: One group will be called a "comparison group" and will only fill out the surveys every 6 months. You will receive $\$ 2$ for the first survey, $\$ 25$ for the second survey, and $\$ 30$ for the final survey. You will get the money as soon as the survey is done.

STAGES Program Group: This group will do the surveys every 6 months (and receive the money for the surveys as listed above) and will also be asked to participate in the new STAGES program being offered by Insights. The STAGES program lasts nine months and provides

1) a counselor who can meet with you in your home on a weekly basis,

2) five, weekly, two-hour education'support groups led by a counselor and other teen parents. The groups will cover topics like "how to make changes in your life", healthy relationships, skills for problem solving and achieving goals, skills for changing behaviors you want to change.

3) incentives for attending the groups. You will receive $\$ 30$ for the first group, $\$ 10$ for each of the other four groups you attend, and a bonus of $\$ 20$ if you attend all five groups.

3. Also, so that we might know how to find you in the future, you will be asked to give us the names, addresses and telephone numbers of people (such as relatives and friends) who will know where you are over the next year.

\section{WHAT IF I DON'T LIKE THE GROUP I END UP IN?}

We can't switch you back and forth between groups. For example, if you end up in the comparison group we can't provide you with the STAGES program services. You may still receive all other 
services for teen parents in Portland. Also, if you don't like the group you end up in, you can drop out of the study.

\section{ARE THERE ANY RISKS?}

There is a possibility that study staff or counseling staff might need to make a report to Services to Children and Families if they suspect child abuse and neglect or elder abuse. This is the state law, and they have a legal duty to report. Also, any mention of harm to self or others will be reported to appropriate officials.

There is also the possibility that you may feel uncomfortable answering some of the questions on the survey. You do not have to answer any questions if you don't want to.

\section{WHAT ARE THE BENEFITS?}

We can learn a lot from your experiences. What we leam from this study may contribute to the knowledge base and help future teen parents by making services better.

\section{IS THE STUDY CONFIDENTIAL?}

Your confidentiality will be protected to the extent permitted by law. Your answers to the survey are confidential. The consent form and any other personal identifying information will be kept apart from the answers to the survey questions. All information collected will be kept in a locked file. Only research staff will know what you say. If you found out about this project through your school or a social service agency, no one from there will know what you say on the surveys. In addition, Insights counseling staff will not knw what you say on the surveys. It's important to know, however, that while any information disclosed in groups will be kept confidential by staff, there is no guarantee that other teens will keep it confidential.

\section{DO I HAVE TO DO THIS STUDY?}

No! Participation in the study is voluntary. You may withdraw from the study at any time. As stated hefore, STAGES is a new program and is in addition to all other resources available to teen parents in Multnomah County. All current resources are still available to you.

\section{HOW DO I GET INTO THE STUDY?}

A staff person from the study will be contacting you by phone in a few days to answer any of your questions and any questions your parent/legal guardian may have. If you are willing to participate, the attached Consent Form must be signed either by you or by your parent/legal guardian (see below.)

1. If you are under age 18 and do not currently have a child, your parent or legal guardian must give permission for you to participate.

2. If you are 18 years of age or are currently parenting a child, your parent or guardian does not need to give permission for you to participate. You may, however, wish to discuss this with her/him and call the study director if there are questions.

\section{WHO CAN I CALL FOR QUESTIONS CONCERNING THIS STUDY?}

If you have questions about the study, please call the study director (NAME) at 503-239-6996 Ext. 249. If you have questions about your rights as a research, please contact the Chair of the Human 
Subjects Committee of Portland State University. Hours are 9:00 am to 5:00 p.m. The office is located at Portland State University, Cramer Hall, Roø 111, 1721 S Broadway, Portland, OR 97201. The telephone is (503) 725-8182.

\section{CONFIDENTIAL}

\section{STAGES PROJECT REFERRAL FORM}

Referral Form Mail or fax to: (name), Intake Manager, Insights, 2020 SE Powell, Portland, OR 97202, fax 503-239-6040. Phone: 503-239-6996x230

Information on Pregnant or Parenting Teen Mother

Are you Pregnant? How many months? Current Age? Number of children?

1. Teen's name:

First Last - - Nickname

2. Date of Birth (moiday/yr): 3. Last 4 digits of SSN (if known):

4. Child(ren)'s name(s) \& Birthdate(s):

4. Can be reached at:

Phone \# Altemate Phone\# Pager or beeper \#

5. Whose phone is this (home, friend, etc.)

6. Best time/day to call:

7. Mailing Address: Street City Zip Code

8. Current School (if in school):

9. Primary language spoken: $\square$ English $\square$ Spanish $\square$ Other (please specify):

10. Primary reading language: $\square$ English $\square$ Spanish $\square$ Other (please specify):

Who is making the referral? $\square$ Teen $\square$ CHN Staff $\square$ Insights Staff $\square$ Other Agency Staff

\begin{tabular}{ll}
\hline Worker's Name & Agency/School Name
\end{tabular}

Address $\quad$ Phone

(If agency referral) has this referral been discussed with the teen? $\square$ Yes $\square$ No 


\section{Appendix D - Copyright Permissions}

\section{Permission to use Impulsivity Scale from Karen Trocki, Ph.D., Alcohol Research Group.}

At 10:02 AM 8/6/2003 -0700, Barb Sussex wrote:

Karen: Hope you are doing well. I'm finally getting around to completing my dissertation. If I'm not mistaken, the impulsivity measure used in the Parenting Adolescent Initiative came from the National Alcohol Survey. I am requesting permission to use the measure for my dissertation. I'm looking at variables related to stage of change in pregnant adolescents' smoking behavior. Thank you.

-..--Original Message-..--

From: Karen Trocki

Sent: Wednesday, August 06, 2003 5:36 PM

To: bsussex@insightstpp.org

Subject: Re: Impulsivity scale

Dear Barbara --

You have my permission. By the way, we used an abbreviated version of our already pretty short scale in the CSAP study. Attached is the whole scale if you haven't started collecting your data yet.

Karen

At 10:19 AM 4/29/2004 -0700, Barb Sussex wrote:

Karen: I m attaching some correspondence we had back in August 2003 regarding using the Impulsivity Scale in my dissertation research. I am about to graduate and am completing the application for copyright of my dissertation through Bell \& Howell. Bell \& Howell states that copyright permission letters state that they may supply copies of my dissertation on demand. I need your permission for this as well. Reply to this e-mail is sufficient. Thank you.

At 8:12 PM 4/29/84, Karen Trocki wrote:

Dear Barb --

Congratulations on finishing up - Yes, you have my permission to distribute the instrument pertaining to impulsivity with your dissertation. Karen 


\section{Permission to use MSPSS from Gregory Zimet, Ph.D., Indiana University School of Medicine}

Dear Barb,

As developer of the MSPSS, I am glad to give permission for Bell \& Howell to supply copies of your dissertation on demand. Please let me know if you need anything more.

Sincerely,

Gregory D. Zimet, $\mathrm{PhD}$

Professor of Pediatrics \& Clinical Psychology

Section of Adolescent Medicine

Indiana University School of Medicine

----Original Message-----

From: Barb Sussex

Sent: Thu 4/29/2004 12:15 PM

To: Zimet, Gregory D.

Subject: RE: permission to use measure

Dr. Zimet: I'm attaching some correspondence we had back in August 2003 regarding using the MSPSS in my dissertation research. I am about to graduate and am completing the application for copyright of my dissertation through Bell \& Howell. Bell \& Howell states that "copyright permission letters state that they may supply copies of my dissertation on demand". I need your permission for this as well. Reply to this e-mail is sufficient. Thank you.

-----Original Message---.--

From: Barb Sussex

Sent: Wednesday, August 06, 2003 11:48 AM

To: Zimet, Gregory D.

Subject: permission to use measure

Dr. Zimet: I am a doctoral student at Portland State University and am working on my dissertation proposal. My topic is smoking by pregnant females. I am requesting permission to use the MSPSS in my research. Thank you.

Dear Ms. Sussex,

I am happy to give you permission to use the MSPSS in your research. I have attached a copy of the scale and a list of references reporting on the scale's psychometric characteristics. Please let me know if you need a letter of permission sent by regular mai] as well.

Sincerely, Greg Zimet 


\section{Permission to use CHKS Resilience Scales from WestEd, California Department of Education, T. Kiku Annon}

On 4/29/04 10:31 AM, "Barb Sussex" wrote:

In August 2003 we signed a Memorandum of Understanding regarding the use of some of the CHKS Resilience scales in my dissertation research. I will be graduating in June and am completing all the paperwork and the application for copyright of my dissertation through Bell \& Howell. Bell \& Howell states that "copyright permission letters state that they may supply copies of my dissertation on demand". I need your permission for this as well. Your reply to this e-mail is sufficient. Thank you.

On 4/29/04 11:39 AM, “T. Kiku Annon" wrote:

I am not EXACTLY sure what you need, but as long as The California Department of Education and WestEd are given proper credit for the Healthy Kids Survey, you have permission to state what is needed by the publishers of your dissertation.

$\mathrm{Ka}$

T. Kiku Annon

Research Associate, WestEd

Regional Coordinator, CHKS

Project Director, CSS 